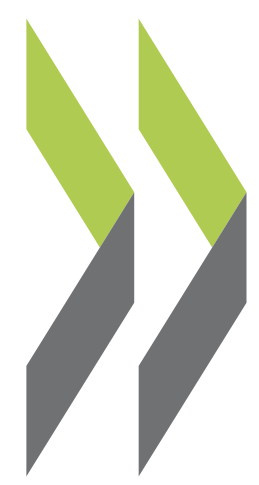

OECD Science, Technology and Industry Working Papers 2009/07

Nanotechnology: An Overview Based on Indicators and Statistics

\section{Christopher Palmberg,}

Hélène Dernis,

Claire Miguet 
Organisation de Coopération et de Développement Économiques

Organisation for Economic Co-operation and Development

25-Jun-2009

DIRECTORATE FOR SCIENCE, TECHNOLOGY AND INDUSTRY

English - Or. English

NANOTECHNOLOGY: AN OVERVIEW BASED ON INDICATORS AND STATISTICS

STI WORKING PAPER 2009/7

Statistical Analysis of Science, Technology and Industry

Christopher Palmberg, Hélène Dernis and Claire Miguet

JT03267289

Document complet disponible sur OLIS dans son format d'origine

Complete document available on OLIS in its original format 


\section{STI WORKING PAPER SERIES}

The Working Paper series of the OECD Directorate for Science, Technology and Industry is designed to make available to a wider readership selected studies prepared by staff in the Directorate or by outside consultants working on OECD projects. The papers included in the series cover a broad range of issues, of both a technical and policy-analytical nature, in the areas of work of the DSTI. The Working Papers are generally available only in their original language - English or French - with a summary in the other.

Comments on the papers are invited, and should be sent to the Directorate for Science, Technology and Industry, OECD, 2 rue André-Pascal, 75775 Paris Cedex 16, France.

The opinions expressed in these papers are the sole responsibility of the author(s) and do not necessarily reflect those of the OECD or of the governments of its member countries.

\section{http://www.oecd.org/sti/working-papers}

OECD/OCDE, 2009

Applications for permission to reproduce or translate all or part of this material should be made to: OECD Publications, 2 rue André-Pascal, 75775 Paris, Cedex 16, France; e-mail: rights@oecd.org 


\title{
NANOTECHNOLOGY: AN OVERVIEW BASED ON INDICATORS AND STATISTICS ${ }^{1}$
}

\begin{abstract}
Nanotechnology is commonly considered to offer considerable promise extending from business opportunities throughout various industries to broader socio-economic benefits, especially in the context of pressing global challenges such as those related to energy, health care, clean water and climate change. Governments around the world have invested heavily in $R \& D$ in this field and companies are also becoming increasingly engaged. Despite this promise, investments and company involvement in nanotechnology developments are still poorly monitored. The objective of this report is to provide a comprehensive overview of these developments through a systematic and critical analysis of available indicators and statistics, while acknowledging that there is a need for further work to both broaden the range of, and develop further, nanotechnology metrics.
\end{abstract}

Nanotechnology developments essentially stem from key enabling inventions in instrumentation during the 1980s and have, since then, developed rapidly in various technological and application fields. Nanotechnology is still at an early phase of development, its future being hard to forecast. Available forecasts suggest a global market for nanotechnology products in the range of USD 150-3100 billion in the coming years while some 2 million new jobs could be created. Nonetheless, these forecasts suffer from difficulties in defining the value-added of nanotechnology to existing manufacturing processes as well as its role for generating new products. It should be noted, however, that the financial/economic crisis unfolding since October 2008 has not yet been taken account of in these projections.

The global distribution of R\&D investments, publications and patents indicate that nanotechnologyrelated research and development activities are concentrated in a few countries and regions of the world. The United States dominates in this context with regions in the San Francisco, Boston, New York and Los Angeles area, followed by Japan and some of the larger European Union countries (Germany, France, the United Kingdom). Nonetheless, some smaller countries also show up as being very active when considering size differences across countries. The rapid entry of "newcomer" countries such as Korea, India and especially China should also be highlighted; all of these countries are characterized by rapid growth rates in the number of publications and patents although from low starting levels. These results suggest that the thrust of nanotechnology R\&D may partly be shifting away from traditional countries which have had a longer history of involvement in nanotechnology.

Publication data highlight the broad-based and inter-disciplinary nature of scientific advances that fuel nanotechnology developments. The number of publications exceeds, by far, patents, as is often the case for emerging technologies. Evidence based on the share of patent citations to the scientific literature also suggests that nanotechnology draws on sciences to a higher degree than other technology fields. Similar to early biotechnology developments, nanotechnology patenting accelerated some 12-13 years after key enabling inventions in instrumentation and related engineering techniques. A further analysis of differences and similarities between bio- and nanotechnologies (and other emerging technologies) could be insightful, especially in light of the cross-pollination and possible convergence between these fields.

1. This paper has benefitted from comments by Jacqueline Allan (OECD), Dirk Pilat (OECD) and delegates to the OECD Working Party on Nanotechnology (WPN). It has been produced as part of the approved work plan of the WPN, supported also financially by participating countries. 


\section{DSTI/DOC(2009)7}

Nanotechnology patenting is distributed across a broad range of sub-areas and application fields, pointing to the multiplicity of applications of this emerging technology and its general purpose nature. Most patenting occurs in nanoelectronics and nanomaterials, both of which are generic technology areas in their own right. Nanotechnology patenting shows the highest growth in the application fields of electronics, chemicals and instruments, while the growth in nanotechnology patenting is higher than the growth in overall patenting. Major multinational enterprises in the electronics industry account for the lion's share of these patents although the share of patents owned by universities is relatively higher in nanotechnology compared with patents in general. It may be that incremental developments related to 'traditional' top-down approaches to nanoscale engineering explain the proliferation of applications in electronics and materials. More disruptive bottom-up approaches may still be confined to university laboratories. The concept "nanotechnology" is too general to capture sectoral specificities in developments and further analysis is needed.

Patent data can also be used to highlight the position and specialisation of countries across nanotechnology sub-areas and application fields. Overall, countries tend to either patent relatively more in the fields of electronics or in the field of chemicals, pharmaceuticals and biotechnologies, while most countries are active in nanomaterials. This finding may suggest an emerging division of labour in nanotechnology innovation, a finding that it would be interesting to analyse further as the technological viability and commercial potentials of different nanotechnology application fields become clearer. Overall, the United States and European Union are more diversified in terms of these application fields while Japan has a higher specialisation in electronics. Further, electronics appears to be an application field in which nanotechnology is building on existing strengths in most countries. Instruments, pharmaceuticals and biotechnologies represent areas in which nanotechnology is contributing to diversification in new fields.

R\&D investment data on nanotechnology are incomplete due to the lack of commonly agreed definitions and statistical frameworks, while publication and patent data only can provide a limited picture of the variegated nature of technological change and innovation. This report also looked at company surveys that have been undertaken in a few countries (the United States, Canada, Germany, Finland and Australia) for complementary insights. It is difficult to define a nanotechnology company, and the number of such companies is still quite small. Those identified through the company surveys tend to be small and distributed across a broad range of industries, mainly in the manufacturing sector. A majority of these companies develop nanomaterials, nanobiotechnologies or nanoelectronics; this finding is roughly comparable with the distribution of patents by nanotechnology sub-areas and application fields. The surveys suggest that nanotechnology impacts the traditional business areas of companies while also creating new opportunities in new markets.

One common theme addressed by all of these company surveys is challenges in commercialising nanotechnology. High processing costs, problems in the scalability of R\&D for prototype and industrial production, the basic research orientation of the related sciences, and concerns about environment, health and safety (EHS) issues (especially the public perception of these) emerge as the key challenges. All of these challenges would require further analysis and verification through qualitative company case studies. A key question is whether these challenges are unique to nanotechnology and hence may require new policy approaches. This report has highlighted some unique features in the development, application and commercialisation of nanotechnology. Better metrics, combined with qualitative case studies, would constitute a necessary basis for the further monitoring and benchmarking of nanotechnology in response to future policy needs. 


\title{
PANORAMA DE LA NANOTECHNOLOGIE : INDICATEURS ET STATISTIQUES ${ }^{2}$
}

\begin{abstract}
RESUME
On s'accorde généralement à reconnaître que la nanotechnologie est extrêmement prometteuse en raison non seulement de ses possibles débouchés commerciaux dans tout un éventail de branches mais aussi de ses retombées socio-économiques plus générales, face notamment à l'urgence des enjeux mondiaux concernant par exemple l'énergie, les soins de santé, l'eau potable et le changement climatique. Des Gouvernements du monde entier ont fortement investi dans la R-D dans ce domaine, dans lequel les entreprises s'engagent également de plus en plus. Malgré ces promesses, les investissements et les participations des entreprises dans les développements de la nanotechnologie sont encore mal mesurés. L'objet de ce rapport est de brosser un panorama détaillé de ces développements à travers une analyse systématique et critique des indicateurs et statistiques disponibles, étant entendu que les travaux doivent être poursuivis pour à la fois élargir et affiner le champ de l'appareil statistique sur la nanotechnologie.

Les développements de la nanotechnologie découlent pour l'essentiel d'inventions structurantes clés en instrumentation dans les années 1980, et cette technologie a connu depuis une progression rapide dans divers domaines technologiques et applicatifs. La nanotechnologie n'en est encore qu'aux premiers stades de son développement et son avenir est difficile à prévoir. Selon certaines prévisions, le marché mondial des produits de la technologie serait compris entre USD 150 et 3100 milliards dans les prochaines années, avec à la clé la création de quelque 2 millions d'emplois nouveaux. Néanmoins ces prévisions sont entachées par les difficultés que pose la définition de la valeur ajoutée de la nanotechnologie dans les processus manufacturiers existants de même que de son rôle dans la création de nouveaux produits. Il faut aussi noter que les crises financières/économiques en cours depuis octobre 2008 n'ont pas encore été prises en compte.
\end{abstract}

La répartition mondiale des investissements dans la $\mathrm{R}-\mathrm{D}$, des publications et des brevets montre que les activités de recherche-développement liées à la nanotechnologie sont concentrées dans un petit nombre de pays et de régions du monde. Les États-Unis dominent à cet égard avec les régions de San Francisco, Boston, New York et Los Angeles, devant le Japon et quelques grands pays de l'UE (Allemagne, France, Royaume-Uni). Néanmoins, quelques petits pays se révèlent également très actifs comte tenu de leur taille relative. L'arrivée rapide de "nouveaux entrants» comme la Corée, l'Inde et notamment la Chine est également à souligner; tous ces pays se caractérisent par de forts taux de progression du nombre des publications et des brevets, bien que leurs niveaux de départ soient faibles. Ces résultats donnent à penser que les pays traditionnels avec un long passé d'implication dans la nanotechnologie pourraient perdre une partie de leur prépondérance dans la R-D en nanotechnologie.

Les chiffres sur les publications font ressortir le caractère pluridisciplinaire et à large assise des progrès scientifiques qui nourrissent les développements de la nanotechnologie. Le nombre des publications dépasse largement celui des brevets, comme c'est souvent le cas pour les technologies émergentes. Les éléments disponibles sur la part des citations de brevets dans les publications scientifiques tendraient également à indiquer que la nanotechnologie s'appuie davantage sur les sciences que d'autres

2.

Ce document a bénéficié des commentaires de Jacqueline Allan (OCDE), de Dirk Pilat (OCDE) et des délégués au Groupe de travail de l'OCDE sur la nanotechnologie (GTN). Il s'inscrit dans le plan de travail approuvé du GTN, et a bénéficié par ailleurs d'une aide financière des pays participants. 


\section{DSTI/DOC(2009)7}

domaines technologiques. Comme lors des débuts de la biotechnologie, les dépôts de brevets sur la nanotechnologie se sont accélérés dans les 12 à 13 ans suivant l'apparition d'inventions structurantes clés dans l'instrumentation et les techniques d'ingénierie apparentées. Une analyse plus approfondie des différences et des similitudes entre la bio- et la nanotechnologie (et d'autres technologies émergentes) pourrait être éclairante, surtout si l'on tient compte de la fertilisation croisée et de la possible convergence entre ces domaines.

Les brevets en nanotechnologie se répartissent sur un large éventail de sous-domaines et champs d'application, signe de la multiplicité des applications de cette technologie émergente et de son caractère polyvalent. La plupart des brevets portent sur la nanoélectronique et les nanomatériaux, qui constituent l'un comme l'autre des domaines technologiques génériques à part entière. Les brevets en nanotechnologie qui progressent le plus portent sur les domaines d'applications de l'électronique, de la chimie et de l'instrumentation, parallèlement au fait que les dépôts de brevets progressent plus vite en nanotechnologie qu'au niveau général. Les grandes multinationales de l'électronique sont à l'origine de la très grande majorité de ces brevets, bien que la part des brevets détenus par les universités soit relativement plus forte dans la nanotechnologie qu'au niveau général. Les avancées progressives induites par les approches traditionnelles de la nano-ingénierie par enlèvement de matière expliquent peut-être cette prolifération d'applications en électronique et dans les matériaux. Les approches par apport de matière, qui marquent davantage une rupture, restent sans doute encore confinées aux laboratoires universitaires. Le concept de « nanotechnologie » est encore trop général pour prendre en compte les spécificités sectorielles dans les développements de cette technologie et de nouvelles analyses seraient nécessaires à cet égard.

Les données sur les brevets peuvent aussi être utilisées pour mettre en évidence la position et la spécialisation des pays dans les différents sous-domaines et domaines d'application de la nanotechnologie. Globalement, les pays ont tendance à déposer relativement plus de brevets soit en électronique soit en chimie, produits pharmaceutiques et biotechnologie, la plupart étant actifs dans les nanomatériaux. Cette constatation tendrait à indiquer l'apparition d'une division du travail dans l'innovation en nanotechnologie, qu'il serait intéressant d'analyser plus en détail à mesure que la viabilité technologique et le potentiel commercial des différents domaines d'application de la nanotechnologie apparaitront plus clairement. De façon générale, les États-Unis et l'UE sont plus diversifiés en ce qui concerne ces domaines d'applications, alors que le Japon est plus fortement spécialisé dans l'électronique. De plus, l'électronique semble être un domaine d'application dans lequel la nanotechnologie s'appuie sur les secteurs porteurs existants dans la plupart des pays. L'instrumentation, les produits pharmaceutiques et la biotechnologie sont des domaines dans lesquels la nanotechnologie contribue à la diversification dans de nouveaux domaines.

Les chiffres sur l'investissement dans la R-D en nanotechnologie sont incomplets faute de définitions et de cadres statistiques généralement admis, alors que les données sur les publications et les brevets ne peuvent donner qu'une image limitée du caractère multiforme du changement technologique et de l'innovation. Le rapport étudie également les enquêtes auprès des entreprises qui ont été réalisées dans quelques pays (États-Unis, Canada, Allemagne, Finlande et Australie) et peuvent apporter des éclairages complémentaires. Il est difficile de définir ce qu'est une entreprise de nanotechnologie, et le nombre de ces entreprises est encore assez faible. Celles qui ont été recensées dans les enquêtes auprès des entreprises sont en général de petite taille et se répartissent dans un grand nombre de branches, principalement dans le secteur manufacturier. La plupart des entreprises développent des nanomatériaux, des nanobiotechnologies ou de la nanoélectronique ; cette observation recoupe pour l'essentiel la répartition des brevets par sousdomaines et domaines d'application de la nanotechnologie. Les enquêtes indiquent que la nanotechnologie a un impact sur les métiers traditionnels des entreprises tout en créant de nouveaux débouchés sur de nouveaux marchés. 
L'un des thèmes communs à toutes ces enquêtes auprès des entreprises concerne les enjeux liés à la commercialisation de la nanotechnologie. Les coûts élevés de transformation, les problèmes du passage de la R-D au prototype puis à la production industrielle, la forte orientation vers la recherche fondamentale des sciences auxquelles il est fait appel, et les préoccupations suscitées par les questions d'environnement, d'hygiène et de sécurité (EHS) (notamment la façon dont elles sont perçues par le public) apparaissent comme les principaux enjeux. Tous nécessiteraient de nouvelles analyses et vérifications par des études de cas qualitatives auprès d'entreprises. Une question clé est de savoir si ces enjeux sont spécifiques à la nanotechnologie et s'ils pourraient donc nécessiter des approches nouvelles de la part des pouvoirs publics. Le rapport a mis en évidence certaines spécificités du développement, de l'application et de la commercialisation de la nanotechnologie. Un meilleur appareil statistique, associé à des études de cas quantitatives, assurerait le socle indispensable pour la poursuite du suivi et de l'évaluation comparative de la nanotechnologie de manière à répondre aux besoins futurs de l'action publique. 


\section{TABLE OF CONTENTS}

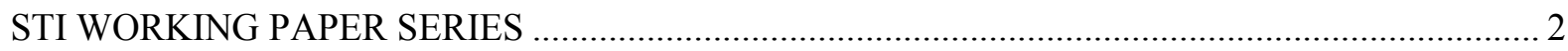

ABSTRACT …

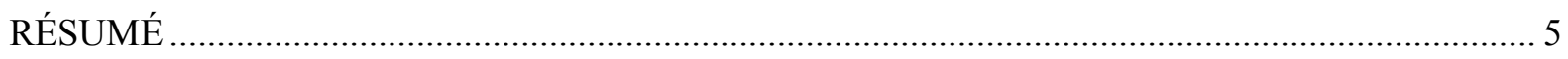

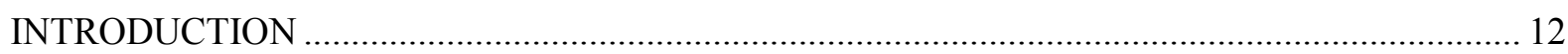

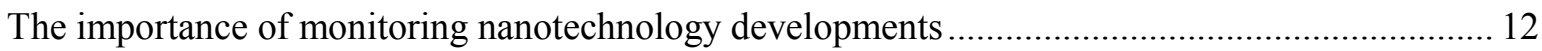

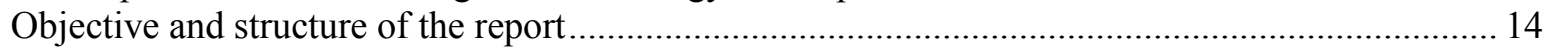

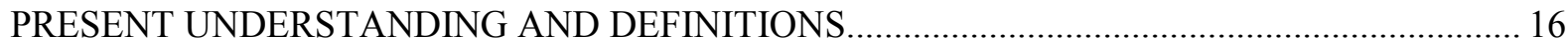

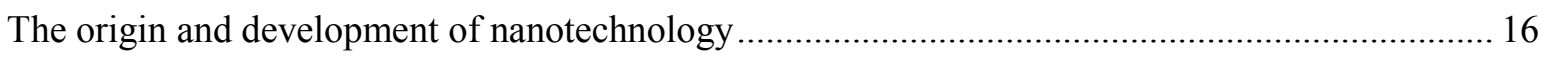

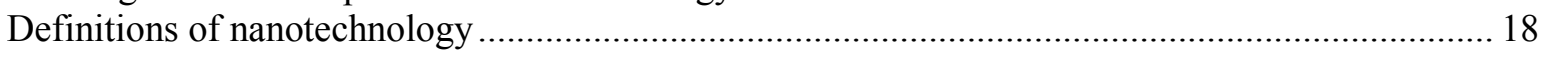

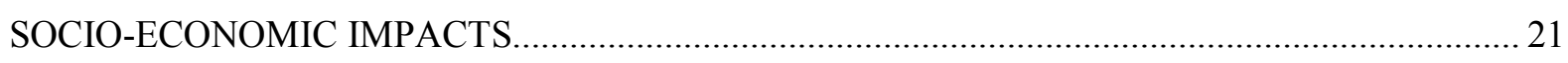

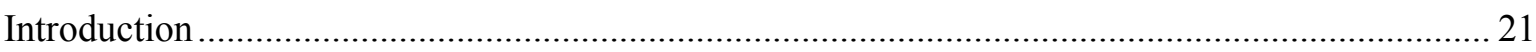

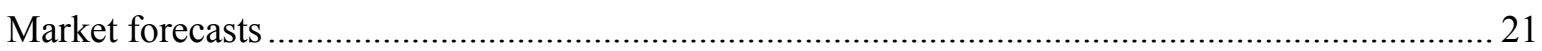

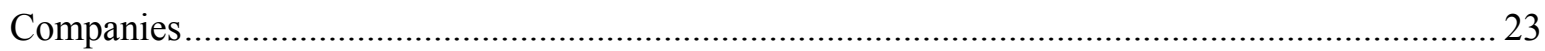

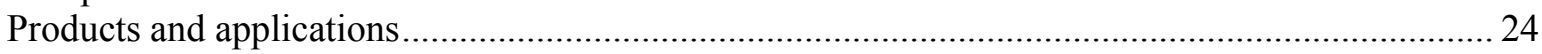

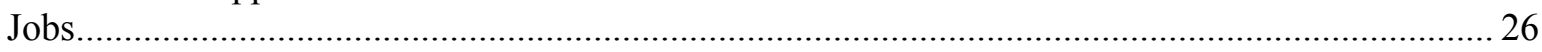

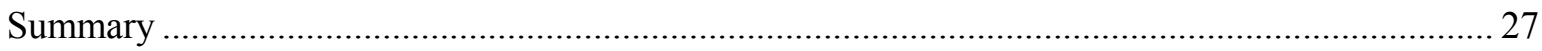

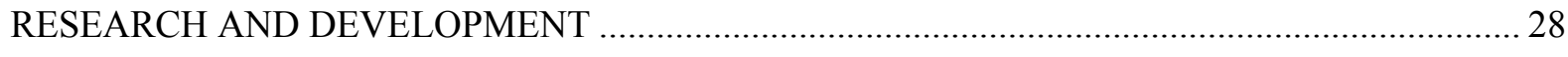

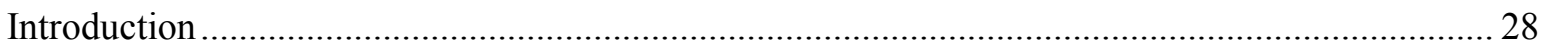

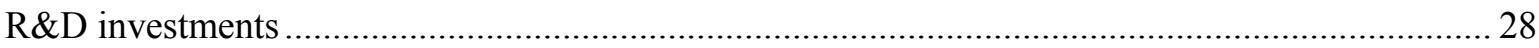

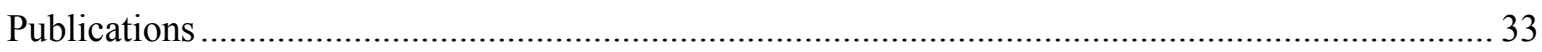

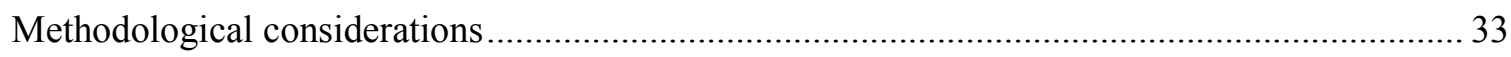

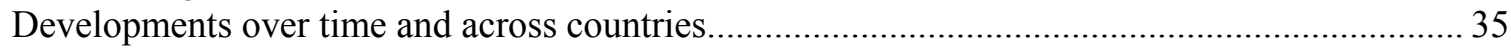

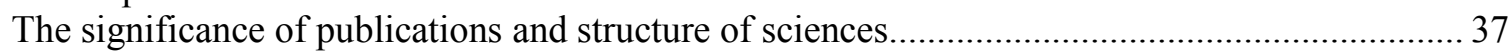

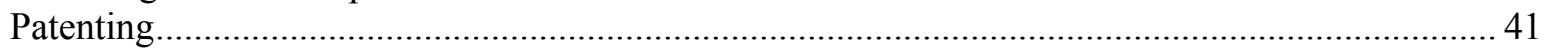

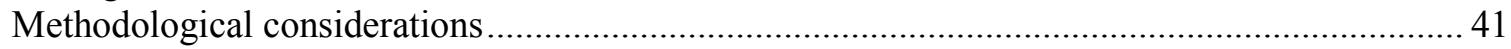

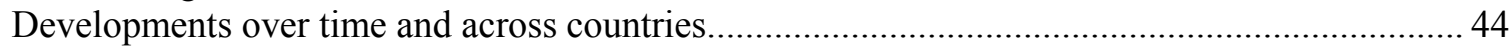

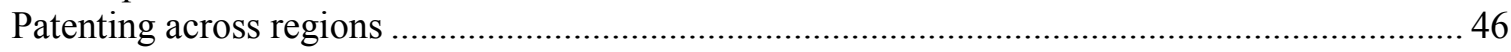

Relationships between publications and patents: non-patent literature citations ............................ 52

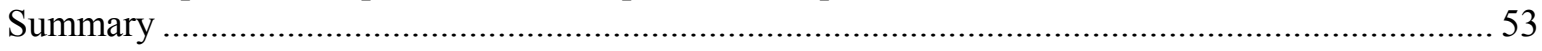

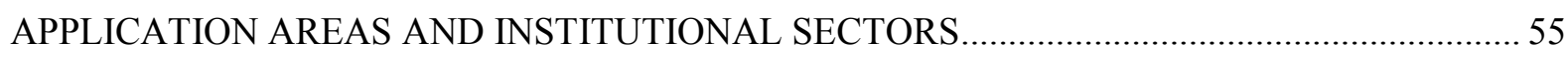

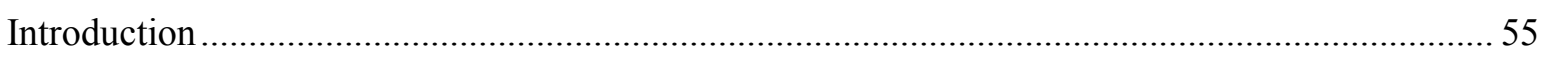

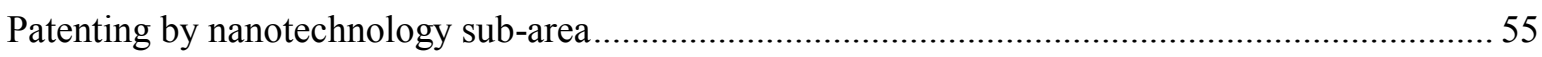

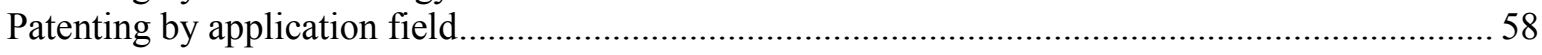

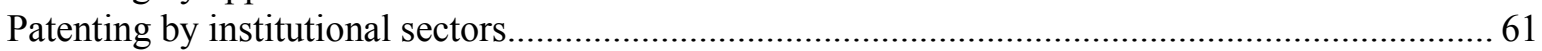

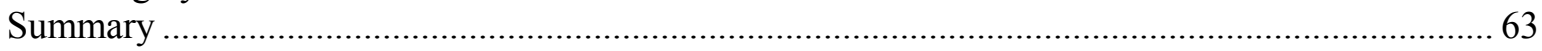

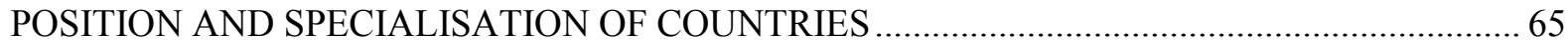

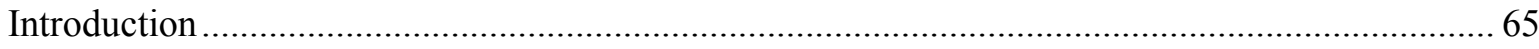




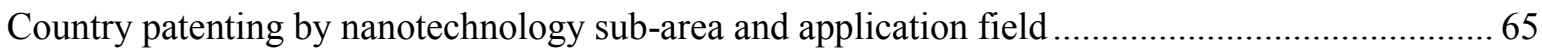

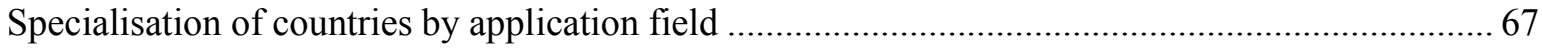

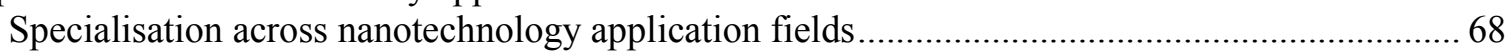

Compatibility between nanotechnology and existing application fields ................................... 70

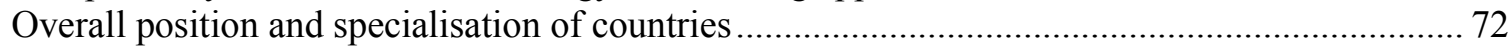

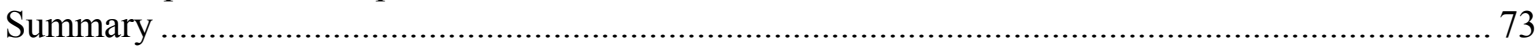

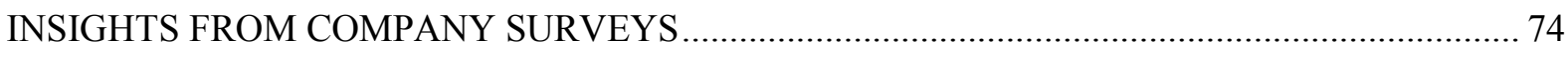

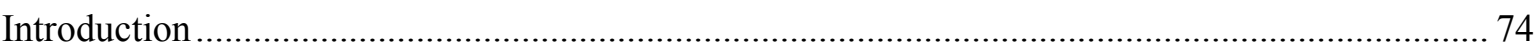

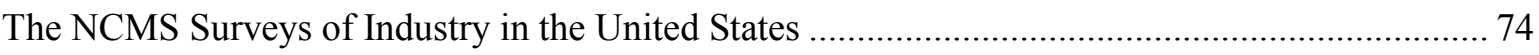

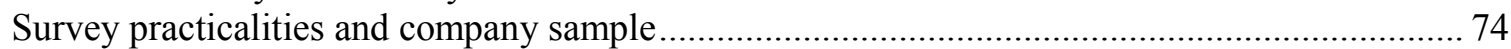

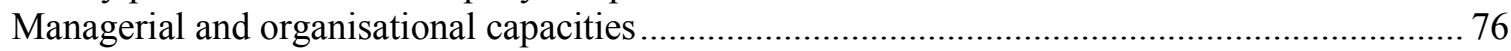

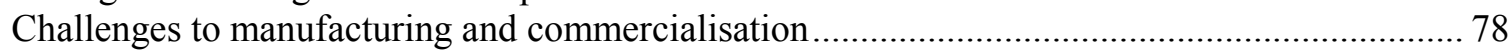

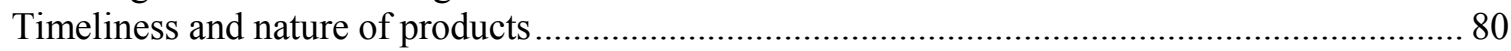

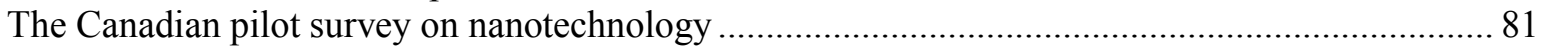

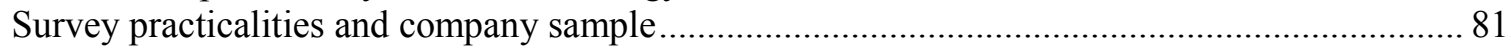

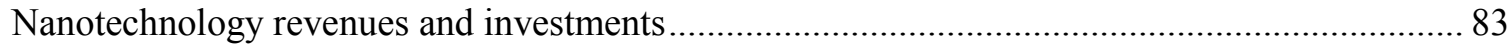

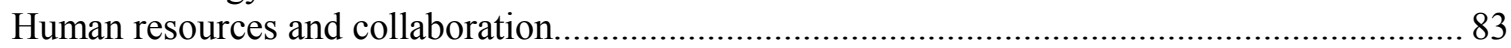

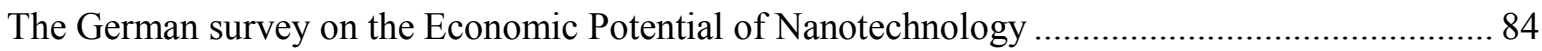

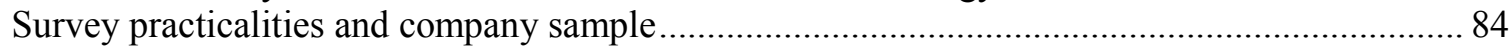

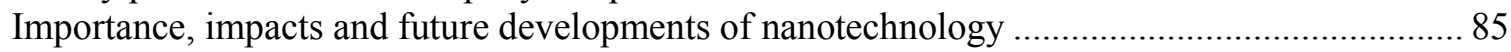

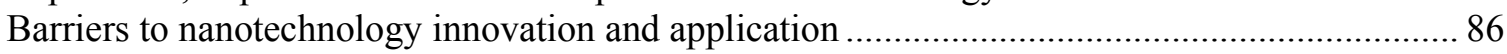

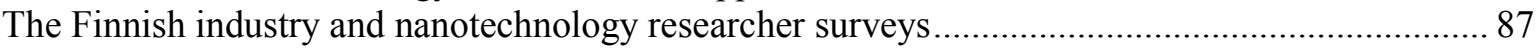

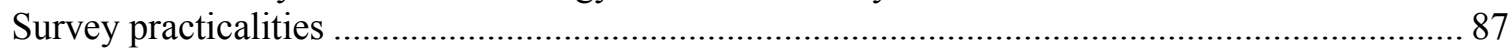

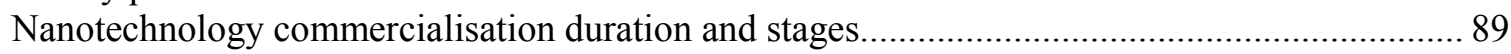

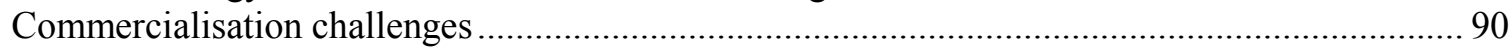

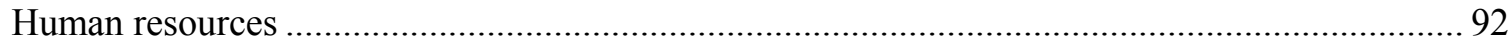

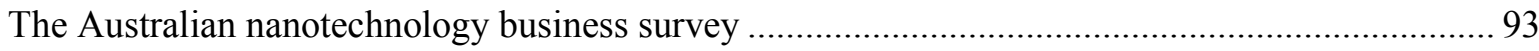

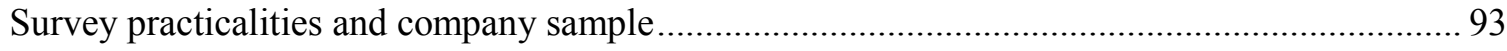

Investments, use and future importance of nanotechnology ......................................................... 94

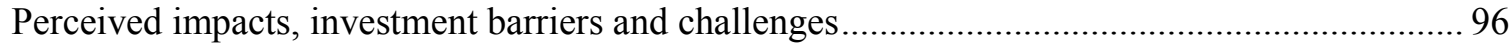

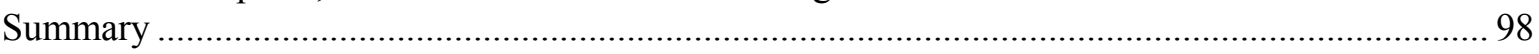

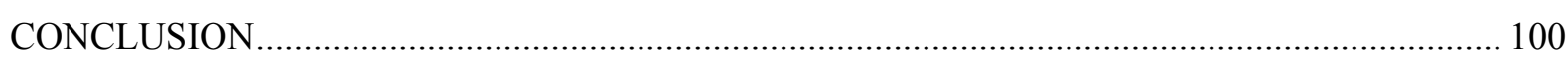

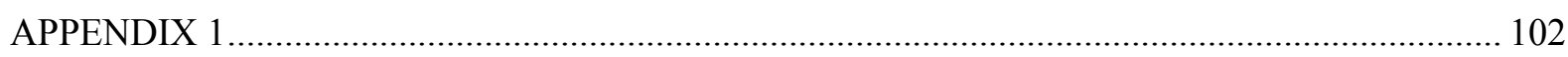

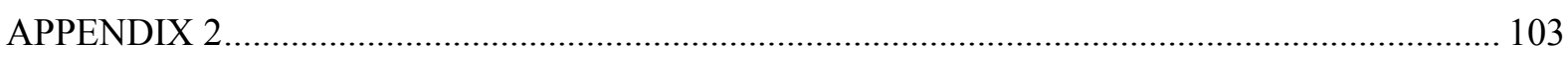

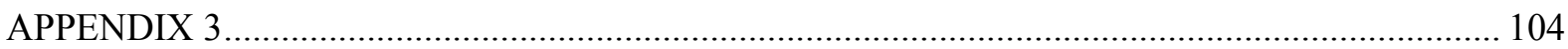

\section{Tables}

Table 2. Selection of global market forecasts for nanotech-enabled products, billion USD ...... 22

Table 3. Nanotechnology-related publications by scientific fields ............................................ 39

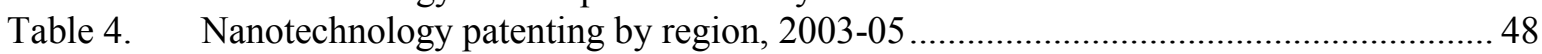

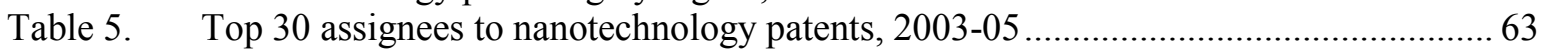

Table 6. Specialisation across nanotechnology application fields by country, until 2005......... 70

Table 7. Compatibility of nanotechnology application fields by country, until 2005................ 72 


\section{Figures}

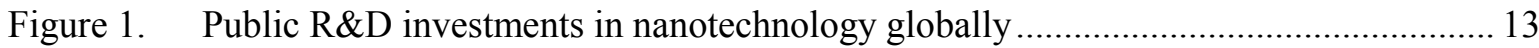

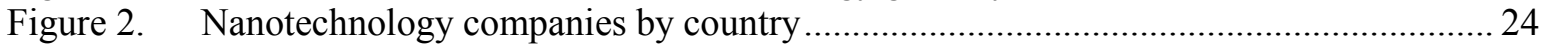

Figure 3. Nanotechnology products by main category and region of origin ................................ 25

Figure 4. Public R\&D investments in nanotechnology by country, 2004 ................................ 30

Figure 5. Public R\&D investments in nanotechnology by country, 2005-2010........................ 31

Figure 6. Relative public R\&D investments in nanotechnology by country, 2006 .................... 32

Figure 7. Structure of R\&D investments in the US, EU and Japan by institutional sector,

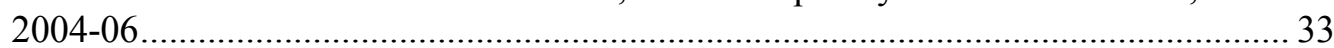

Figure 8. Share of nanotechnology-related and all publications by country, 1991-2007 ............ 35

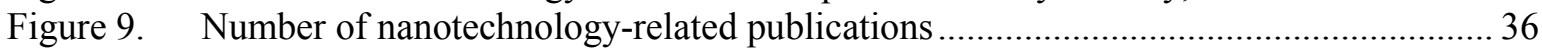

Figure 10. Average annual growth rates of nanotechnology-related and all publications by

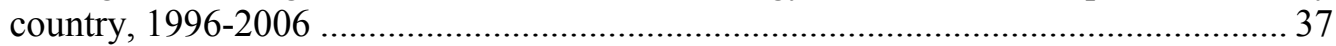

Figure 11. Share of core and citing nanotechnology-related publications by country,

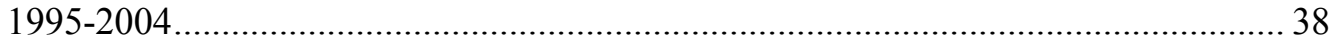

Figure 12. The structure of nanotechnology-related sciences by publications across disciplines,

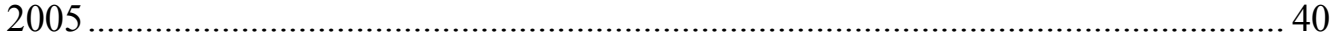

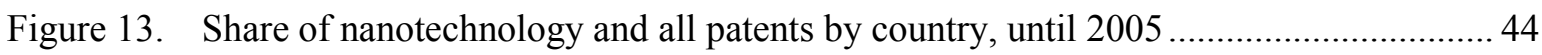

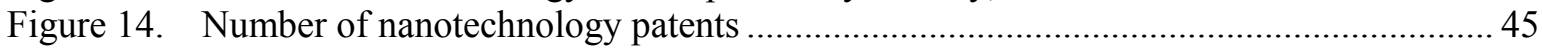

Figure 15. Average annual growth rates of nanotechnology and all patents by country,

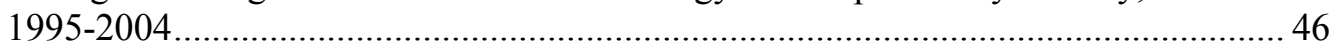

Figure 16. Geographic concentration of nanotechnology and all patenting by country, 2005 ...... 47

Figure 17. Number of nanotechnology patents across regions in the United States, until 2005 ... 49

Figure 18. Number of nanotechnology patents across regions in Europe, until 2005 ..................50

Figure 19. Number of nanotechnology patents across regions in Japan and Korea, until 2005.... 51

Figure 20. Share of NPL citations: nanotechnology versus all patents by country, until 2006..... 53

Figure 21. Share of patents by nanotechnology sub-areas, 1995-2005 …..................................... 56

Figure 22. Number of patents by nanotechnology sub-area..................................................... 57

Figure 23. Share of patents in nanotechnology sub-areas by main application field, until $2005 \ldots 58$

Figure 24. Number of nanotechnology patents by application field ...........................................5 59

Figure 25. Average annual growth rates of nanotechnology and all patents across

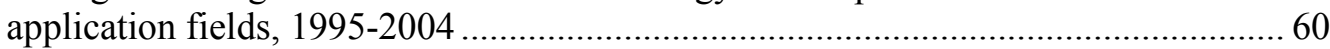

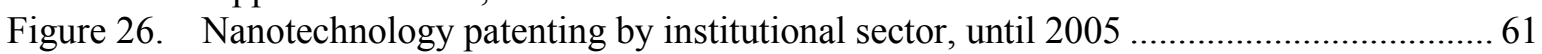

Figure 27. Share of nanotechnology patents by institutional sources, until 2005 ........................ 62

Figure 28. Share of patents across nanotechnology sub-areas by country, until 2005 .................. 66

Figure 29. Share of nanotechnology patents across application fields by country, until 2005 ...... 67

Figure 30. Specialisation across nanotechnology application fields: the US, Japan, EU and

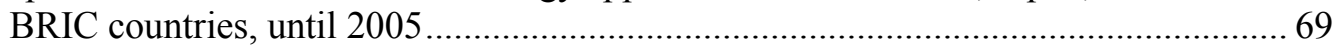

Figure 31. Compatibility of nanotechnology application fields: the US, Japan, EU and

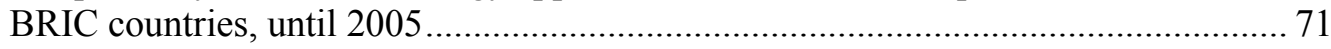

Figure 32. Position of US nanotech companies in value chains and application areas ..................76

Figure 33. Managerial capacity amongst US nanotechnology companies.................................... 77

Figure 34. Organisational capacity amongst US nanotechnology companies...............................78

Figure 35. Challenges in manufacturing and commercialisation amongst US

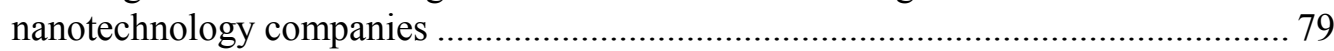

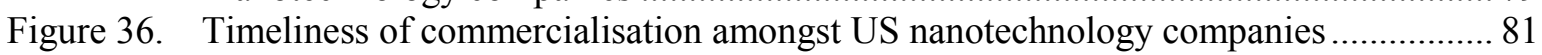

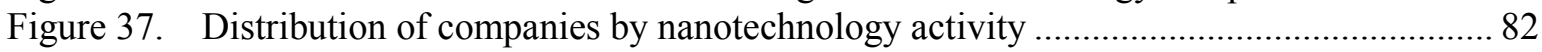

Figure 38. Main industries of German nanotechnology companies................................................ 84

Figure 39. Relevance of nanotechnology for competitive position of German companies............ 85

Figure 40. Barriers to innovation amongst German nanotechnology companies............................ 87 
Figure 41. Distribution of Finnish nanotechnology companies by industry ............................... 88

Figure 42. Time to market duration of research amongst Finnish nanotechnology companies ..... 89

Figure 43. Challenges in commercialisation amongst Finnish nanotechnology companies .......... 91

Figure 44. Challenges in commercialisation amongst Finnish nanotechnology researchers .........92

Figure 45. Extent of difficulties in recruiting skilled people according to Finnish companies......93

Figure 46. Australian nanotechnology companies by principal industry ...................................... 94

Figure 47. Nanotechnology investments amongst Australian companies by industry and size..... 95

Figure 48. Importance of nanotechnology amongst Australian companies by industry and size .. 96

Figure 49. Areas of greatest impact of nanotechnology amongst Australian companies...............97

Figure 50. Barriers for nanotechnology investments amongst Australian companies ................... 98

Figure 51. Scatter-plots: technological specialisation and compatibility of nanotechnology application fields.

\section{Boxes}

Box 1. Characteristics of a general purpose technology ……........................................................ 14

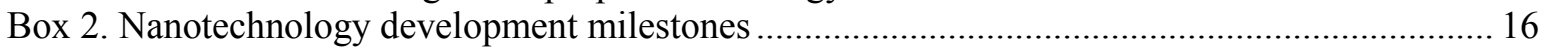

Box 3. Considerations related to interpreting nanotechnology market forecasts .............................. 23

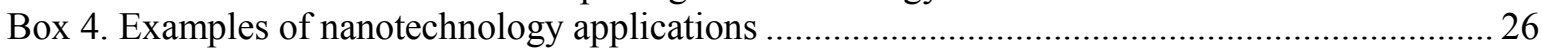

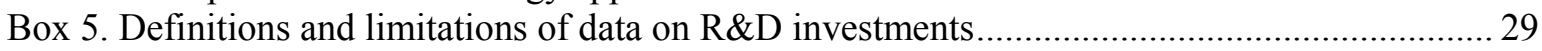

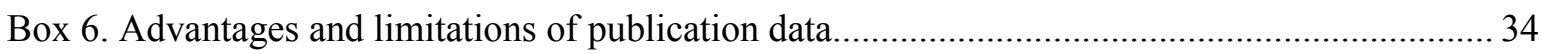

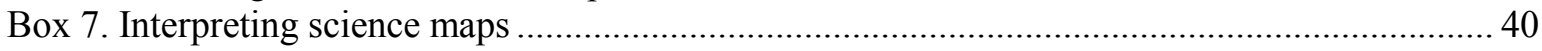

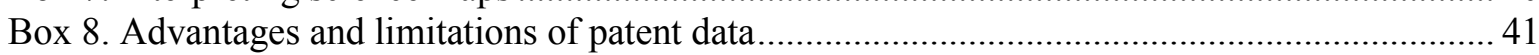

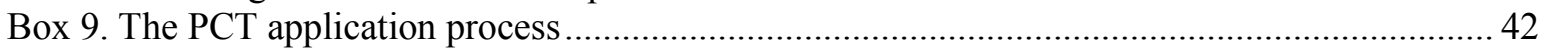

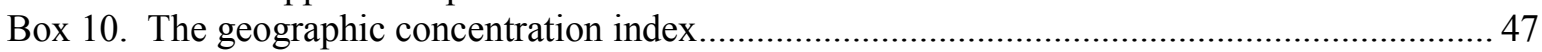

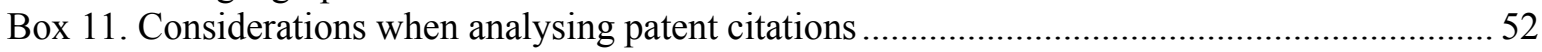

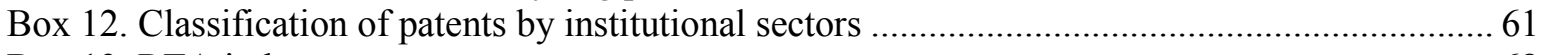

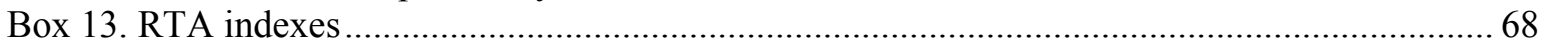


DSTI/DOC(2009)7

\section{INTRODUCTION}

"Nanotechnology is the understanding and control of matter and processes at the nanoscale, typically, but not exclusively, below 100 nanometers in one or more dimensions where the onset of sizedependant phenomena usually enables novel applications ",3

\section{The importance of monitoring nanotechnology developments}

Nanotechnology is commonly considered to offer considerable promise which extends from business opportunities throughout various industries to broader socio-economic benefits globally. It can have implications for almost every type of manufacturing process and product in industries, ranging from electronics and engineering, chemicals, health care and pharmaceuticals, pulp \& paper, textiles and construction to defence, energy and water. Nanotechnology is also seen as potentially able to help to address some of the most pressing global challenges such as those related to energy constraints, climate change, affordable health care and global access to clean water.

This socio-economic promise of nanotechnology has contributed to very rapid growth in public R\&D investments in this field (Figure 1) (Roco, 2007). In fact, hardly any other technology field has benefited from as much public R\&D investment globally in such a short time as nanotechnology, and private sector investment is also picking up. The returns on these investments in terms of future market size have been estimated somewhere in the range of USD 150 billion in 2010 to as much as USD 3.1 trillion in 2015. This could lead to an expected 2 million jobs globally (Hullmann, 2007, see also LuxResearch, 2006).

3. Working definition of the International Organisation for Standardisation (ISO). 
Figure 1. Public R\&D investments in nanotechnology globally

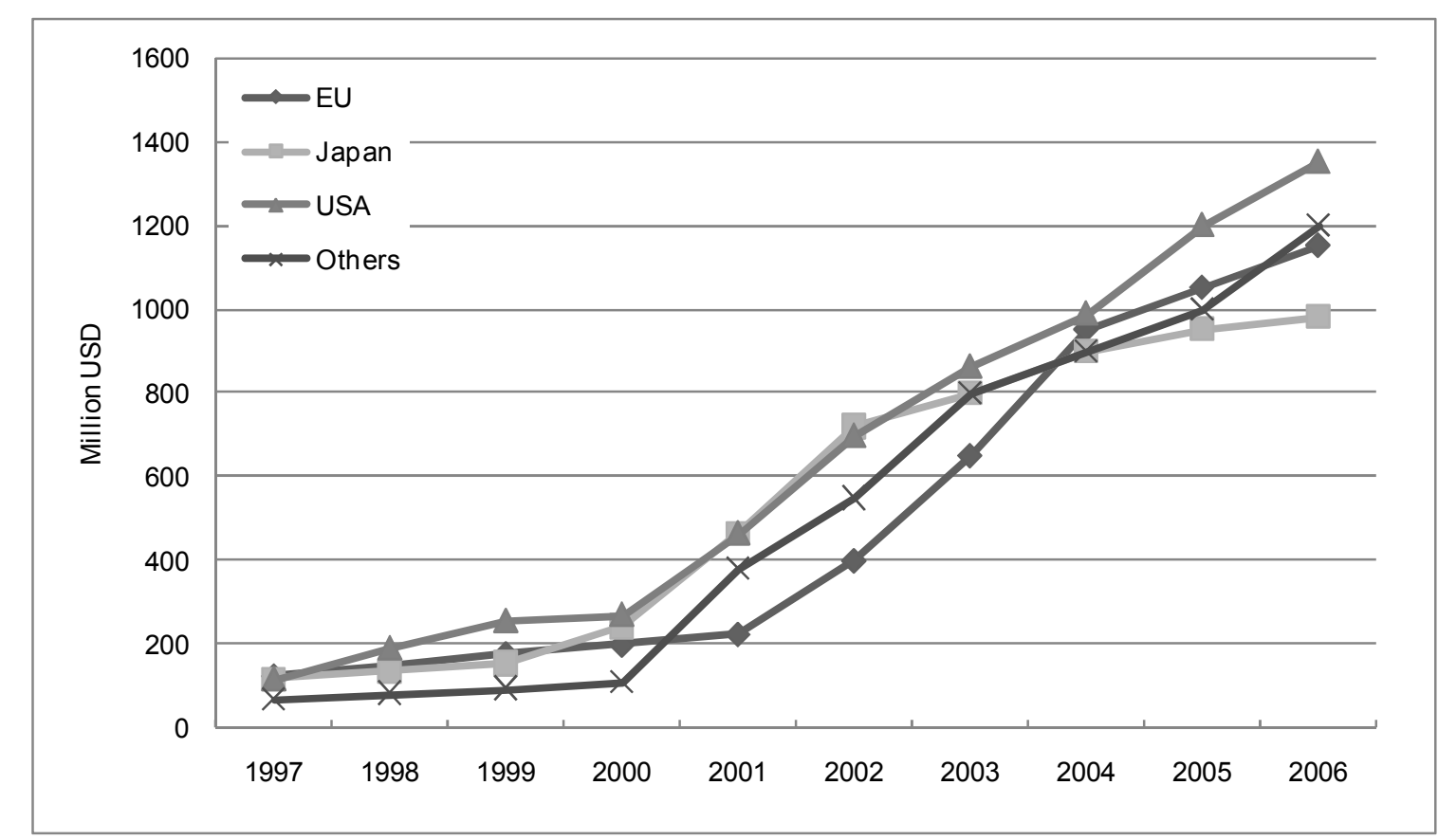

Source: (Roco, 2007).

While these forecasts appear inflated due to difficulties in measuring nanotechnology and its impacts, analysts have suggested that nanotechnology may develop into the next so-called general purpose technology and engine of growth for the $21^{\text {th }}$ century, following in the footsteps of information and communication technology (ICT)(see e.g. Lipsey et al., 2005, Youtie et al., 2007). A general purpose technology is characterised by rapid and significant scope for improvement over existing technologies in economic terms, a widening variety of uses and sectors of applications as it develops. It both initiates and requires a whole range of complementary technologies, organisations and institutions. If nanotechnology could develop into such a general purpose technology previous experience suggests that the effects on productivity and economic growth could be significant even though these may sometimes come with a more significant, time lag (Helpman, 1998).

It should however be stressed that the effects of the economic crisis, unfolding since October 2008, on $R \& D$ investments and forecasts have not yet been analysed nor integrated into these considerations. 


\section{Box 1. Characteristics of a general purpose technology}

1. Should provide rapid and significant scope for improvements over existing technologies in economic terms. This characteristic is intended to reflect the performance of some function that is vital to the functioning of a large segment of existing or potential products and production systems. For example, "continuous rotary motion" and "binary logic" can be considered to embody these characteristics of steam power and ICT respectively as key examples of previous general purpose technologies.

2. Should have a widening variety of uses in a widening number of application areas and industries. This characteristic is intended to reflect the enabling and generic nature of general purpose technologies that support its widespread adoption through industries and economies. The widespread adoption may not only be a consequence of the scope of improvements of a technology, it also relates to a variety of actors, and co-ordinating beliefs about the promise of the technology.

3. Should also both generate, and depend for its widespread use on, the development of a range of other complementary technologies or innovations. These technologies and innovations may not only relate to e.g. supporting production methods, components and other intermediaries. They may also relate to new organisations of companies and industries, different types of business models or changes in the overall business environment of companies.

Source: Based on Helpman (1998), Lipsey et al. (2005).

Nanotechnology is a collective term for a set of interlinked sciences and technologies which jointly contribute to the understanding and control of matter and processes at very small length scales (typically in the range of 1-100 nanometres). One nanometre is one billionth of a meter; hence nanotechnology is essentially the engineering of matter even down to the level of individual atoms. At these small scales there is a move from traditional to quantum physics domains that are not well understood at present. Traditional materials take on new optical, mechanical and reactive properties, thereby enabling new functionalities as well as the development of completely novel materials, devices and products. The emerging nature of nanotechnology implies that it is important to understand better the origin, significance and socioeconomic impacts of the developments. Science, technology and innovation (STI) policies in this field have to be founded on validated and comparable indicators, statistics and other systematic insights.

\section{Objective and structure of the report}

Market forecasts are available through consultancies but diverging methodologies and predictions cast doubt on their reliability. Since nanotechnology suffers from a lack of commonly agreed statistical definitions, there is uncertainty about the volume and content of R\&D funding, especially in the private sector. Publication and patent data can provide some further indication of R\&D activities in the field, of emerging application areas, and the position and specialisation of countries. Further, company case studies can shed some light. However, apart from these scattered studies, and sometimes limited data, nanotechnology developments are still poorly monitored (see Hullman (2007), Meyer (2007) and OECD (2008) for two recent overviews of existing studies on nanotechnology developments).

Given the present low level of monitoring of nanotechnology the objective of this report is to provide a comprehensive overview of nanotechnology developments globally through a systematic and also critical analysis of already available and comparable indicators and statistic. In particular, the report aims to assess the following questions:

1. What is nanotechnology and how has this field developed?

2. Which are the expected socio-economic impacts of nanotechnology?

3. What is the extent, nature and distribution of nanotechnology R\&D activities?

4. Which are the main, emerging, application fields of nanotechnology?

5. How are countries positioned and specialised in nanotechnology application fields?

6. How are companies responding, which are the main challenges in commercialisation? 
The report is structured as follows. Section 2 starts with a discussion about basic concepts and present understandings of nanotechnology. It recalls the origins and some milestones of nanotechnology developments and highlights definitions that have been used. Section 3 assesses the significance of nanotechnology based on its expected socio-economic impacts when considering market and job forecasts, the involvement of companies and emerging products.

Section 4 looks at the volume, nature and distribution of R\&D activities based on data on investments, and also refers to publications and patents as the only data presently available to trace nanotechnology developments over time, across technologies and countries. Section 5 extends the analysis of patent data to nanotechnology sub-areas, application fields and institutional sectors, while section 6 assesses the position and specialisation of countries across application fields.

In Section 7 the report moves to company surveys undertaken in some countries. While these surveys cannot be generalised and compared in a strict statistical sense they nonetheless provide interesting insights into how companies are approaching nanotechnology and which challenges they are experiencing in commercialisation. Section 8 concludes the report. 


\section{PRESENT UNDERSTANDING AND DEFINITIONS}

\section{The origin and development of nanotechnology}

The relevance of what later became known as nanotechnology was first highlighted by the physicist Richard Feynman in his seminal talk in 1959 at the meeting of the American Physical Society, at the Californian Institute of Technology, entitled "There is plenty of room at the bottom". In this talk he anticipated the possibility of controlling matter at a very small scale and thus introduced the scientific community to a new field of enquiry. The term "nanotechnology" was first introduced in 1974 by Norio Tangichi from the Tokyo University of Science, while the basic idea of this technology was explored in greater detail by Eric Drexler in his much-cited book "Engines of Creation - The Coming Era of Nanotechnology" from 1986.

However, the main impetus for nanotechnology developments came from certain key inventions during the 1980s in the field of instrumentation. A milestone was the invention of the Scanning Tunneling Microscope (STM) in 1981 by Gerd Binning and Heinrich Rohrer at the IBM Research Laboratory in Zurich. The STM enables atomic-scale imaging of various surfaces that could not be achieved using previous microscopes. The range of materials that could be characterized with the STM increased significantly with the invention in 1986 of the Atomic Force Microscope (AFM), again by Gerd Binning and his colleagues at IBM. These inventions earned them the Nobel Prize.

Since then, developments have resulted from key discoveries of nanotechnology-enabled new materials, or so-called nanomaterials (see Box 2). Examples include quantum dots, fullerenes or "buckyballs", carbon nanotubes, and a range of other new materials and additional instrumentation. Many of these new nanomaterials can feed into a whole range of application areas for enhancing already available products and processes or creating completely new ones. For example, fullerenes are a new class of carbon material at the nanoscale with novel chemical, physical and electrical properties. They are mechanically very strong but also flexible and conduct electricity extremely well. Applications are to be found in new functionalities of solar cells, various coatings, sports equipment, memory chips etc.

\section{Box 2. Nanotechnology development milestones}

\begin{tabular}{|c|c|}
\hline 1959 & Nobel prize winner in physics Robert Feynman's "There's plenty of room at the bottom" \\
\hline 1966 & Quantum confinement effect discovered by Alan Fowler and colleagues at IBM \\
\hline 1974 & "Nanotechnology" concept proposed by Norio Taniguchi of the Tokyo University of Science \\
\hline 1981 & STM invented by Gerd Binning and Heinrich Rohrer of IBM, US \\
\hline 1982 & Quantum dot, laser application proposed by Yasuhiko Arakawa and Hiroyuki Sakaki of the University of Tokyo \\
\hline 1984 & Fullerenes discovered by Richard Smilley an colleagues of Rice University in the US \\
\hline 1986 & AFM invented by Gerd Binning and colleagues at IBM \\
\hline 1986 & Eric Drexler of the MIT in the US publishes "Engines of Creation: The Coming Era of Nanotechnology" \\
\hline 1986 & Foresight Nanotech Institute established as the first one to educate society about the benefits and risks \\
\hline 1987 & First commercial STM shipped by Digital Instruments in the US \\
\hline 1989 & First commercial AFM shipped by Digital Instruments in the US \\
\hline
\end{tabular}




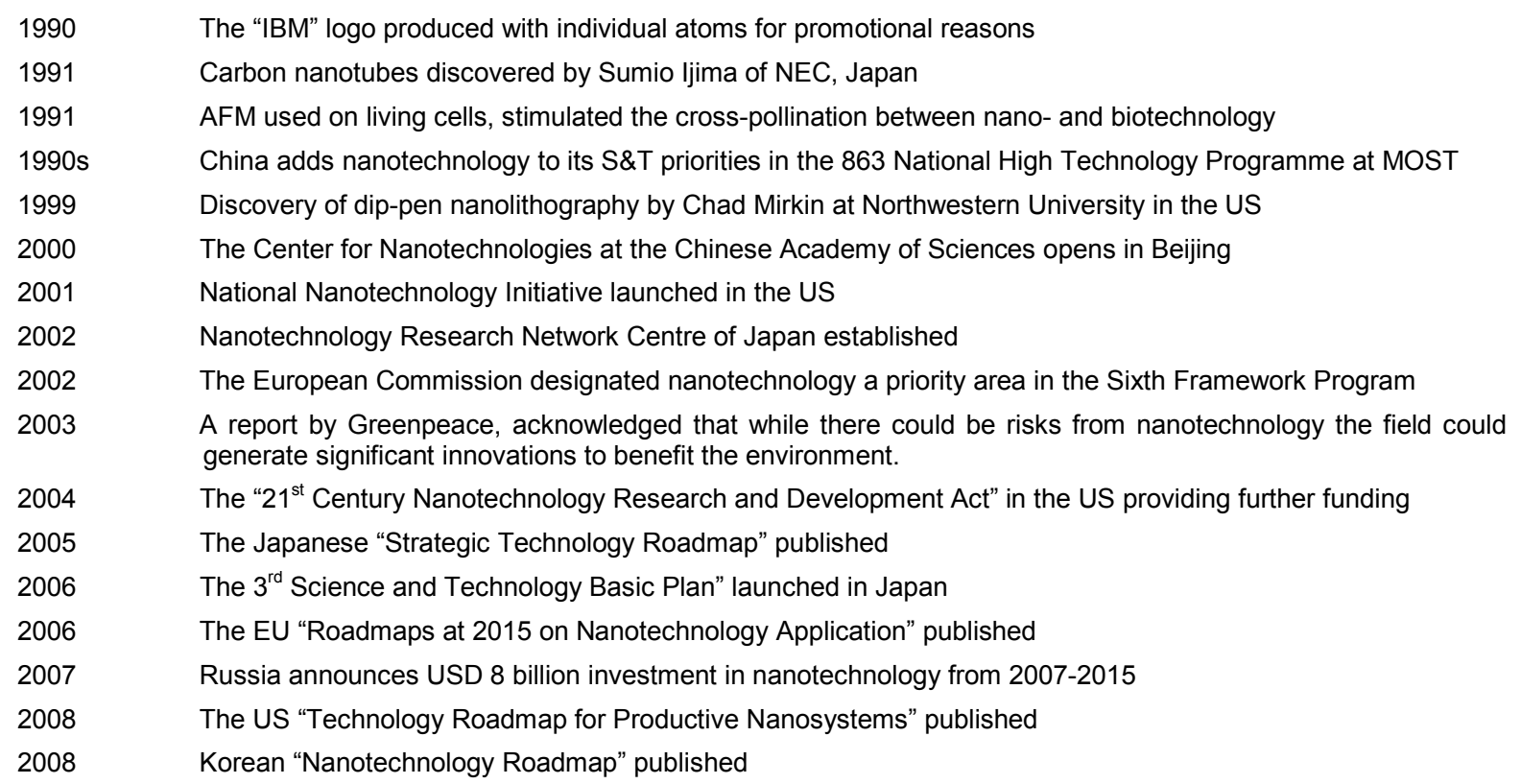

The "IBM" logo produced with individual atoms for promotional reasons Carbon nanotubes discovered by Sumio Ijima of NEC, Japan

AFM used on living cells, stimulated the cross-pollination between nano- and biotechnology China adds nanotechnology to its S\&T priorities in the 863 National High Technology Programme at MOST Discovery of dip-pen nanolithography by Chad Mirkin at Northwestern University in the US The Center for Nanotechnologies at the Chinese Academy of Sciences opens in Beijing National Nanotechnology Initiative launched in the US

Nanotechnology Research Network Centre of Japan established

The European Commission designated nanotechnology a priority area in the Sixth Framework Program A report by Greenpeace, acknowledged that while there could be risks from nanotechnology the field could generate significant innovations to benefit the environment.

The " $21^{\text {st }}$ Century Nanotechnology Research and Development Act" in the US providing further funding

The Japanese "Strategic Technology Roadmap" published

The $3^{\text {rd }}$ Science and Technology Basic Plan" launched in Japan

The EU "Roadmaps at 2015 on Nanotechnology Application" published

Russia announces USD 8 billion investment in nanotechnology from 2007-2015

The US "Technology Roadmap for Productive Nanosystems" published

Korean "Nanotechnology Roadmap" published

Source: True Nano, Kaiser (2006), various www-sites.

The present attention that nanotechnology enjoys in policy is largely due to the establishment of the National Nanotechnology Initiative (NNI) in 2001 in the United States. The NNI initiative was soon followed by extensive nanotechnology initiatives in Japan and several other countries, as well as the European Union (EU). In Japan nanotechnology was highlighted in the second Science and Technology Basic Plan 2001-2005, and emphasised further in the third plan that was launched in 2006. In the EU, nanotechnology was designated a priority area in the Sixth Framework Program for Research and Technological Development, initiated in 2002. The European Commission of the EU adopted the "Communication Towards a European Strategy for Nanotechnology" in 2004 and the action plan "Nanosciences and nanotechnologies: An action plan for Europe 2005-2009" in 2005. Nanotechnology is also included in the Seventh Framework Program for 2007-2013.

Nanotechnology is now a commonly used term. But there is still an ongoing debate about the degree to which this term really describes a new scientific and technological area or also contributes to relabeling already existing research. This issue is significant since unrealistic economic expectations about new technologies often can lead to financial bubbles and backlashes with adverse effects for their further development (Perez, 2002). Relabeling also complicates the R\&D funding landscape for both public and private sector actors. The conceptual debate about nanotechnology is an important one and will continue. This report takes as a point of departure a few fundamental stylized facts that highlight some of the novel and unique aspects of nanotechnology while not dwelling further on the conceptual debate.

Nanotechnology has emerged from converging developments of various subfields within physics, biology and chemistry through the joint realisation of new opportunities of research and engineering at the nanoscale. A distinction is often made between the so-called 'top-down' and the 'bottom-up' approaches to nanoscale engineering. The 'top-down' approach is essentially an incremental continuation of research and development trajectories of physics. This top down approach manipulates materials down to the nanoscale through elaborations of existing lithography, cutting, etching, electro-spinning or milling techniques. 


\section{DSTI/DOC(2009)7}

The 'bottom-up' approach follows a different trajectory in that it creates new materials at the nanoscale through e.g. various deposition, nanoparticle synthesis, and liquid-phase processes. Further, this approach has been envisioned to involve the controlled self-assembly of molecules and their macrostructures, based on manipulation of individual atoms. The bottom-up approach also draws on biotechnology. The top-down approach is currently the more common one, especially due to its application in the electronics industry as a major user of nanotechnology. The bottom-up approach still faces many bottlenecks, especially when considering the cost-efficient scaling of some of the techniques for industrial use, as well as ethical, legal and social (ELS) and environmental, health and safety (EHS) concerns. Some of the more optimistic visions of what nanotechnology can do are inspired by bottom-up approaches (see e.g. Hall, 2005).

As suggested earlier, the main impetus for nanotechnology developments came from certain key inventions in the field of instrumentation, such as the STM and AFM, during the 1980s. The economic significance of these inventions is that they enabled the characterisation of materials at the nanoscale through relatively routine procedures, thereby contributing to the worldwide diffusion of basic nanotechnology techniques. Even though nanotechnology has already produced applications, and is entering industries and markets through these applications, it is clear that it still is in a very early phase of development. Nanotechnology does not constitute an industry at this point in time and may not ever become one. Rather, it is possible to identify specific application fields and commercialisation avenues, some of which are contributing to the formation of rudimentary value chains.

LuxResearch, a consultancy company, has proposed a nanotechnology value chain model. The first upstream segment of this value chain comprises raw-materials producers, such as carbon nanotubes, quantum dots, and fullerenes. The next segment is populated by companies using nanotechnology raw materials to develop intermediate products with nanoscale features, such as coatings and various composite materials. Many of the companies in this segment are new start-ups. The third segment, further downstream, is largely populated by existing and larger companies that develop and produce nano-enabled end-products based on the intermediate products. Finally, the role of companies involved in developing various enabling instrumentations are also highlighted.

\section{Definitions of nanotechnology}

Nanotechnology is characterised by certain novel and unique aspects that underline its relevance as a concept and subject for STI policy, even though it also contributes to relabeling of already existing R\&D. Various agencies have proposed definitions of nanotechnology for planning and implementing policies and initiatives in the field. However, as yet no commonly agreed-upon international framework exists; the International Organisation for Standardisation (ISO) is engaged in this task while the OECD is also considering definitions for statistical work. Awaiting further work on nanotechnology definitions, this report has to rely on a set of general policy-related definitions.

Table 1 lists the definitions used by the United States, European Union and Japan as the main countries/regions in terms of public investments in nanotechnology R\&D. The table also includes the socalled scoping definition under development by the ISO as it constitutes the framework for the present working definition of nanotechnology of the OECD Working Party on Nanotechnology. The table also includes the definition used by the European Patent Office (EPO) as the main source for internationally comparable patent data on nanotechnology. 
DSTI/DOC(2009)7

Table 1. Common nanotechnology definitions

\begin{tabular}{|c|c|}
\hline Source & Definition \\
\hline $\begin{array}{l}\text { US: National } \\
\text { Nanotechnology Initiative } \\
(2001-)\end{array}$ & $\begin{array}{l}\text { Nanotechnology is the understanding and control of matter at dimensions of roughly } \\
1 \text { to } 100 \text { nanometers, where unique phenomena enable novel applications. Encompassing nanoscale } \\
\text { science, engineering and technology, nanotechnology involves imaging, measuring, modelling, and } \\
\text { manipulating matter at this length scale. }\end{array}$ \\
\hline $\begin{array}{l}\text { EU: 7th Framework } \\
\text { Programme (2007-2013) }\end{array}$ & $\begin{array}{l}\text { Generating new knowledge on interface and size-dependent phenomena; nano-scale control of } \\
\text { material properties for new applications; integration of technologies at the nano-scale; self-assembling } \\
\text { properties; nano-motors; machines and systems; methods and tools for characterisation and } \\
\text { manipulation at nano dimensions; nano precision technologies in chemistry for the manufacture of } \\
\text { basic materials and components; impact on human safety, health and the environment; metrology, } \\
\text { monitoring and sensing, nomenclature and standards; exploration of new concepts and approaches for } \\
\text { sectoral applications, including the integration and convergence of emerging technologies. }\end{array}$ \\
\hline $\begin{array}{l}\text { Japan: Second Science } \\
\text { and Technology Basic } \\
\text { Plan (2001-2005) }\end{array}$ & $\begin{array}{l}\text { Nanotechnology is an interdisciplinary S\&T that encompasses IT technology, the environmental } \\
\text { sciences, life sciences, materials science, etc. It is for controlling and handling atoms and molecules in } \\
\text { the order of nano }(1 / 1000000000) \text { meter, enabling discovery of new functions by taking advantage of } \\
\text { its material characteristics unique to nano size, so that it can bring technological innovation in various } \\
\text { fields. }\end{array}$ \\
\hline $\begin{array}{l}\text { Working definition of ISO } \\
\text { TCC } 229 \text { in } 2007\end{array}$ & $\begin{array}{l}\text { Understanding and control of matter and processes at the nanoscale, typically, but not exclusively, } \\
\text { below } 100 \text { nanometers in one or more dimensions where the onset of size-dependent phenomena } \\
\text { usually enables novel applications. Utilising the properties of nanoscale materials that differ from the } \\
\text { properties of individual atoms, molecules, and bulk matter, to create improved materials, devices, and } \\
\text { systems that exploit these new properties. }\end{array}$ \\
\hline European Patent Office & $\begin{array}{l}\text { The term nanotechnology covers entities with a geometrical size of at least one functional component } \\
\text { below } 100 \text { nanometers in one or more dimensions susceptible of making physical, chemical or } \\
\text { biological effects available which are intrinsic to that size. It covers equipment and methods for } \\
\text { controlled analysis, manipulation, processing, fabrication or measurement with a precision below } \\
100 \text { nanometers. }\end{array}$ \\
\hline
\end{tabular}

While the precise wording of each of these definitions differs, all refer to three common aspects of nanotechnology. First, nanotechnology is considered to involve the purposeful "control", "manipulation" or "handling" of matter at a very small scale. This is intended to eliminate from the definition any material or process that has come about through 'accidental' nanotechnology, i.e. nanotechnology that is naturally occurring or that has occurred without purposeful engineering. One example of 'accidental nanotechnology' could be the techniques used to produce coloured, stained glass windows of medieval churches based on the optical properties of nanosized gold particles. In modern times synthetic zeolites primarily used to make detergents, catalyse petrochemical processes and serve as desiccants, have been 'accidentally' manufactured through nanotechnology processes. There are also numerous examples of nanotechnology in nature.

The second common aspect of the definitions is the emphasis on a particular measurement scale where research and engineering moves into the nanotechnology domain by the onset of size-dependent phenomena due to substantial increases in surface area, or other effects that only emerge at the nanoscale. In the US, ISO and EPO definition a threshold of 100 nanometres is suggested for the onset of such sizedependent phenomena. In practice this threshold is not fixed as size-dependent phenomena emerge along a continuum that can extend above 100 nanometers. The threshold is merely indicative of a point along the continuum where classical rules of physics start to give way to quantum mechanical effects and the related new, and as of yet less well-known, phenomena that nanotechnology relies on in important ways. 
The third aspect of the definitions is the most critical from the viewpoint of the commercialisation, namely that nanotechnology also enables "novel" or "new" industrial applications or "technological innovations". This feature has led some analysts to call nanotechnology a next general-purpose technology, as discussed above. For example, the EU definition emphasises the integration of technologies at the nanoscale, highlights various applications areas and stresses the characteristic of nanotechnology in the context of the "integration and convergence of emerging technologies". The Japanese definition proposes that nanotechnology can "bring technological innovation in various fields".

The convergent nature of nanotechnology is also often highlighted. It refers to the commonly held belief that the possibilities to use the same/similar basic building blocks (e.g. atoms and molecules) and tools of analysis (microscopy, high capacity computers etc.) across various scientific disciplines will lead to the partial fusion of nanotechnology, modern biotechnology, information technology and cognitive sciences (this fusion is sometimes referred to with the acronym "NBIC") (see e.g. Roco, 2006).

On closer examination it is also clear that many policy documents use both single definitions of nanotechnology, like those above, and so-called list based definitions. The list-based definitions comprise of a list of agreed upon scientific and technology areas that can be considered to be covered by the term nanotechnology. Single-based definitions may be useful for general communication and consensus building, as well as for defining overall policy strategies. List-based definitions can e.g. communicate better with companies involved in the technology and industrial areas in which nanotechnology may be applied. 


\section{SOCIO-ECONOMIC IMPACTS}

\section{Introduction}

Large socio-economic promises of nanotechnology have been the main reasons behind rapidly increasing public R\&D investments. These investments also relate to the promotion of other adjacent scientific and technological areas, while they undoubtedly conceal some relabeling of existing R\&D agendas. In the private sector $R \& D$ investments will be more narrowly motivated by expected revenues due to forecasted large markets for nanotechnology-enabled products and potential productivity benefits. However, due to the lack of indicators and statistics, combined with the emerging nature of nanotechnology, assessments of socio-economic impacts have been scarce and difficult to undertake.

Literature analysis, expert interviews, company and product inventories, and market forecasts have thus far been the main sources for assessing socio-economic impacts. Market forecasts have also constituted a basis for assessing the impacts of nanotechnology on labour markets. Nanotechnologyenabled products are developed by both new and established companies although it is still unclear what the impacts will be on the structure and dynamics of industries. It is difficult to identify companies active in the field as nanotechnology may only constitute one among many other technologies in their competence base, especially in the case of larger companies. A few attempts have been made to identify nanotechnology products and to assess the demand for nanotechnology workers, although similar definitional challenges arise.

\section{Market forecasts}

Interest in forecasting the market for nanotechnology products emerged in the early 2000s, in parallel with the initiation of dedicated nanotechnology funding programme in many countries. One of the first, and much referred to, long-term forecasts was provided in 2001 by the National Science Foundation (NSF) in the United States (Roco and Bainbridge, 2001). Apart from the NSF, some large banks and consultancy companies have been active.

Amongst the most well-known of these consultancies are LuxResearch, the Business Communication Company (BCC), Científica and RNCONS. All of these companies have continued to provide market forecasts on a regular basis, some of which have become quite influential. Table 2 provides a selection of some of these market forecasts since the early 2000s (see also Malanowksi et al., 2006 and Hullmann, 2007). In addition, some associations representing industry, such as the NanoBusinessAlliance in the United States and the Nanotechnology Industries Association (NIA) in the United Kingdom, have also provided market forecasts and impact assessments. 
DSTI/DOC(2009)7

Table 2. Selection of global market forecasts for nanotech-enabled products, billion USD

\begin{tabular}{|c|c|c|c|c|c|c|c|c|c|c|c|}
\hline & 2005 & 2006 & 2007 & 2008 & 2009 & 2010 & 2011 & 2012 & 2013 & 2014 & 2015 \\
\hline LuxResearch $(2006,2008)$ & 30 & & 147 & & & & & & & 2600 & 3100 \\
\hline BCC (2008) & & & 12 & 13 & & & 27 & & & & \\
\hline Cientifica (2008) & & & & 167 & & & & 263 & & & 1500 \\
\hline RNCOS (2006) & & & & & & 1000 & & & & & \\
\hline Wintergreen (2004) & & & & & & & & & & & 750 \\
\hline MRI (2002) & 66 & & & & & 148 & & & & & \\
\hline Evolution Capital (2001) & 105 & & & & & 700 & & & & & \\
\hline NSF (2001) & 54 & & & & & & & & & & 1000 \\
\hline
\end{tabular}

Source: Publicly available information on private market forecasts.

While each market forecast adheres to different definitions and methodologies, all one of them predict a very rapid growth of the market for nanotechnology products. The most optimistic market forecast of USD 3100 billion by 2015 suggest a very large market for these types of products indeed; actually exceeded the total US manufacturing output in 2007. It also implies a market volume for nanotechnology products by 2015 that would be roughly ten times larger than consultancy estimates of the biotechnology market, while reaching the same volume as that of the ICT market (see Hullmann, 2007).

In market forecasts reference is made either to the whole set of products along the value chain that are believed to become, in some way, affected by nanotechnology, to the specific subset of nanotechnology raw materials (for example carbon nanotubes, quantum dots, fullerenes), components (for example nanocoatings or composites, electronic devices etc.), or other types of intermediaries. Some of these raw materials, components or intermediaries may be completely new and replace available products while others are expected to enhance already existing products with new functionalities.

A critical issue in interpreting these market forecasts is the definition of nanotechnology products. The most optimistic market forecasts refer to the total market value of all end products that embody a nanotechnology component, rather than the value of end-products that can be directly attributed to this component. For example, if a tenth of a gram of a nanocoating - costing EUR 0,10 - is present in a dose of a drug costing EUR 100 then the value of this 'nanotechnology product' would be calculated as EUR 100 rather than the EUR 0,10. The more modest ones tend to narrow down their focus to a few types of nanotechnology products. A preferred, although practically tricky, approach would be to calculate the price differences between the nanotechnology-enabled product and its non-nanotechnology equivalent. This price difference could then be an indicator for the value added by nanotechnology.

Naturally the inclusion of the total market value of all end products, rather than the nanotechnology value added, will lead to significant overstatements. However, while the market forecasts have to be read with great care they do at the very least suggest that nanotechnology may have a large economic impact in the longer term. Having noted this, it is also important to stress that the effects of the unfolding economic crises since October 2008 have not yet been analysed systematically nor considered in greater detail in any of the available nanotechnology market forecasts. The crises may potentially hit hard on science-based technologies as these require risk-tolerating and long-term investments. Real or perceived concerns about EHS issues are not been considered either. 


\section{Box 3. Considerations related to interpreting nanotechnology market forecasts}

- Which definition of nanotechnology is used? Is it a general or list-based definition (e.g. including only specific nanotechnology application areas)?

- Which methodologies and databases underpin the presented figures? Is data exploration of existing figures used, or have new surveys been conducted? What has been the subject of the survey, may there be biases inherent in the data?

- When have the market forecasts been made, what is their time horizon and how may recent developments affect the forecasts (scientific developments, EHS risks and public perceptions of these, financial/economic crises etc.)?

- To which value-added stage of production do the market forecast figures relate? Is the specific value-added of the nanotechnology raw-material, component or intermediary singled out or do the figures cover the value of the complete end-product?

- Is there a risk of double-counting, e.g. may the value of products of different value-added stages repeatedly be brought into the calculations even though they are based on the same nanotechnology input?

Source: OECD, based on Malanowksi and Zweck (2007).

\section{Companies}

Various nanotechnology business registers have been compiled, of which the Nanovip International Nanotechnology Business Directory appears to be the most extensive. ${ }^{4}$ This directory identifies 1608 nanotechnology companies at November 2008, with the reservations that no internationally accepted definition of such companies exists and that new and smaller companies are easier to identify as they are more eager to advertise their nanotechnology involvement for promotional reasons. Figure 2 shows the distribution of these companies by country. Information on the turnover or number of employees is not easily obtainable.

The Nanovip business register suggests that the economic impacts of nanotechnology mainly have manifested themselves through company involvement in the United States. However, as also stressed by Nanovip the register hardly provides an accurate count of nanotechnology-related companies globally or at the country level. For example, a recent study in Germany identified 450 companies that most likely are active in nanotechnology compared to 113 in the Nanovip directory (Malanowski et al., 2006). Similar studies in Finland have identified 130-150 companies, roughly 50\% of these are nanotechnology dedicated ones and for the most part new and small start-ups (Palmberg and Nikulainen, 2008). In the Finnish case, the Nanovip directory only identifies 22 companies.

5. See also http://akseli.tekes.fi/opencms/opencms/OhjelmaPortaali/ohjelmat/NANO/en/etusivu.html 
Figure 2. Nanotechnology companies by country

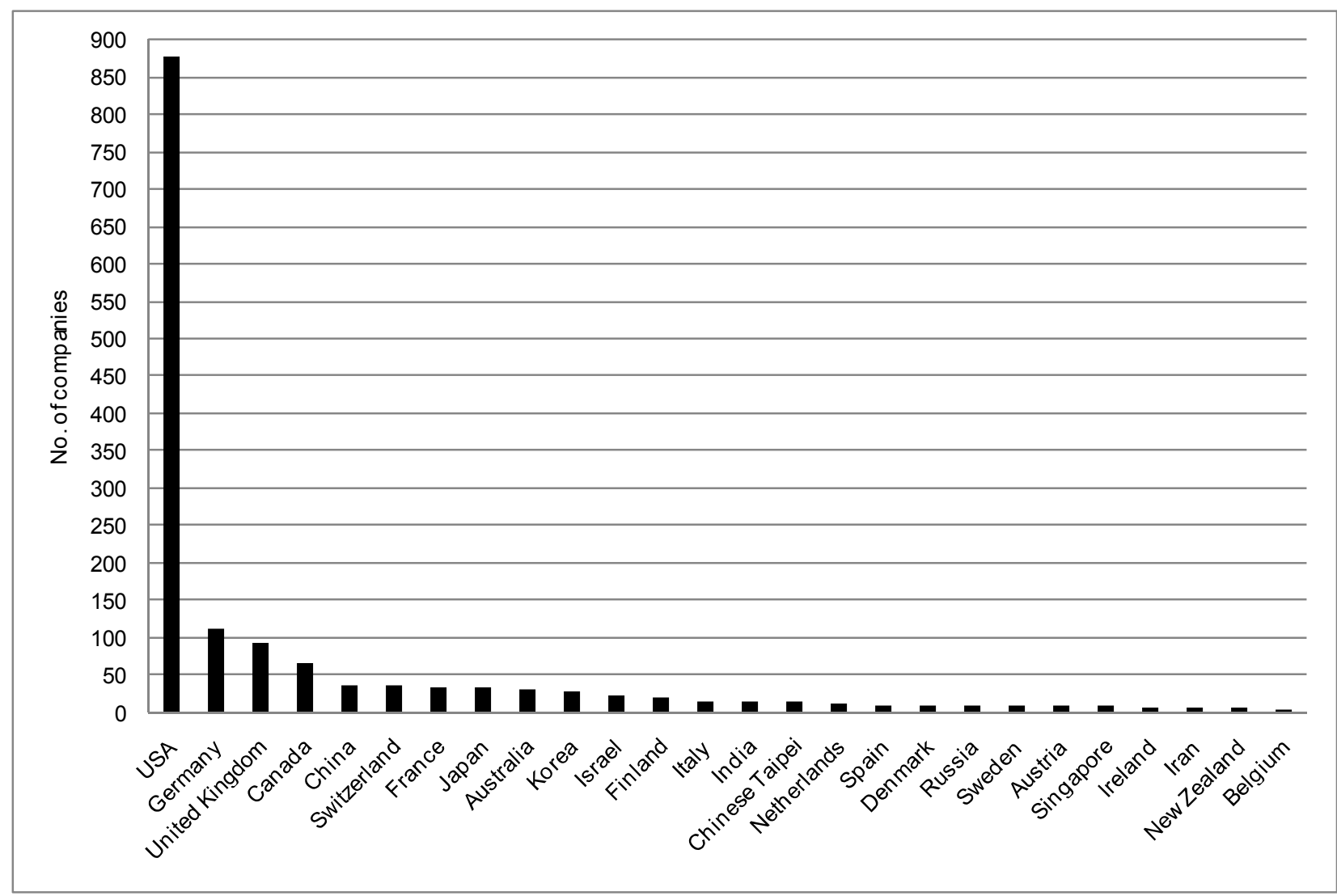

The figure includes countries with at least 2 nanotechnology companies by this data source.

Source: www.nanovip.com.

\section{Products and applications}

Very little is yet known about how companies are using nanotechnology for innovation and product development. Some indication about this can be gained from a recent nanotechnology product inventory by the Project on Emerging Nanotechnologies at the Woodrow Wilson International Centre for Scholars in the United States (see www.nanotechproject.org). Product listings for this inventory have been compiled through web-based searches using three selection criteria; namely that the products can be readily purchased by consumers, that they can be readily identified as nanotechnology-based by the manufacturer or another source, and that the nanotechnology-based claims for the products appear reasonable. The first version of the inventory was publicised in March 2006, with the latest update in August 2008.

At present the inventory contains 803 nanotechnology products or product lines globally, up substantially from 2006 when it contained 212 products. The number of products appears intuitively small when compared with the volume of R\&D investments and the rapid growth in patenting (see analysis of patenting in the following sections). Even though products often relate to multiple patent applications, and may often be protected also by other means, the large difference between the growth of patenting and the number of products suggests that nanotechnology commercialisation still is at a very early phase. 
Figure 3. Nanotechnology products by main category and region of origin

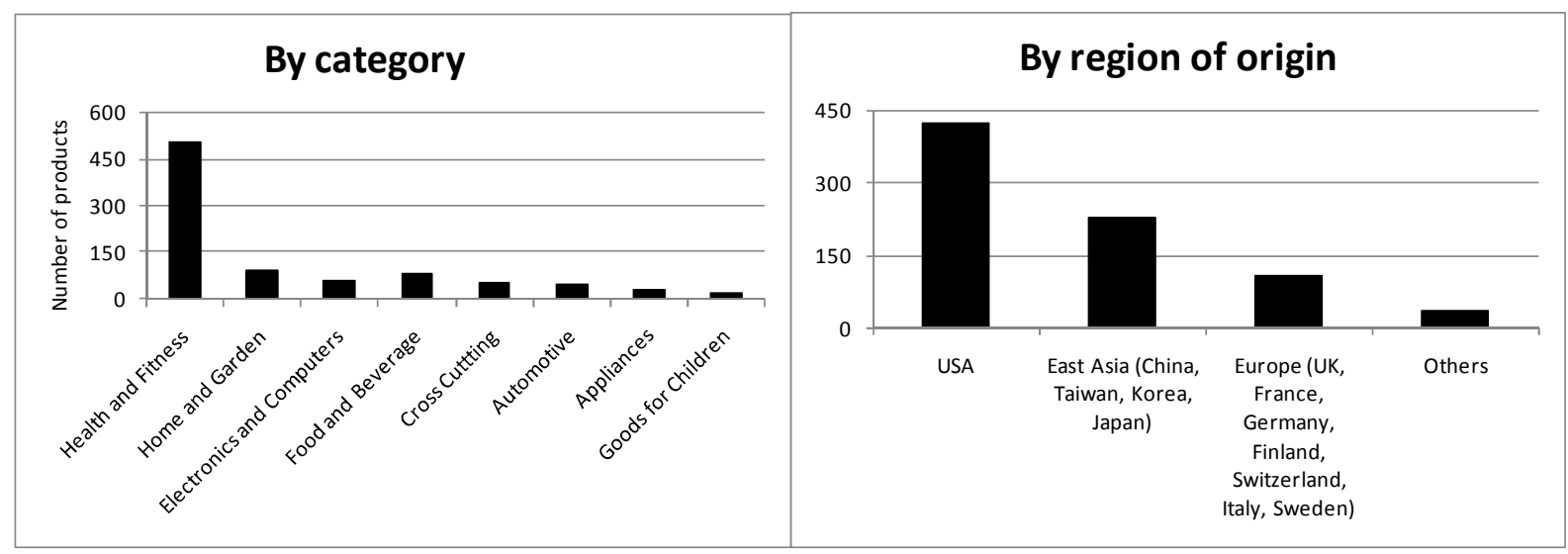

Source: Woodrow Wilson International Centre for Scholars (2008).

The inventory also contains information on the manufacturer of the product, its country of origin and category. Figure 3 displays the distribution of these products by category (left-hand chart in the figure) and region of country (right-hand chart). Altogether 21 countries are involved, including the US, Korea, Japan, the United Kingdom, Germany, France, China, Chinese Taipei, Australia, Israel, Finland, Mexico, Switzerland, New Zealand, Malaysia, Thailand, Sweden, Singapore, Canada and Italy. However, the dominance of US companies is again clear with 426 products, followed by East Asian countries (China, Chinese Taipei, Korea and Japan) with 227 and Europe (United Kingdom, France, Germany, Finland, Switzerland, Italy and Sweden) with 108.

The categorisation of nanotech products indicates a concentration in the fields of health and fitness products. The largest sub-categories are cosmetics, clothing, personal care and sporting equipment. The remaining products are relatively evenly distributed across the main categories of home and garden, electronics and computers, food and beverages, cross cutting (e.g. multiple uses), automotive, appliances and goods for children. However, the limitations of this data should also be borne in mind, namely the absence of clear-cut definitions and an unclear sampling frame as the publicising of these products on the Internet may be influenced by many different factors. The inventory suggests that nanotechnology presently mainly affects the consumer goods industries, although any far-reaching interpretations should be made with care. Nanotechnology is also potentially enabling a broad range of less-visible applications in multiple sectors as exemplified in Box 4, although only few technology roadmaps have been undertaken due to the broadness of the field. 
DSTI/DOC(2009)7

\section{Box 4. Examples of nanotechnology applications}

\section{Electronics and communications}

Data storage media with very high recording densities, new flat-panel plastic display technologies, new materials for semiconductors that increase processing speeds, the realisation of molecular or biomolecular electronics, spintronics and quantum computing.

\section{Materials and construction}

Use of nanoparticles and coatings for reinforced materials and machinery parts, super-hard and tough drill bits and cutting tools, "smart" magnetic fluids for vacuum seals and lubricants, scratch-proof or non-wettable surfaces, anti-bacterial construction material, self-cleaning and reactive eco-efficient windows.

\section{Pharmaceuticals and health care}

Potential applications include miniaturised diagnostics that could be implanted for the early diagnosis and monitoring of illnesses, nanoscale coatings to improve the bioactivity and biocompatibility of implants, ultra-precise nanostructured drug delivery systems, sensors for labs-on-a-chip, new materials for bone and tissue regeneration.

\section{Machinery and tools}

Nanopowders sintered into bulk materials giving special properties, extremely sensitive sensors to detect incipient failures and actuators to repair problems, chemical-mechanical polishing with nanoparticles, self-assembling of structures from molecules, bio-inspired materials and biostructures.

\section{Energy}

New types of batteries, artificial photosynthesis for clean energy, efficient low-cost photovoltaic solar cells (e.g. solar "paint"), safe storage of hydrogen for use as a clean fuel.

\section{Environment and water}

Enhanced membranes for water purification, nanostructured filters for removing pollutants from industrial effluents, improved remediation methods (e.g. photo-catalytic techniques)

Source : OECD (2005), OECD (2008) and others.

\section{Jobs}

The creation of new companies, or the diversification of established ones towards business that incorporates nanotechnology, will eventually affect the labour market. However, it is still too early to assess, in a reliable way, the future demand and supply for nanotechnology-related workers. One approach has been to extrapolate the number of workers demanded in the future from the current proportion of the users of key instrumentation (e.g. AFMs and STMs). Another approach has been to identify nanotechnology-related job-ads. The first approach was used by the NSF in the early 2000s as the most widely referred job forecast. Independent researchers have pursued the second approach of identifying jobads.

The NSF's job forecast from 2001 predicted a demand for as many as 2 million new nanotechnology workers worldwide by 2015 of which 0.8-0.9 million would be in the United States, 0.5-0.6 million in Japan, 0.3-0.4 million in Europe, about 0.2 million in the Asia-Pacific region excluding Japan and 0.1 million in other regions (Roco and Bainbridge, 2001). Most of these jobs were predicted for small and medium-sized companies. If these figures are extrapolated further based on experience in the information technology sector, where for each worker another 2.5 jobs are created in related areas, nanotechnology would have the potential to create 5 million additional jobs globally by 2015 (Roco, 2003). Similar extrapolations have also been made by consultancies and resulted in even more optimistic forecasts. For example, in 2004, LuxResearch forecasted 10 million manufacturing jobs related to nanotechnology by 2014. Again, it should be noted that the unfolding financial/economic crisis has not yet been accounted for in these forecasts. 
The second approach to identifying existing nanotechnology-related job-ads has been pursued by Stephan et al. (2007). The focus was on job-ads advertised in the scientific journal Science during 2002 and 2005, as well job-ads listed on nine major recruitment websites during 2005-06 and based on the keywords "nano" and "MEMS" (Micro Electro-Mechanical Systems). The inclusion of a major scientific journal biases the results towards jobs in academia while the chosen websites mainly cover Englishspeaking regions of the world. Further, the use of simple keywords produces a non-exhaustive list of jobads.

Nonetheless, this study provides at least some factual insights. Stephan et al. (2007) note that job-ads have grown at an annual rate of $43 \%$ during the period analysed although from very low starting levels: altogether 171 job-ads were identified in Nature along with 125 on the websites. These job-ads represent less than $0.1 \%$ of all individuals trained in the United States in physics, chemistry, material science and electrical engineering. Unlike the early days of biotechnology, the market includes both small and larger companies. They also note that is has become less common to require a $\mathrm{PhD}$ degree.

Overall there still seems to be a large discrepancy between the present and forecasted size of the labour market for nanotechnology workers, and more analysis is needed once the field develops further and nanotechnology-related companies can be identified with greater certainty. The above-mentioned forecasts look at the demand side for nanotechnology workers. If the demand for such workers grows as expected the supply side may also need further attention to avoid bottlenecks that could dampen the economic returns of investing in nanotechnology.

\section{Summary}

- The potential socio-economic impacts of nanotechnology are considered very large especially in terms of forecast market size for nanotechnology-related products, the multiplicity of applications and their potential to contribute to addressing global challenges such as those related to energy constraints, climate change, affordable health care and global access to clean water.

- However, reliable assessments of these socio-economic impacts suffer from a lack of indicators and statistics, jointly agreed definitions of nanotechnology and methodologies for its measurement. Available market forecasts, company and nanotechnology product inventories are only indicative while technology roadmaps are difficult to undertake due to the broadness of the field.

- A publicly available register on nanotechnology-related companies indicates that the United States dominates by the number of companies. More detailed studies in some other countries also identify a relatively large number of companies. However, it is difficult to define a nanotechnology company and company counts may not be a reliable indicator for economic impacts of this emerging field.

- Registers of nanotechnology-related products also indicate US dominance. The largest sub-categories of products are cosmetics, clothing, personal care and sporting equipment. This suggests that nanotechnology presently mainly impacts the consumer goods industries; however these types of products may also be more frequently registered publicly compared e.g. with business-to-business products.

- An early forecast suggests that 2 million new nanotechnology-related jobs could be created globally by 2015. A subsequent study, based on actual data, does suggest a growth in the number of related job-ads during 2005-2006, although from a very low starting level. If the future growth in demand for nanotechnology jobs will be rapid this may constitute a bottleneck for the further development of the field. These projections do not take account of the economic crisis that emerged as October 2008. 


\section{RESEARCH AND DEVELOPMENT}

\section{Introduction}

Nanotechnology is an emerging field that has benefited - perhaps more than any other field previously - from rapidly increasing public R\&D investments over a very short period of time. While there are well-established guidelines for collecting data on R\&D investments the available data on nanotechnology R\&D investments are still limited due to the lack of common statistical definitions and model questions. Some data have been compiled based on information from national agencies involved in the funding of nanotechnology $\mathrm{R} \& \mathrm{D}$, but there is still a substantial lack of information about how these R\&D investments are distributed across nanotechnology sub-areas, including research on environmental, health and safety (EHS) and other socio-economic issues. Consultancy companies have extended information gathering to the private sector although the public availability of such data is particularly poor.

$R \& D$ investments are indicators for the main inputs into science-based innovation although R\&D only covers one aspect of technological change and innovation. R\&D investment data typically exclude incremental changes and non-technological innovation e.g. related to organisational change, marketing, services, etc. Publication and patent data can provide complementary indicators for research and development activities, while also capturing intermediate outputs. However, publications and patents suffer from similar limitations. In the context of nanotechnology publication and patent data offer the only data that are available as long time series, comparable across countries and rich in information, thus enabling various types of analysis (see OECD, 2008).

\section{R\&D investments}

The primary sources for public R\&D investment data are compilations by agencies related to the US National Nanotechnology initiative (NNI), the European Commission and various consultancies. The Working Party on Nanotechnology (WPN) has attempted to collect more reliable data through a questionnaire on nanotechnology policies that also provide time series from 2005 and estimates until 2010 and some sectoral disaggregation. In the following the existing compilations are first used to provide crosssection data for a large number of countries. Thereafter reference will be made to the new data for 20052010 , available only for a smaller number of countries. 


\section{Box 5. Definitions and limitations of data on R\&D investments}

Resources allocated to a country's R\&D efforts are measured using two indicators, R\&D funding expenditure and personnel. For R\&D expenditures, the main aggregate used for international comparisons is gross domestic expenditure on R\&D (GERD), which represents a country's domestic R\&D-related expenditure for a given year. This information is usually collected by national statistical agencies. The R\&D data are compiled on the basis of the methodology of the Frascati Manual 2002 which defines R\&D as "creative work undertaken on a systematic basis in order to increase the stock of knowledge, including knowledge of man, culture and society, and the use of knowledge to devise new applications". The magnitude of estimated resources allocated to R\&D

is affected by several national characteristics, principally:

- Coverage of national surveys on R\&D in terms of industries, firm size, sampling methods.

- $\quad$ Frequency of national surveys.

- Methodology used, e.g. for the US, capital expenditure is not covered.

- The type of research personnel that is included.

The collection of data on R\&D investments in nanotechnology is complicated further by the lack of a jointly agreed statistical definition of nanotechnology and related model questions while only a few countries presently have dedicated questions on this in their national R\&D surveys.

Source : Based on OECD (2007).

Consultancies have also collected some information on private sector R\&D investments. However, here the focus will mainly be on public sector data as this data is based on publicly available and more transparent sources. The European Commission (EC) report "Some Figures about Nanotechnology R\&D in Europe and Beyond" from 2005 appears to be the best source, as also referred to in Hullmann (2007). This source provides a cross-section of data for 2004 with the caveat that they may not be complete and depend on the quality of the primary data sources. In addition, some updates on this data have kindly been provided by the EC based on personal communication with those responsible for compiling the data. The charts in Figure 4 present these data as absolute and per capita comparisons across countries. 
Figure 4. Public R\&D investments in nanotechnology by country, 2004

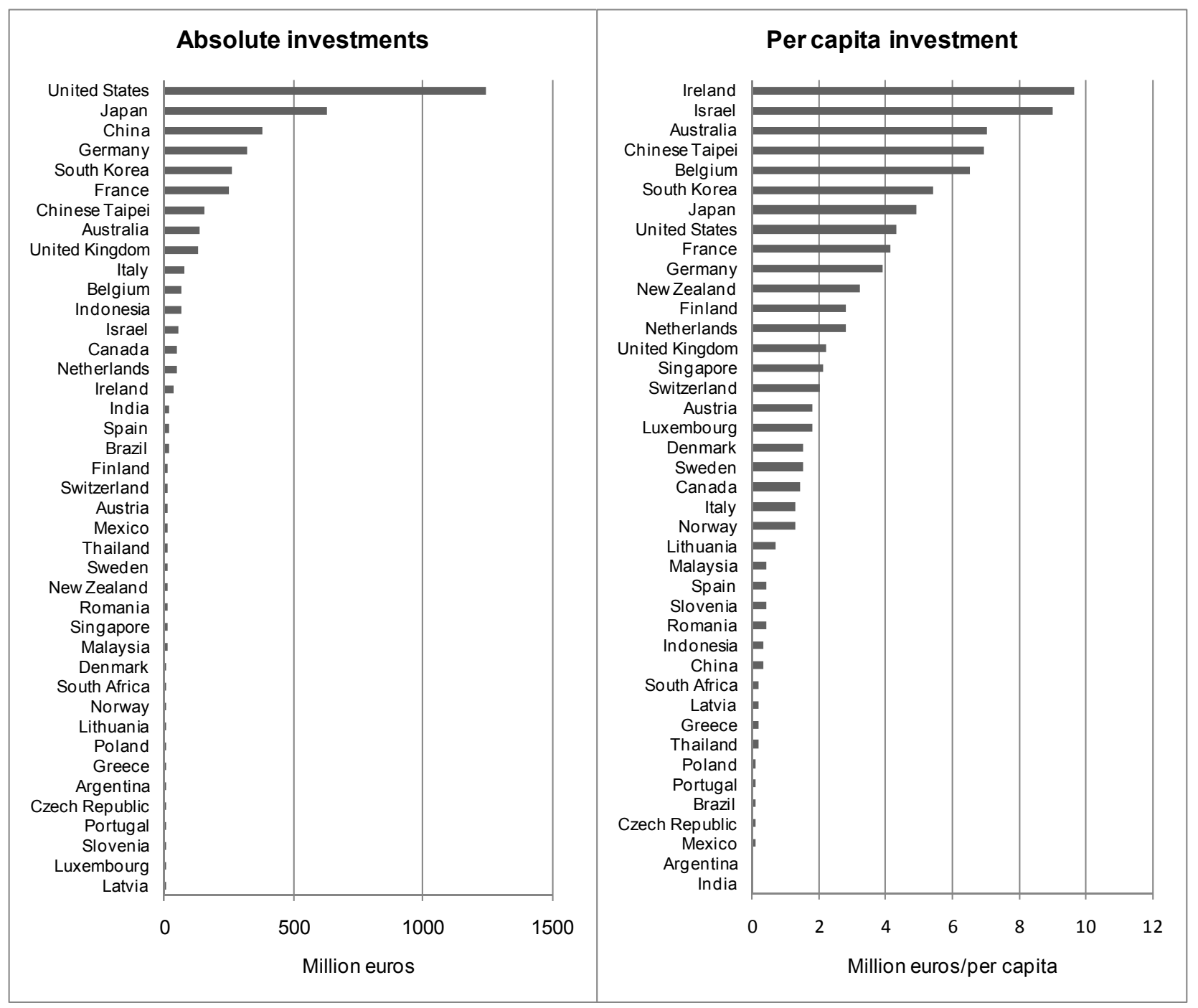

Source: EC (2005).

The absolute figures (left-hand chart) naturally reflect global trends that are displayed in Figure 1 in the introduction to this report. The United States, Japan, and the larger EU countries invest the most. Nonetheless, it is interesting to note that when breaking up the "others" category of the global figures (Figure 1 above) China and Chinese Taipei, South Korea and Indonesia emerge as significant players. For the case of China and Indonesia, these R\&D investment volumes mainly reflect their economic size but still appear significant when considering, for example, that wage levels of scientists, researchers and engineers still tend to be lower in labour-intensive countries.

When considering the relative country figures (right-hand chart), on a per capita basis, the situation changes quite significantly as some of the smaller countries come out more strongly. In particular Ireland, Israel, Chinese Taipei, New Zealand, the Netherlands, Finland and Australia stand out, while the position of the United States, Japan, China and Indonesia diminishes somewhat. 
Figure 5. Public R\&D investments in nanotechnology by country, 2005-2010

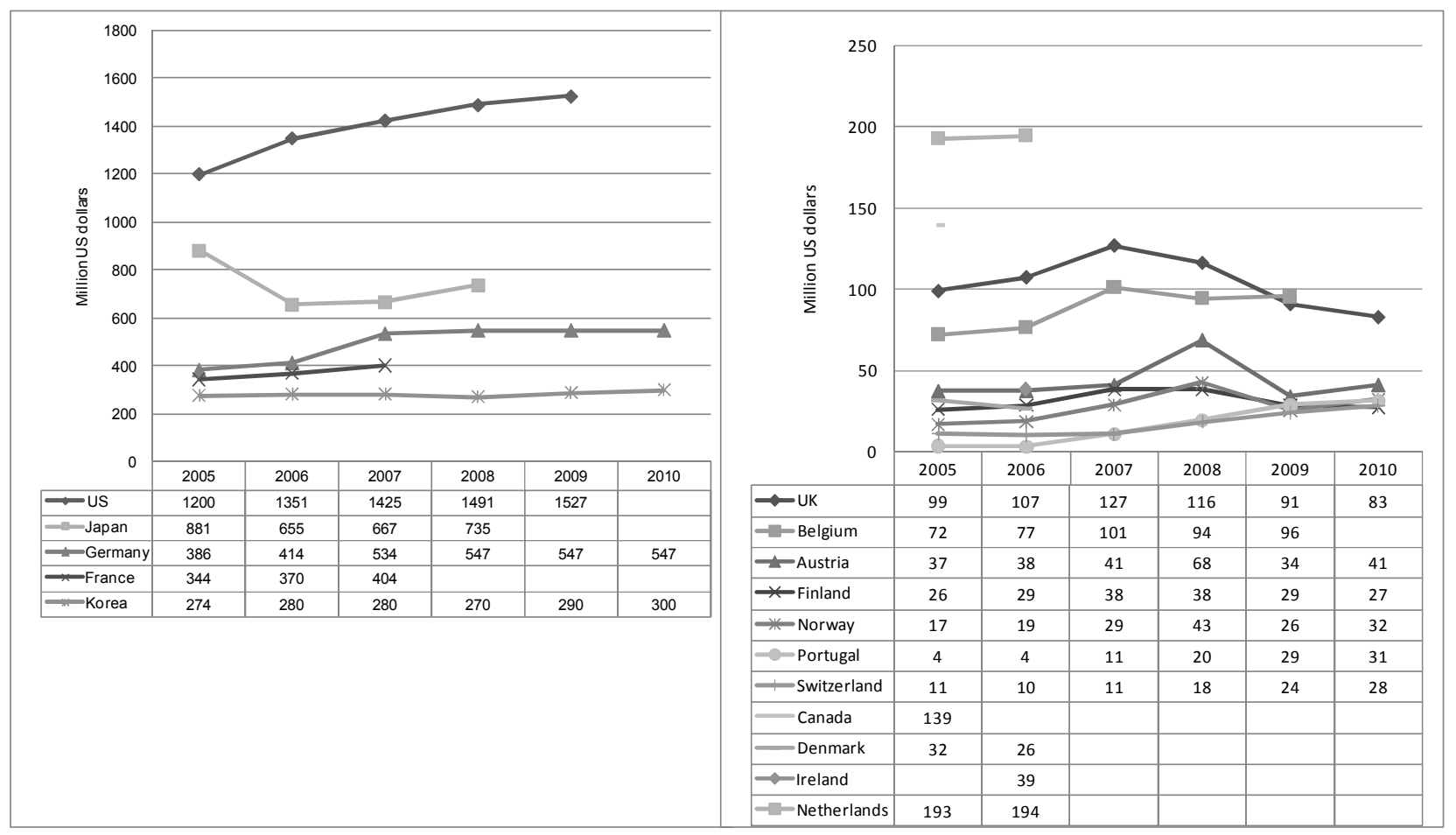

Figures for 2008-2010 are estimates.

Source: WPN Policy Questionnaire (2008).

The new data collected by the WPN for 2005-2010 (Figure 5) confirm the dominance of the US, Japan and the larger European countries - Germany, France and the United Kingdom. However, these new data also highlight Korea as a significant global player. Overall, current levels of public R\&D investments in nanotechnology are estimated to increase for the majority of countries, although the estimates beyond 2007 should be read with care (e.g. in light of the economic crises).

When considering the relative share of public R\&D investments in nanotechnology, as a percentage of total investments for 2006 and adjusted by purchasing power parities, the position of some of the smaller countries is again pronounced (Figure 6). The Netherlands, Ireland, Belgium and Korea invest a relatively much higher share of their total public R\&D investments in nanotechnology compared with, e.g. Japan and the United States. The relative investments in nanotechnology of other smaller countries, such as Denmark, Austria, Finland and Norway, are on similar levels to Japan and the United States. 
Figure 6. Relative public R\&D investments in nanotechnology by country, 2006

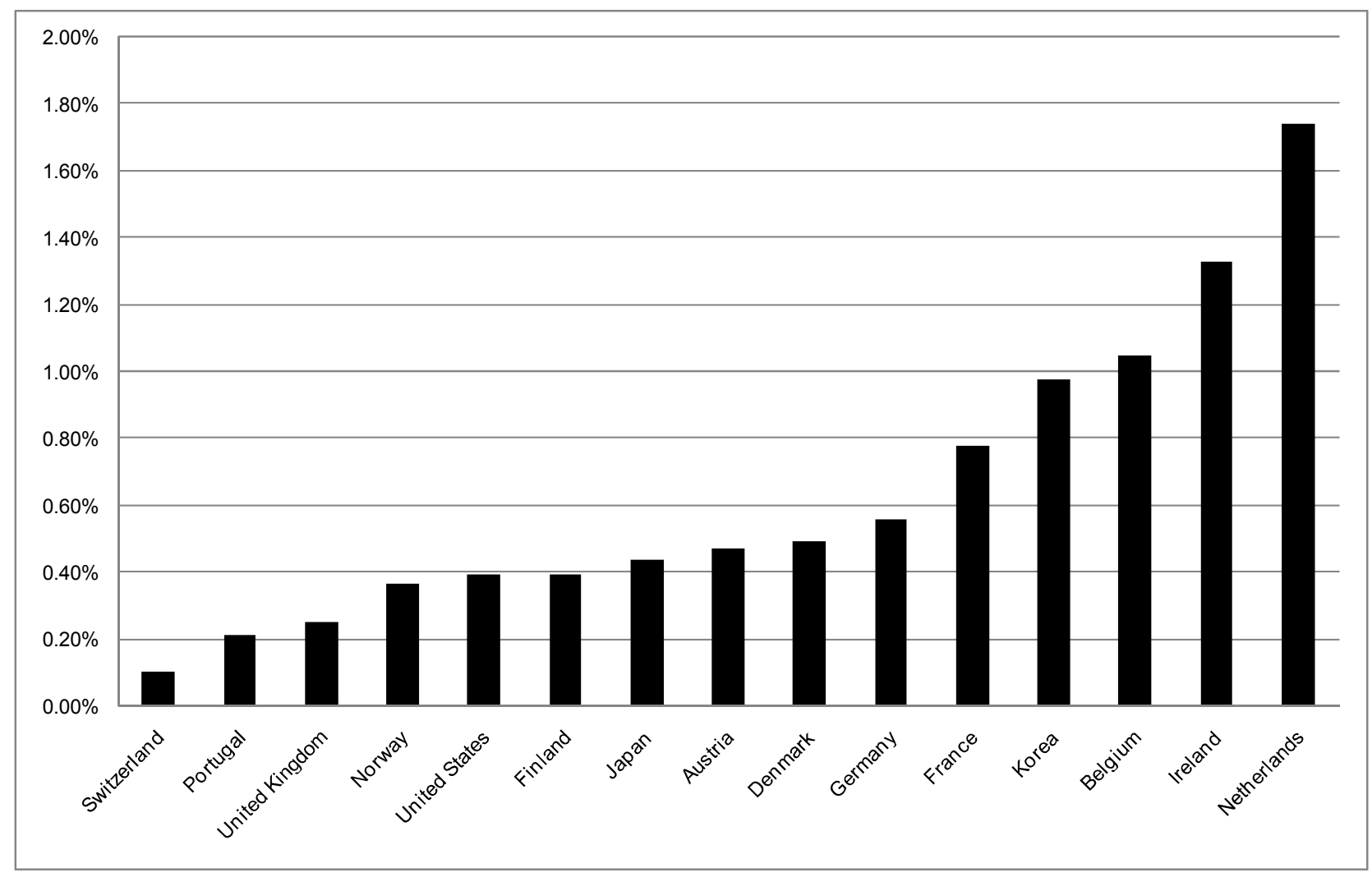

Adjusted by purchasing power parities.

Source : WPN Policy Questionnaire (2008).

Data on private sector investments have also been compiled by the European Commission and are shown in Figure 7 for the European Union, the United States, Japan, as well as the rest of the world. This Figure suggests a clear difference in the structure of R\&D investment. The United States and Japan have a significantly higher share of private versus public R\&D investments when compared with the European Union and others (more so, if EC funding and those of member countries are included). This structural difference is interesting and calls for further investigation once more detailed data becomes available. 
Figure 7. Structure of R\&D investments in the US, EU and Japan by institutional sector, 2004-06

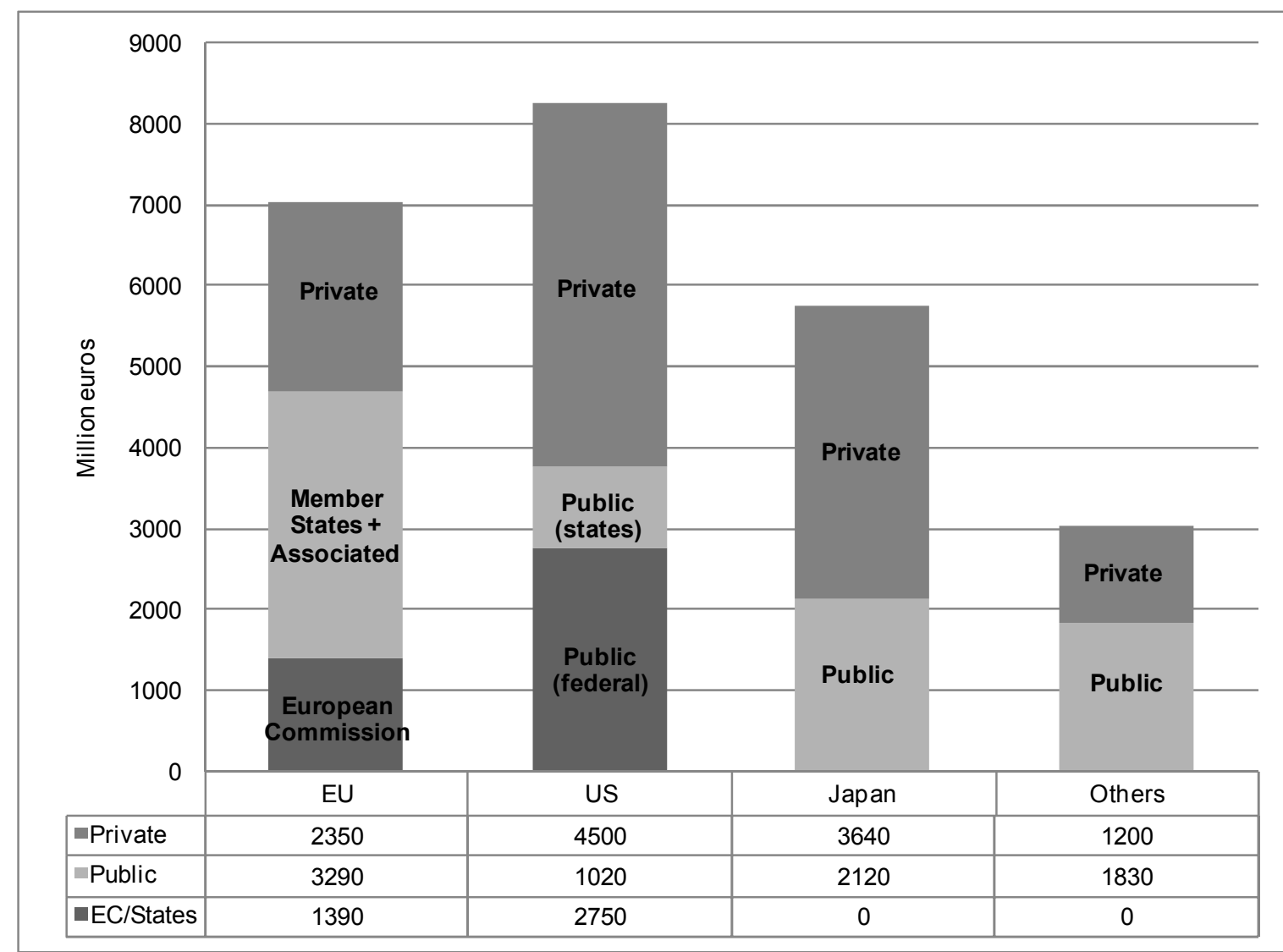

Source : Personal communication with the EC in 2009.

\section{Publications}

\section{Methodological considerations}

Publication data are used to capture research and development activities closer to basic science while patent data highlight activities further downstream from basic science. The many thousands of articles, notes, letters and reviews that are published daily in scientific journals, along with millions of citations between these publications, provide a paper trail of the development, structural relationships, and diffusion of scientific knowledge. Publications and their citations are also often used as indicators for the performance of the public research system of countries or specific universities and institutes. 


\section{Box 6. Advantages and limitations of publication data}

\section{Advantages:}

- Publications are closely linked to research activity

- They have been subject to peer-review for quality control

- They cover a broad range of scientific disciplines

- Publication data are available as long time series

- They are publicly available at a low cost

Limitations:

- Publication databases are biased in favour of English-language journals as the mainstream outlets

- They combine different journal-specific databases whereby targeted searches are cumbersome

- Publication data only cover the codified aspects of scientific research

- Citation data may not only reflect genuine interrelationships and quality of research

- Publication behaviour and propensities may vary significantly across disciplinary fields

Publication databases are very large and can sometimes be poorly indexed as they collect data from various journals with different indexing systems and nomenclatures. Emerging fields of science can be particularly hard to identify as new and dedicated journals come into being with a lag. As a consequence the delimitation of subsets of publications of specific scientific fields have typically been done using advanced keyword search algorithms that also consider cross-citation patterns and expert opinion. In the case of nanotechnology, an overview of some of the common approaches can be found in Porter et al. (2006) (see also Mogoutov and Kahane, 2007).

This section mainly draws on a dataset of nanotechnology-related publications based on the keyword search algorithm developed by a research group at the GeorgiaTech School of Public Policy in Atlanta, in the United States. The publication data has been extracted from the ISI Web of Knowledge database as provided by Thomson Reuters (see Porter et al. 2006 for a lengthier discussion). This keyword search algorithm and data sources identifies 563497 nanotechnology publications accumulated until 1 January 2008, corresponding to some $3 \%$ of all scientific publications in the database. It should be emphasized that the number of nanotechnology-related publications varies significantly depending on the definitions used in the search algorithms as well as on the data sources. ${ }^{6}$ Accordingly, more attention should be given to trends over time rather than to absolute numbers.

Publications can be assigned to countries through the affiliation of the authors, leading to a rather skewed picture as a few large countries tend to dominate in scientific activity. ${ }^{7}$ When considering the distribution of nanotechnology-related publications versus all publications by country, in Figure 8 , the dominance of the United States (22\%), China (11\%), Japan (10\%), as well as Germany (8\%), France (6\%), and the United Kingdom (5\%) is clear. These six countries account for $63 \%$ of all nanotechnology-related publications; they are also the ones that have been 'traditionally' most visible in terms of R\&D initiatives in nanotechnology and they also dominate by the number of all publications.

6. See Porter (2006) and Li et al. (2007) for a further discussion on the variability in the number of publications and patents.

7. Please note that the same publication $t$ may thereby be assigned to multiple countries whereby the sum of country totals may not add up to the total number of publications. The alternative approach of using fractional counts, giving proportional allocation of publications to countries by the affiliation of authors, could not be readily calculated. 
Figure 8. Share of nanotechnology-related and all publications by country, 1991-2007

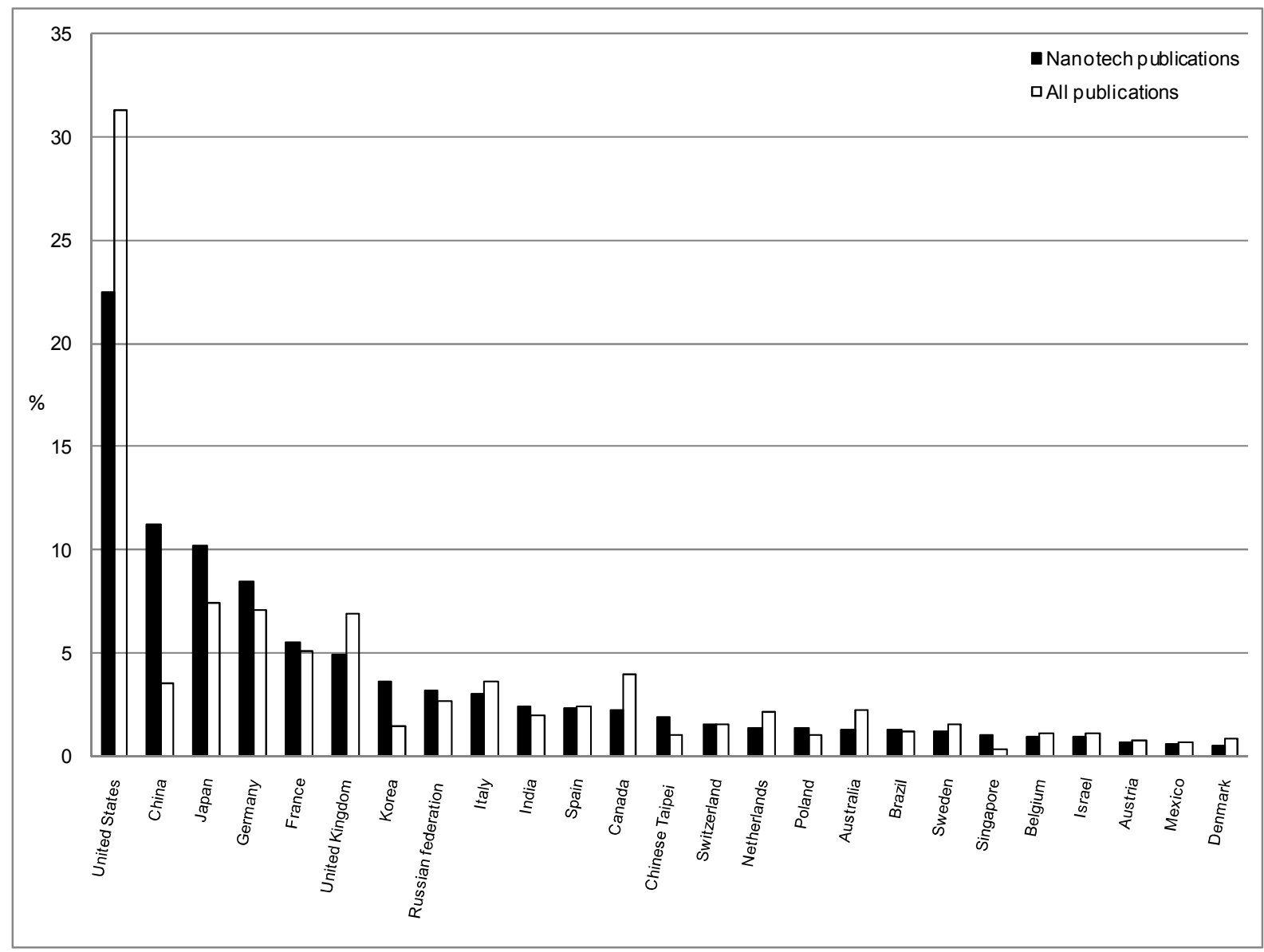

The Figure includes the top 25 countries by the share of nanotechnology-related publications 1991-2007.

Source: ISI Web of Knowledge, January 2008.

When considering the share of nanotechnology publications relative to that of all publications China, Korea, and Singapore are the only countries with a significantly higher share of nanotechnology-related publications. In so far as this indicator captures the scientific focus of researchers, it points to the growing role that these rapidly developing countries are playing in nanotechnology-related sciences. Other countries with a similar, although less pronounced, focus on nanotechnology-related sciences include Japan, Germany, France, Russia, India, Poland, Chinese Taipei and some smaller countries. Contrary to this, the United States, United Kingdom, Canada and Australia have the opposite focus with a higher share of all publications when compared with that of nanotechnology-related publications.

\section{Developments over time and across countries}

Overall, nanotechnology-related publications are increasing at rates that clearly exceed those for all publications contained in the database. This may be due to an increasing emphasis on nanotechnology in STI policy, as demonstrated by the NNI initiative in the United States and similar initiatives in Japan and the European Union. However, it is also possible that a few high-profile scientific discoveries have led to the coalescence around the term 'nanotechnology', which in turn solidified its use, while also encouraging researchers from adjacent fields (e.g. biology, engineering generally) to begin to work on nanotechnology topics. 
Figure 9. Number of nanotechnology-related publications

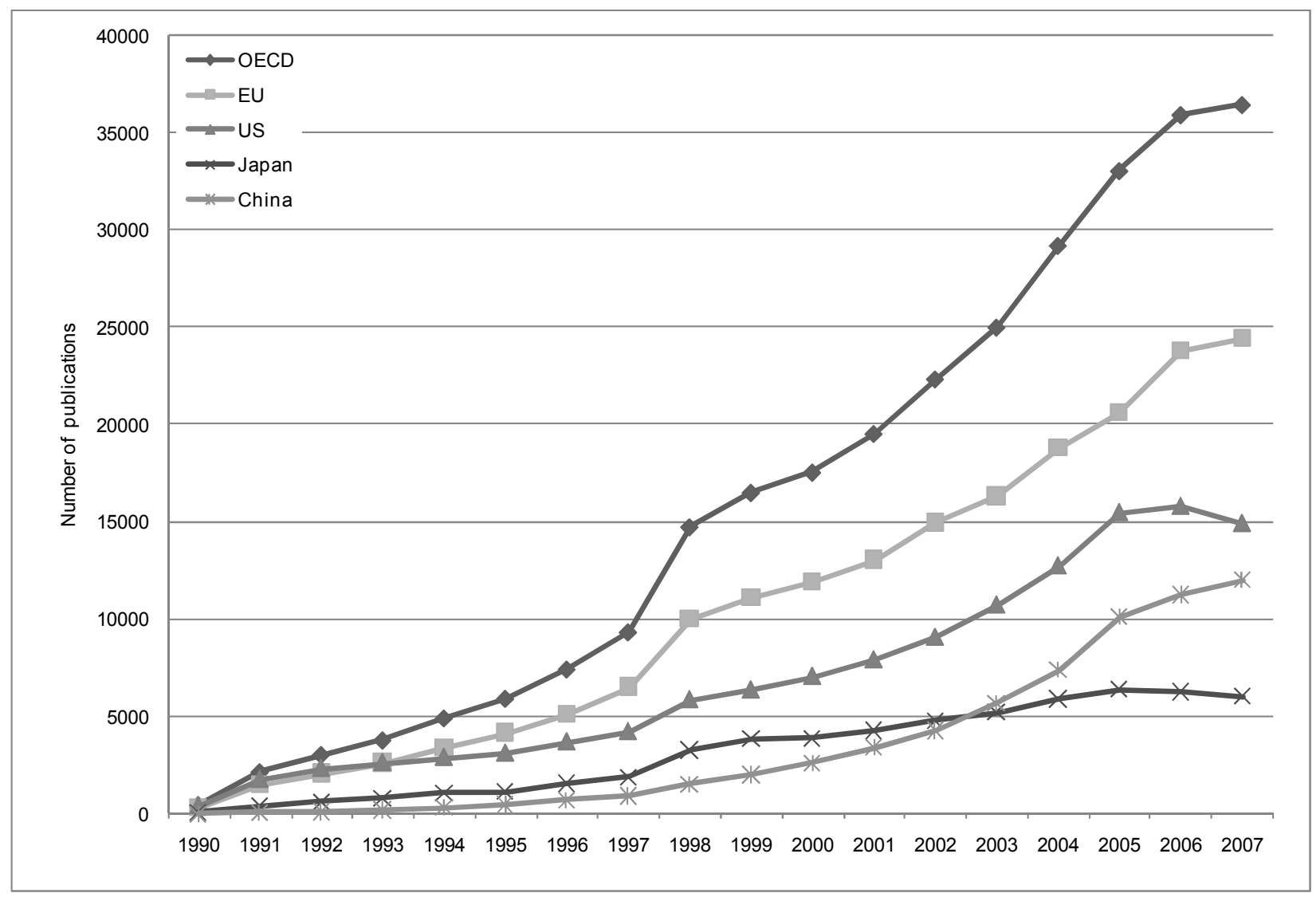

Source: ISI Web of Knowledge database, January 2008.

Figure 9 presents the growth in the number of nanotechnology publications over time across the main economic regions of the world, including China as well as the OECD and EU (includes all $27 \mathrm{EU}$ member countries) for comparison ${ }^{8}$.

The European Union fares well in this comparison. Developments in the United States and Japan are as expected, based on their shares of total nanotechnology publications. However, the rapid growth of Chinese publications is especially noteworthy. China has already overtaken Japan and is approaching the United States and the European Union in the number of publications, and may soon account for a significant share of all nanotechnology-related publications. Michelson (2008) suggests that China is starting to play a key role in R\&D in this field, thereby becoming an important collaborative partner for other countries. However, Appelbaum and Parker (2008) also highlight lags in the commercialisation of nanotechnology in China.

8. Please note that the total number of publications for the United States, European Union and Japan exceeds the OECD total as one publication may be assigned to multiple countries; authors from the United States, European Union and Japan contribute relatively much more frequently to publications in this (and other) fields compared to the remaining countries. 
Figure 10. Average annual growth rates of nanotechnology-related and all publications by country, 1996-2006

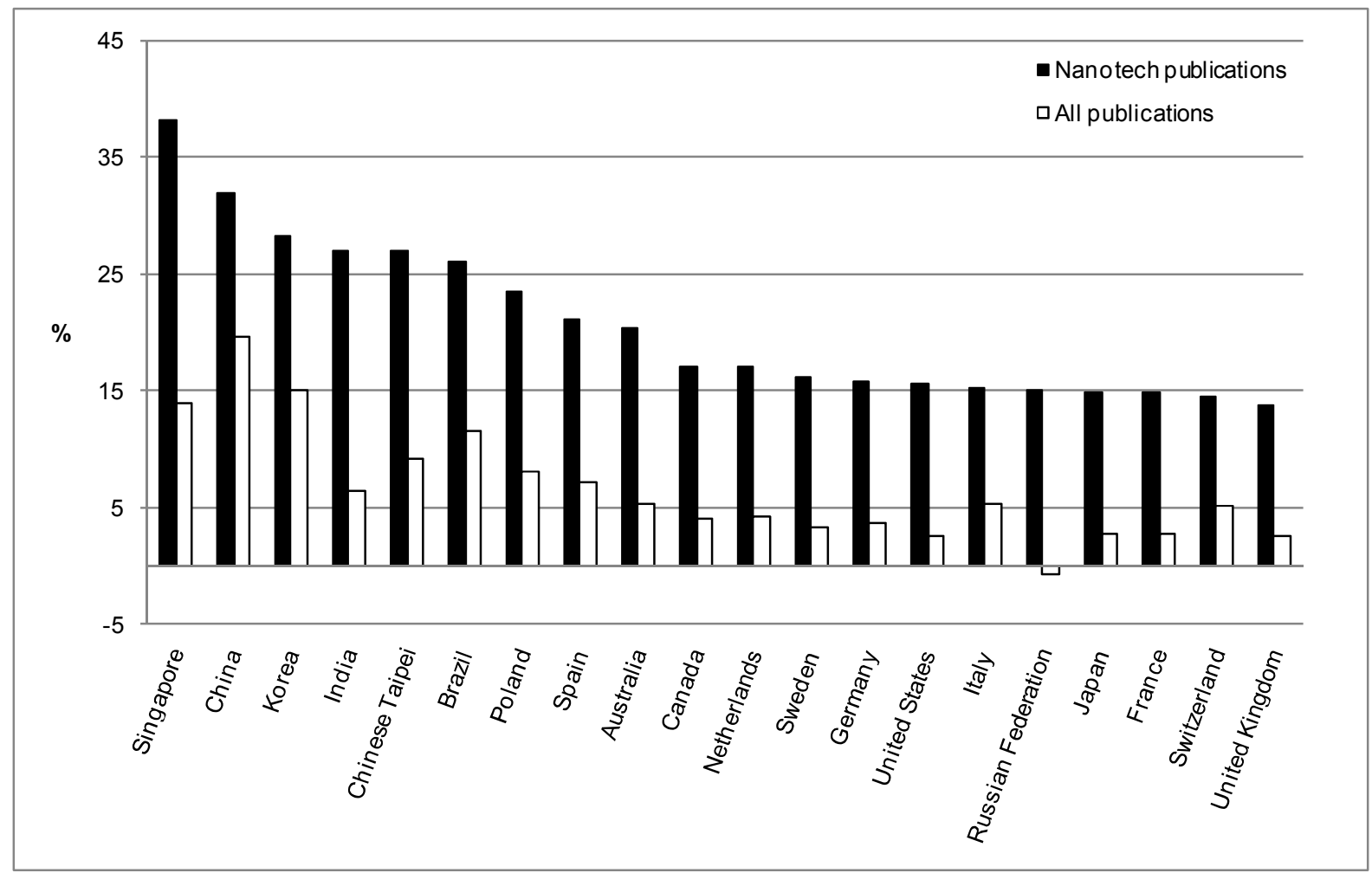

The Figure includes the top 20 countries by the growth rate of nanotechnology-related publications 1996-2006.

Source: ISI Web of Knowledge Database, January 2008.

For further insights, Figure 10 illustrates average annual growth rates in nanotechnology-related publications across countries, while also comparing these with the growth rates for all publications of the countries. As could be expected the dominating countries (United States, Japan, Germany, the United Kingdom and France) by the number of nanotechnology-related publications have witnessed lower growth rates when compared with the "newcomers" such as China, Korea, India, Chinese Taipei and Singapore (although growth starts from low levels in these countries). Rapid and above average growth rates are also noticeable in Brazil, Poland, Spain, Australia and Canada, as well as in the Russian Federation.

\section{The significance of publications and structure of sciences}

Publications counts such as those above, will give an overall view of developments over time and across countries. However, the significance of publications will also differ - the volume of publications may only point to the level of scientific activity of countries rather than to its quality. Data on citations between publications can be used as one indicator of the significance of publications, for example by identifying a subset of highly-cited publications under the assumption that the more citations a particular paper receives in subsequent publications the higher its quality.

Igami and Saka (2007) identify such a subset of publications in the ISI Web of Knowledge database for 1999-2004. Their methodology identifies 47218 publications classified as highly cited ('core publications') based on a pre-defined citation threshold, and another subset of publications which cite these core publications ('citing publications'). They propose that these two indicators can highlight the position of countries vis-à-vis the scientific frontier of specific areas (the core publications) and their position in 
terms of "catching-up" with this scientific frontier (the citing publications). The position of countries in the field of "nanoscience and materials" with respect to these two indicators is displayed in Figure 11.

Figure 11. Share of core and citing nanotechnology-related publications by country, 1995-2004

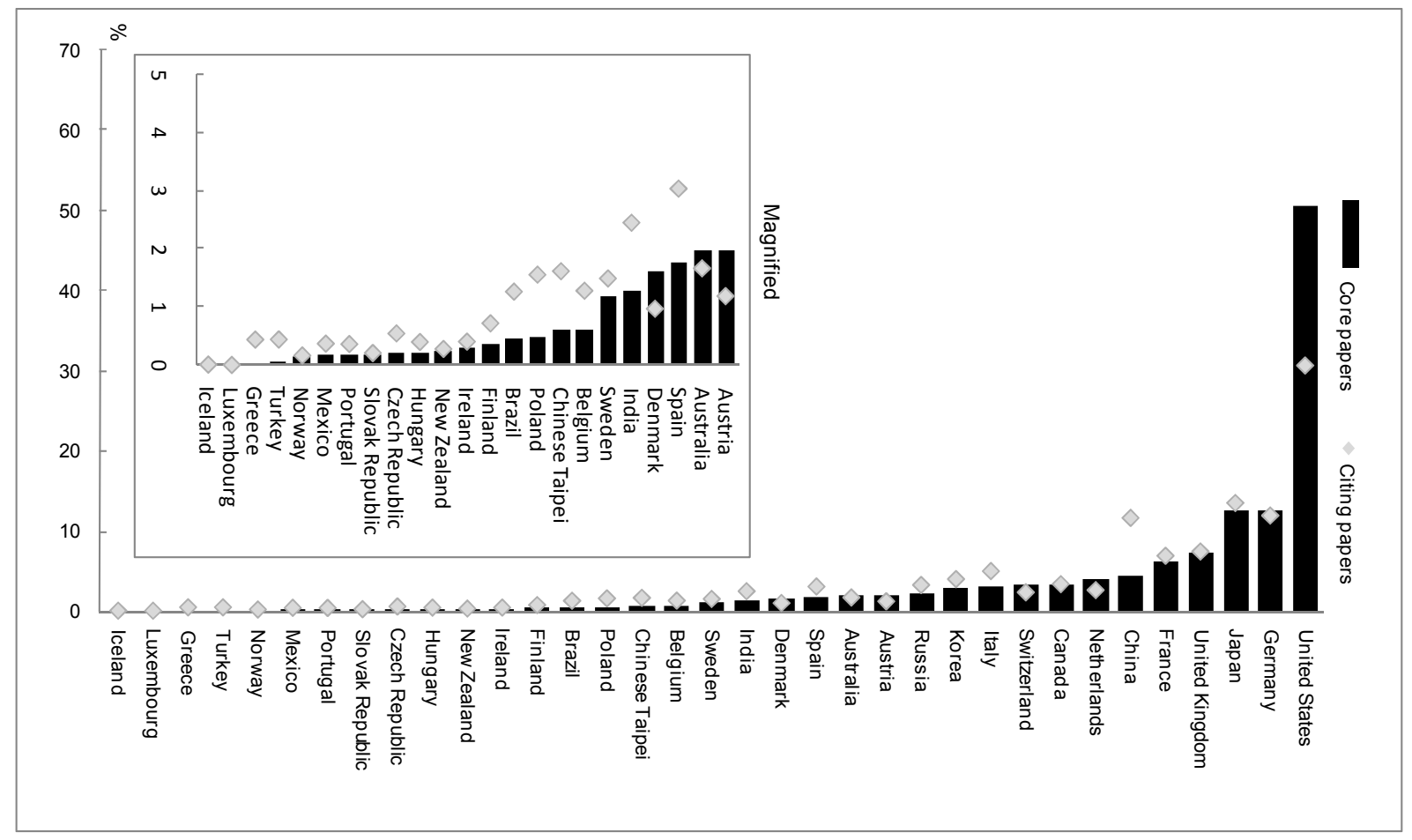

Source: Igami and Saka (2007).

The Figure reinforces the impression of the dominating role of the United States also when a threshold criteria for the significance of publications is included. Beyond this the picture is more varied. Japan's overall performance is good; while European Union countries perform relatively better in the subfields of chemical synthesis, superconductivity and quantum computing (the sub-fields are not shown in the Figure). The Asian countries China, Korea, India and Chinese Taipei perform relatively better in the subfields of nanomaterials and devices. Igami and Saka (2007) conclude that especially China appears to be catching-up with the scientific frontier of nanotechnology based on its growing share of citing publications. Hence the rise of China is also evident when considering a quality threshold for publications (a similar observation is made in Zhou and Leydersdorff 2006).

A final viewpoint is to consider the knowledge base of nanotechnology-related publications in terms of the different scientific disciplines to which these publications relate. The interdisciplinary nature of research in nanotechnology should show up in the broadness of scientific disciplines in which publications originate and especially in the interrelationships between these disciplines. A practical approach to consider this is to analyse a random sample of some 900 of all nanotechnology publications for selected years for which more detailed information was obtained. Of prime interest are the so-called subject categories to which publications in the database are assigned, displayed in Table 3 as shares of the number of publications across all subject categories for 1991, 1995, 2001 and 2005. 
DSTI/DOC(2009)7

Table 3. Nanotechnology-related publications by scientific fields

\begin{tabular}{|c|c|c|c|c|}
\hline Subject categories of publications & 1991 & 1995 & 2000 & 2005 \\
\hline Materials Science, Multidisciplinary & $9 \%$ & $14 \%$ & $12 \%$ & $14 \%$ \\
\hline Physics, Applied & $17 \%$ & $13 \%$ & $13 \%$ & $11 \%$ \\
\hline Chemistry, Physical & $7 \%$ & $8 \%$ & $9 \%$ & $10 \%$ \\
\hline Physics, Condensed Matter & $13 \%$ & $11 \%$ & $12 \%$ & $9 \%$ \\
\hline Chemistry, Multidisciplinary & $3 \%$ & $4 \%$ & $4 \%$ & $7 \%$ \\
\hline Polymer Science & $3 \%$ & $5 \%$ & $4 \%$ & $5 \%$ \\
\hline Engineering, Electrical \& Electronic & $7 \%$ & $5 \%$ & $3 \%$ & $3 \%$ \\
\hline Physics, Multidisciplinary & $2 \%$ & $3 \%$ & $3 \%$ & $3 \%$ \\
\hline Physics, Atomic, Mol. \& Chemical & $3 \%$ & $2 \%$ & $2 \%$ & $3 \%$ \\
\hline Optics & $2 \%$ & $2 \%$ & $3 \%$ & $2 \%$ \\
\hline Electrochemistry & $1 \%$ & $2 \%$ & $1 \%$ & $2 \%$ \\
\hline Biochemistry \& Molecular Biology & $1 \%$ & $1 \%$ & $1 \%$ & $2 \%$ \\
\hline Engineering, Chemical & $0 \%$ & $1 \%$ & $2 \%$ & $2 \%$ \\
\hline Chemistry, Analytical & $2 \%$ & $2 \%$ & $2 \%$ & $2 \%$ \\
\hline Materials Science, Ceramics & $0 \%$ & $1 \%$ & $1 \%$ & $2 \%$ \\
\hline Materials Science, Coatings \& Films & $3 \%$ & $1 \%$ & $2 \%$ & $1 \%$ \\
\hline Metallurgy \& Metallurgical Engineering & $1 \%$ & $2 \%$ & $2 \%$ & $1 \%$ \\
\hline Crystallography & $2 \%$ & $1 \%$ & $2 \%$ & $1 \%$ \\
\hline Biophysics & $1 \%$ & $1 \%$ & $1 \%$ & $1 \%$ \\
\hline Chemistry, Inorganic \& Nuclear & $1 \%$ & $1 \%$ & $1 \%$ & $1 \%$ \\
\hline Engineering, Multidisciplinary & $0 \%$ & $0 \%$ & $0 \%$ & $1 \%$ \\
\hline Multidisciplinary Sciences & $2 \%$ & $1 \%$ & $1 \%$ & $1 \%$ \\
\hline Instruments \& Instrumentation & $1 \%$ & $1 \%$ & $1 \%$ & $1 \%$ \\
\hline Materials Science, Biomaterials & $0 \%$ & $1 \%$ & $1 \%$ & $1 \%$ \\
\hline Engineering, Mechanical & $0 \%$ & $0 \%$ & $1 \%$ & $1 \%$ \\
\hline Environmental Sciences & $0 \%$ & $0 \%$ & $0 \%$ & $1 \%$ \\
\hline Biochemical Research Methods & $0 \%$ & $0 \%$ & $1 \%$ & $1 \%$ \\
\hline Chemistry, Organic & $0 \%$ & $0 \%$ & $1 \%$ & $1 \%$ \\
\hline
\end{tabular}

The Table includes the 30 most frequent scientific disciplines as defined by ISI Web of Knowledge.

Source: Rafols and Porter (2008).

The table provides some evidence of the broad-based nature of nanotechnology-related research. Materials science and various sub-fields of physics and chemistry account for the largest shares with little variations throughout the period. Based on the table it is difficult to assess the contribution of biotechnology research as this field is not defined separately, although the shares of fields such as biochemistry and molecular biology, chemical engineering, analytical chemistry, crystallography, biophysics etc. are rather small. However, it is possible to consider how these scientific disciplines are interrelated with each other to assess the role of interdisciplinarity using a so-called map of science. Figure 12 presents such a map based on this same randomly drawn sample of nanotechnology-related publications. 


\section{DSTI/DOC(2009)7}

Figure 12. The structure of nanotechnology-related sciences by publications across disciplines, 2005

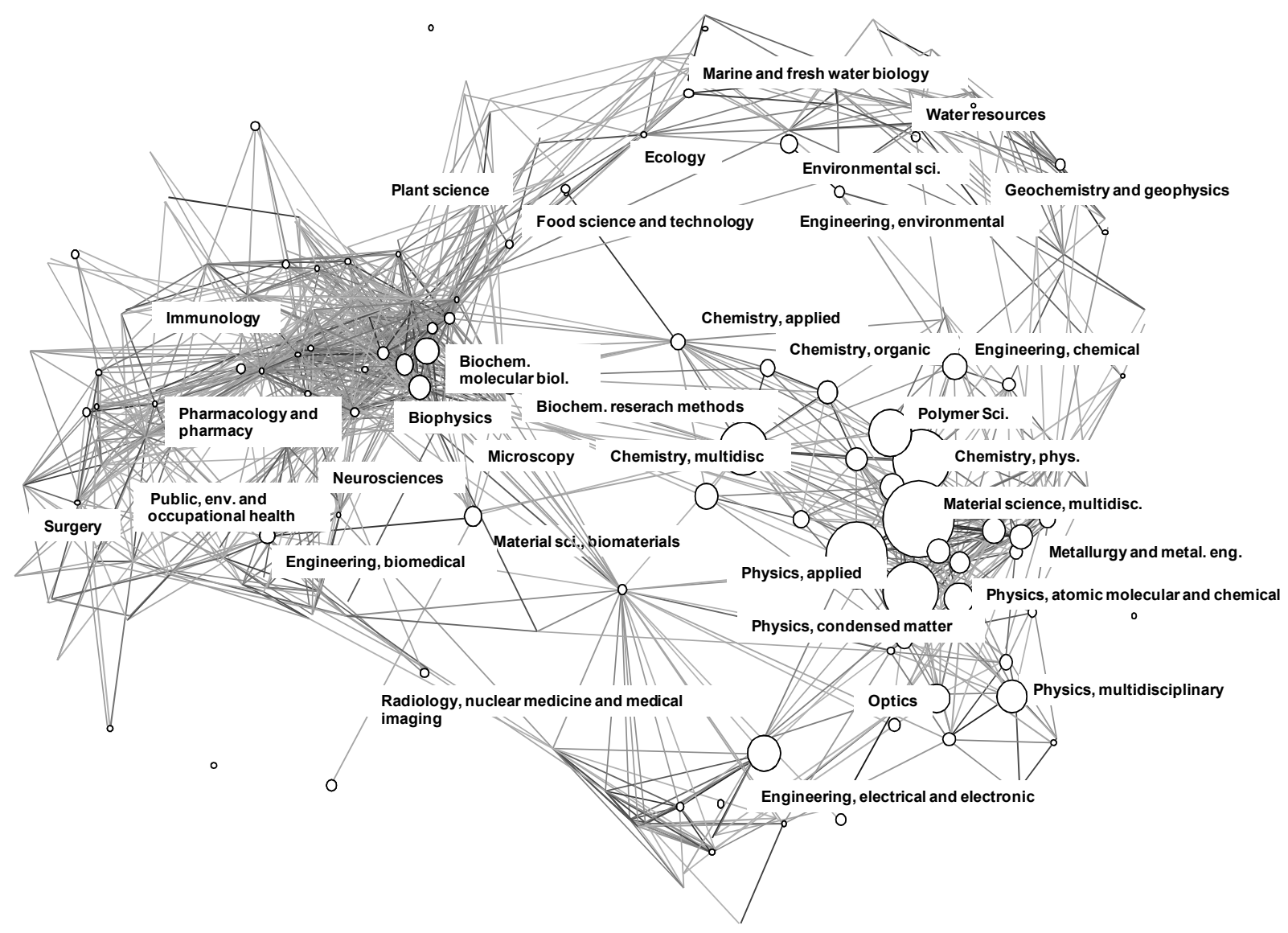

Source: Rafols and Porter (2008).

In this Figure each circle represents those specific scientific disciplines that have been the subject of more intense publication activity with the size of the circle indicating the number of nanotechnologyrelated publications. The lines connecting the circles represent overlaps in citations between the scientific disciplines and thus give an indication of the similarity between disciplines. The Figure indicates the degree to which nanotechnology draws on a variety of different disciplines (see Box 7 below for a further discussion about the methodology).

\section{Box 7. Interpreting science maps}

The structure of the science map in Figure 12 was obtained as follows. Data from 2006 from the Journal Citation Reports was aggregated by scientific disciplines. The resulting cross-citation matrix was then used to compute cosine correlation between disciplines. These correlations determined the relative distance between disciplines according to standard network visualisation algorithms. On this full-science backbone, circles with size proportional to square root of the number of nanotechnology-related publications were overlaid (see Porter et al. (2006) for details).

Source : Rafols and Porter ( 2008).

The main scientific disciplines are found in the broader field of physics, even though the role of chemistry is also noteworthy. Some of the core fields include materials sciences, applied and condensed matter physics, with lesser clustering of publications in the specific fields of atomic, molecular and chemical physics, optics, polymer sciences, applied and organic chemistry. Figure 12 also highlights linkages between physics, chemistry and biology-related fields. Some of the more significant biology- 
related fields include biochemistry, biophysics as well as various fields (pharmacology and pharmacy, immunology, biomedical engineering and cardiac and cardiovascular systems) that assumedly relate to nanobiotechnology and its relevance to pharmaceuticals and health care. It is also interesting to note adjacent fields, such as marine and fresh water biology, water resources, environmental sciences, geochemistry and geophysics, and electrical and electronic engineering.

An analysis of scientific linkages between publications over time, extending back to the early 1990s, does not provide an indication of significant change (this analysis is not shown here); there is similarity in the distribution of publications by disciplines as well as by the interrelationships between them. Likewise, the elaborated analysis of the degree of interactions and coherence across the scientific fields does not show noteworthy increases in the extent of these interactions, nor in their overall coherence. Accordingly, while scientific advances related to nanotechnology appear to depend on interdisciplinarity, the structure of this interdisciplinarity does not appear to have changed significantly over time.

\section{Patenting}

\section{Methodological considerations}

Even though limitations have to be acknowledged also when using patent data, these data provide a good source for tracing nanotechnology research and development activities further downstream from basic science. Patent data capture the intermediate stages of innovation activities and are thus especially relevant for analysing emerging technologies, such as nanotechnology. Patent data provide a rich source of information on various aspects of innovation activities and they are also available as long time series (see Box 8 for advantages and limitations of using patent data).

\section{Box 8. Advantages and limitations of patent data}

Advantages:

- Patents are closely linked to inventions

- They cover a broad range of technologies on which there are sometimes few other data sources

- The content of patent documents is a rich source of information

- Patent data are available as long time series and across many (most) countries

- They are readily available from patent offices

Limitations:

- The value distribution of patents is skewed as many patents have no industrial application (and hence are of little value to society) whereas a few are of substantial value

- Many inventions are not patented because they are not patentable or inventors may protect their inventions using other means

- The propensity to patent differs across countries, industries and companies

- Differences in patent regulations make it difficult to compare counts across countries

- Changes in patent law over the years make it difficult to analyze trends over time

Source : OECD Patent Manual 2008.

Nanotechnology patents have been identified by keyword searches of the title, abstracts, keywords or complete text files of patents in a similar way that publications are identified. Since the mid-2000s the identification of these patents has become easier as the United States, Japanese and European patent offices have started to tag nanotechnology patents through standardised procedures. The ensuing analysis of nanotechnology patenting is based on so called PCT (Patent Cooperation Treaty) patent applications designated to the European Patent Office (EPO); also called Euro-PCT applications. This source offers the most comprehensive coverage of international patent applications while also avoiding some of the country 


\section{DSTI/DOC(2009)7}

biases when using country offices such as the US Patent Office (USPTO) or the Japanese Patent Office (JPO). Moreover, as PCT applications target a global market it can be argued that they represent more significant technologies and inventions than those applications in national patent systems alone (see Box 9).

\section{Box 9. The PCT application process}

Applications filed under the Patent Cooperation Treaty (PCT) now constitute a large and increasing share of filings at the EPO. A PCT treatment gives the applicant the option of launching the patent application in up to 115 signatory countries within 30 months of the filing, or so-called priority date. PCT applications are advantageous for several reasons. First, they allow the expansion of patent protection to a large number of countries without incurring the full costs and complexity of national applications. Second, applications will receive an international search report within a relatively short period of time, informing them about prior art that may be relevant tor their own applications' likelihood of being granted. Third, when compared with a national or regional application a PCT application has greater option value since it allows applicants to delay decisions about the countries for which they seek patent protection for up to 30 months (and not just the duration of the priority year as with national or regional applications). PCT applications can also receive a preliminary international examination which is authoritative but non-binding for the national or regional offices finally granting the patent. It should be noted that a PCT application bears some similarity to the concept of a patent family as one such application can be broken down into a number of individual patents designated to specific countries.

Source: OECD Patent Manual 2008

The tagging of patents to nanotechnology by the EPO is based on the definition presented in Table 1 above. It was initiated through the establishment in 2003 of a working group, where nanotechnology patents have been tagged through a continuous process of using both keyword searches and consultations with experts. This tagging exercise was also undertaken retroactively for years before 2003 to give proper time series (Scheu et al., 2006). One issue that complicates patent analysis is the concept of a patent family. A patent family is a group of patent publications related to a single invention, filed by the same applicant(s) in one or more countries. Thus, while each patent of the family usually targets different geographical markets they may be considered to be duplicate observations for the same underlying invention. A patent family can thereby inflate patent counts if the focus is on individual inventions rather than on overall trends, as in this report.

For this report all nanotechnology applications designated to EPO up to 1 January 2008 were identified (i.e. the same end-date as the publication data discussed above). The criteria of PCT applications narrowed down a bigger dataset to 9848 applications, some of which may belong to the same patent family, as discussed above. ${ }^{9}$ The decision to focus on applications rather than grants is based on data truncation and coverage issues. PCT applications are made public on average some 18 months earlier than grants and thus represent more timely data. Furthermore, applications indicate ongoing innovation activities while grants only include those patents that have not subsequently been withdrawn or rejected (despite the important difference between applications and grants the word patents will be used from here on for the sake of clarity). All figures showing trends over time are based on the priority date of the application; the priority date is the closest to the date of the invention. The latest complete year of the data is 2004 while they also contain observations from 2005.

Before proceeding it is important to consider how the actual counts of nanotechnology patents should be interpreted as the number of patents vary significantly from one study to the next. For example, at the one extreme Huang et al. (2004) and Li et al. (2007) identify some 60 000-80 000 patent applications related to nanotechnology and filed at the USPTO during 1976-2003, while Marinova and McAleer (2003) detect since the mid 1990s annual numbers in the range of 4000 in the same data source. At the other

9.

According to a rough estimate some $35 \%$ of all patents (applications and grants) tagged to the EPO nanotechnology class are members of patent families. 
extreme there are the studies such as Noyons et al. (2003) and Heinze (2004), Hullmann (2006) and the OECD (2007) which identify far less.

These discrepancies in the numbers are mainly related to the definitions of nanotechnology and the data sources used (compare also with Li et al. (2007)). Thus both Marinova and McAleer (2003) and Huang et al. (2004) use very broad keywords searches directed at either the full-text or title claims of patents and only search the USPTO database with a higher probability of including patenting by domestic US inventors. Noyons et al. (2003) and Heinze (2004) base their definitions on more elaborated keyword search algorithms while limiting the data sources to EPO and/or international applications, such as in this report. Further, as noted above, the treatment of patent families in these analyses varies and this also results in different counts.

Patents can be assigned to countries through the affiliation of the inventors, leading to an even more skewed picture when compared with publications, as the United States has a $48 \%$ share of all nanotechnology patents, followed by, Japan (14\%) and Germany (10\%) (see Figure 13). The remaining countries individually account for less than $5 \%$ of all of these patents; this corresponds to less than 500 patents per country with a large share having less than 50 patents. When comparing countries shares of total nanotechnology-related patents to those of all patents, the United States and Japan has a significantly higher share relative to all patents while the opposite is true for Germany. The remaining countries appear more active in patenting generally speaking. In contrast to the publication data, all patent figures arranged by country in this report are based on fractional counts of the country affiliation of the inventors involved in the patents. ${ }^{10}$

10. Fractional counts imply that each country affiliation of inventors is given a proportional allocation of patents. As a consequence, the sum of country totals will add up to the sum of the total number of patents. This approach is thus different compared with the one used for nanotechnology-related publications assigned to countries. 
Figure 13. Share of nanotechnology and all patents by country, until 2005

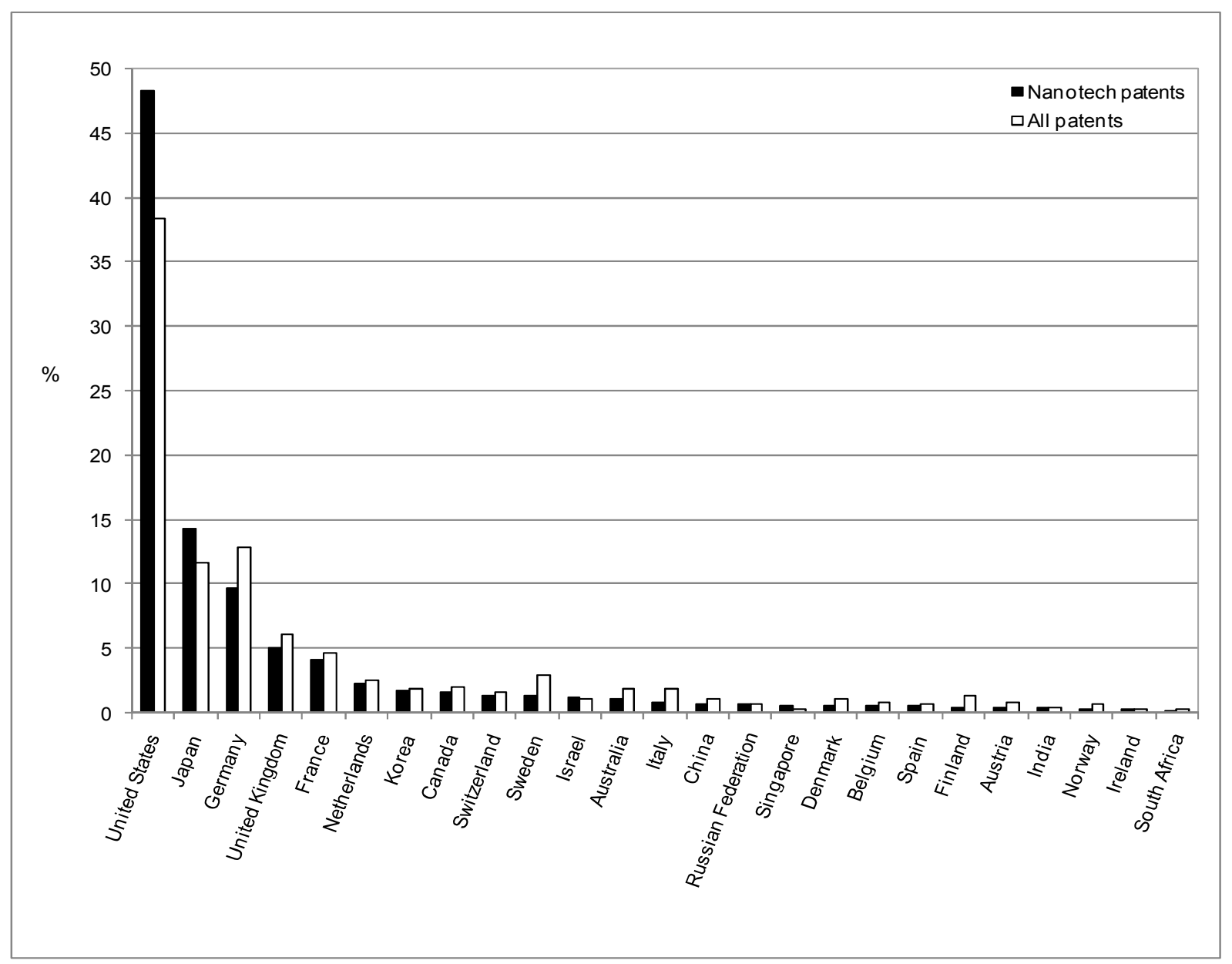

The Figure includes the top 25 countries by the share of nanotechnology patents accumulated until 2005 by priority date.

Source: OECD, Patent database, January 2008.

\section{Developments over time and across countries}

Compared with publications the number of patents (i.e. 9848 patents compared with 563497 publications) is still relatively small; this is typically the case for emerging technologies. Growth in nanotechnology patenting has started recently and from very low levels, although this growth now clearly exceeds that for overall patenting. Nanotechnology patenting has probably been stimulated by the introduction and further diffusion of key enabling inventions in instrumentation since the mid-1980s, such as the STM and AFM (Kaiser, 2006). Similarly to publications, the acceleration in patenting since the early 2000s has surely also been nurtured by the establishment of the NNI initiative in the United States and other nanotechnology programme in Europe and Asia (see Huang et al., 2005; Roco, 2006). 
Figure 14. Number of nanotechnology patents

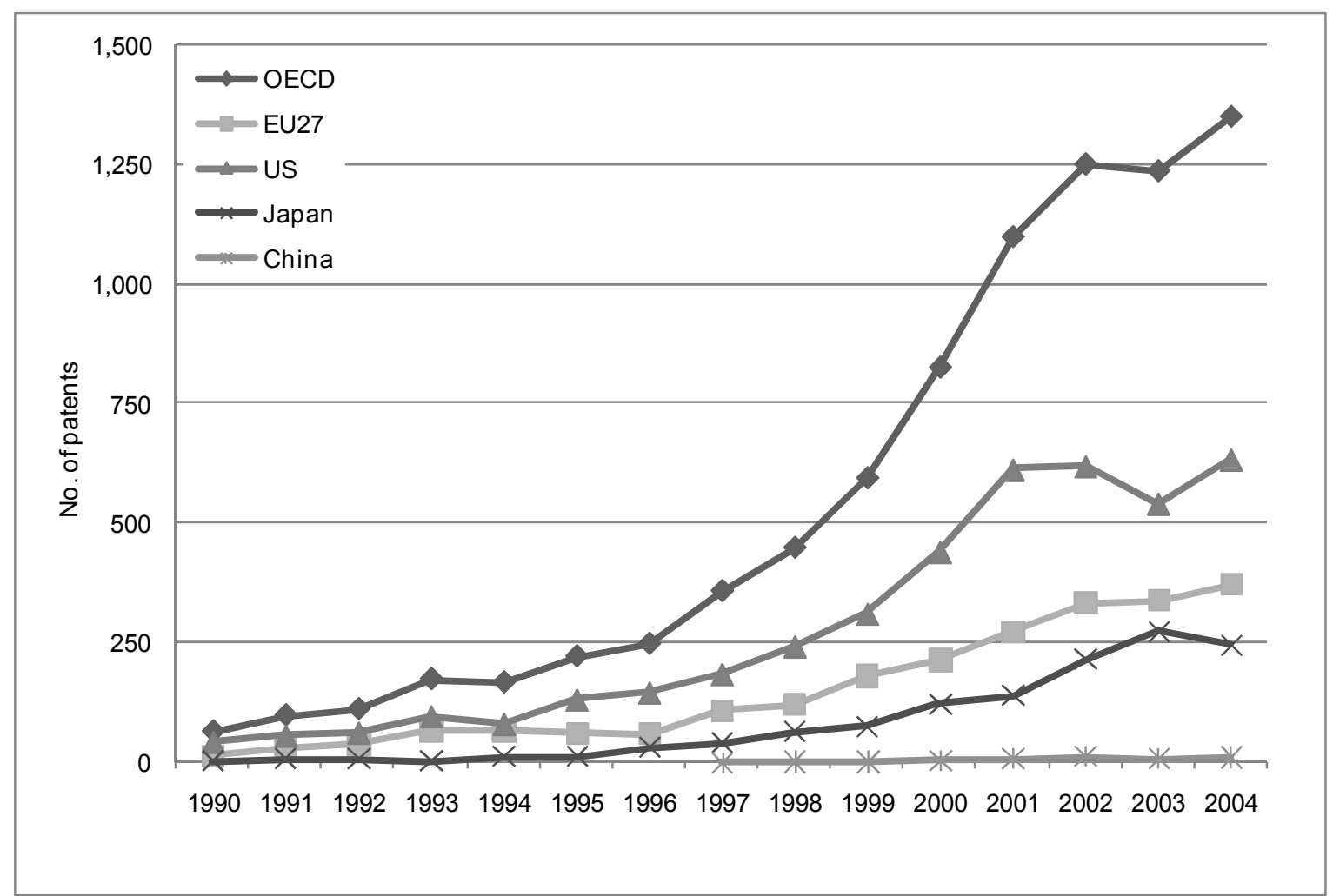

Source: OECD, Patent database, January 2008.

Figure 14 presents the number of nanotechnology patents over time across the main economic regions/countries of the world, including OECD total for comparison. These developments are similar to trends in nanotechnology-related publications, although China does not proliferate in nearly the same way as it does for publications.

Overall, it can be noted that nanotechnology patenting bears some resemblance to developments in biotechnology following the introduction and diffusion of certain key enabling inventions. When normalising the growth of biotechnology and nanotechnology patents to the base years of these key enabling inventions (in the case of biotechnology this concerns the invention of recombinant DNA in 1973 while for nanotechnology it concerns the STM and AFM related to microscopy and invented in the mid1980s) a similar time lag of about 12-13 years in the surge in patenting can be observed (Zucker and Darby, 2005). This resemblance can point to certain similarities in the sources of bio- and nanotechnology innovation, such as the reliance on underlying scientific developments.

Figure 15 illustrates the average annual growth rate across the top 25 countries, while also comparing nanotechnology patenting with overall patenting. As expected, countries with a larger overall share of nanotechnology patents have experienced lower growth rates, while recent entrants to the field have experienced much higher growth rates. Korea, India, Poland, China and the Russian Federation are amongst the top ten in terms of growth rates, along with Japan and France as the more established countries. Even though growth starts from very low levels in the newcomer countries the figure does suggest that the thrust of innovation in nanotechnology is spreading also beyond the United States and the European Union towards BRIC countries (Brazil, Russia, India and China) and Korea. 
Figure 15. Average annual growth rates of nanotechnology and all patents by country, 1995-2004

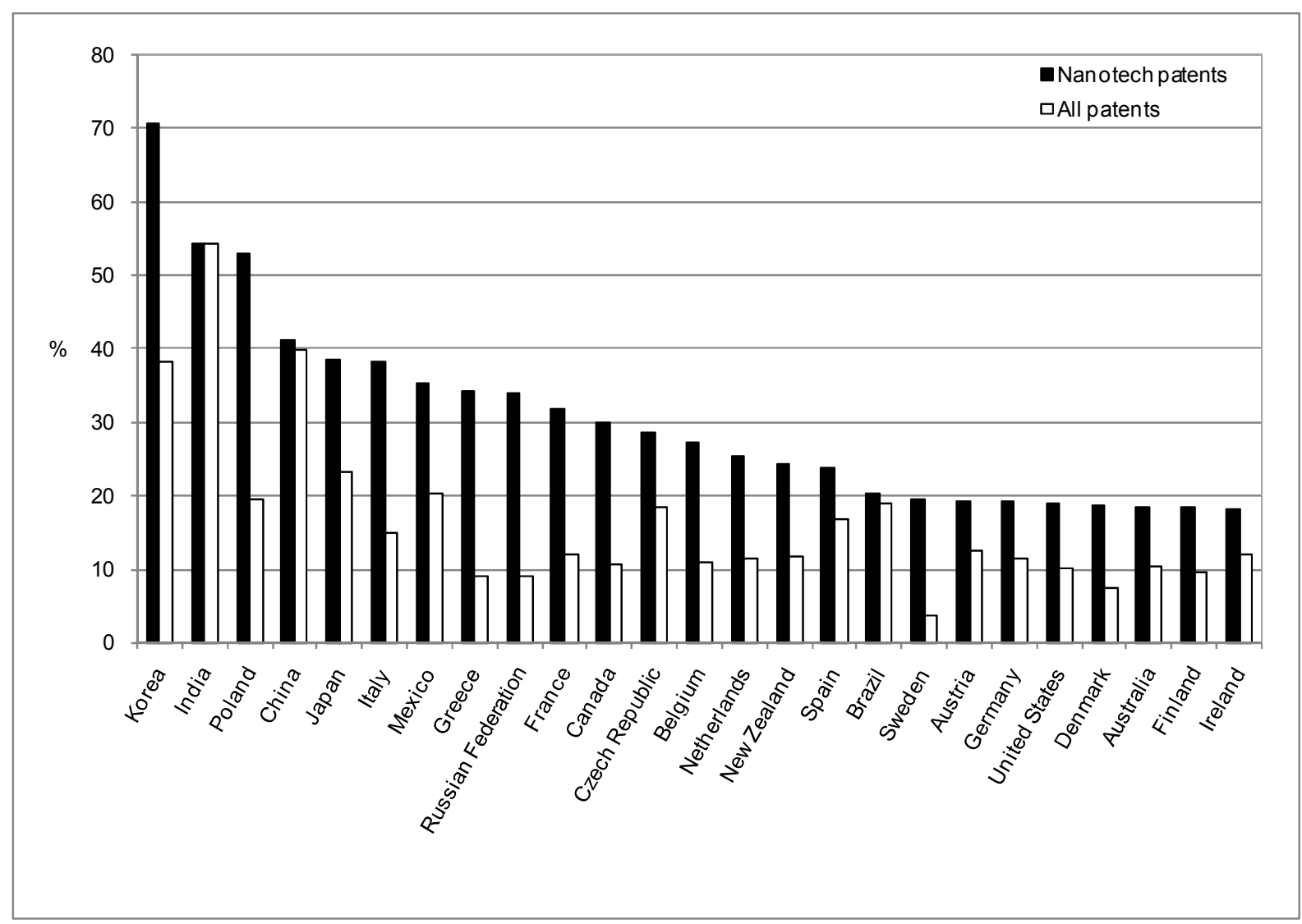

The Figure includes the top 25 countries by the growth rate of nanotechnology patents 1995-2004.

Source: OECD Patent database, January 2008.

These figures are also in line with previous studies to which reference was made above. Similar growth trends are evident when looking at nanotechnology patent applications at the US patent office. Further, the same countries emerge as newcomers in the 2000s even when nationality is defined by the residence of the owner rather than the inventors of the patents. Due to a probable country bias in some of these other studies the dominant position of the United States in patenting is even more striking while Canada and some other European countries also rank somewhat higher in terms of growth rates in recent years.

\section{Patenting across regions}

One feature of R\&D activities is their agglomeration to specific regions rather than being evenly distributed within countries. Interesting questions are whether nanotechnology-related activities tend to concentrate in certain regions, and whether these regions are the traditional hotspots for emerging technologies, e.g. the location of top universities, the availability of key researchers and skilled engineers, supporting large companies or an overall favourable environment for innovation. Patents can be assigned to specific regions based on the postal code of the affiliation of inventors. 


\section{Box 10. The geographic concentration index}

The geographic concentration index is defined for the variable $y$ as: where $y_{i}$ is the share of patents of region $i$ to the national total, $a_{i}$ is the area of region $i$ as a percentage of the country area and $\mathrm{N}$ stands for the number of regions. The index ranges from 0 (no concentration) to 100 (maximum concentration) in all countries and is suitable for international comparisons of geographic concentration.

$$
\left[\sum_{i=1}^{N}\left|y_{i}-a_{i}\right| / 2\right] \times 100
$$

The value of the geographic concentration index is affected by the size of regions. Consequently, differences in geographic concentration between countries may be partially due to differences in the average size of regions in each country.

The classification of regions is based on so-called territorial levels (TELs) as defined by the OECD and closely responds to the NUTS classification of Eurostat in Europe, the state-level and BEA Economic Areas in the US, the prefectures in Japan and other similar types of classifications in other countries. The figures on the regional distribution of nanotechnology patenting adhere to TEL3 of the OECD classification. In Europe these correspond to the NUTS3 level, in the US to BEA Economic Areas, and in Japan to the prefectures.

Source: "The OECD REGPAT Database: a presentation". OECD Science, Technology and Industry Working Paper 2008/1, Directorate for Science, Technology and Industry. OECD Paris, www.oecd.org/sti/working-papers.

Overall, R\&D activities within countries tend to be concentrated in a smaller number of regions when compared with the distribution of the population. This insight is based on a so-called geographic concentration index (see Box 10). Figure 16 extends this analysis to the case of nanotechnology. The index value varies between 1 and 100 where a value closer to 100 indicates a higher concentration. For practical reasons these calculations are limited to patenting in 2005 as the most recent reliable year, and the Figure only covers countries with some 50 or more nanotechnology patents.

Figure 16. Geographic concentration of nanotechnology and all patenting by country, 2005

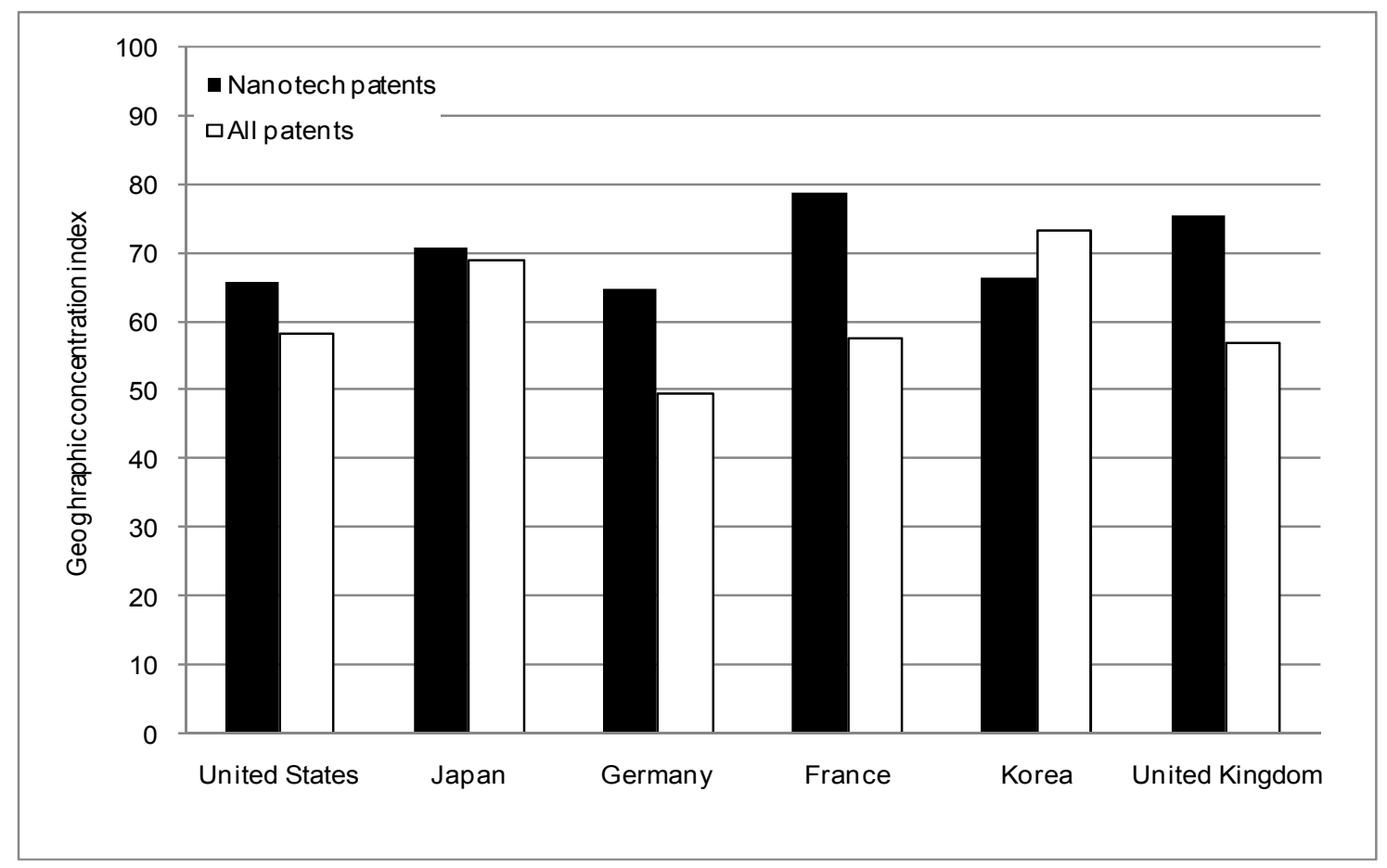

The Figure includes countries with around 50 or more patents in 2005.

Source: OECD Patent database, January 2008. 


\section{DSTI/DOC(2009)7}

Figure 16 suggests that nanotechnology patenting in these key countries is significantly more concentrated to specific regions when compared with patenting in general. These findings may point to the reliance of nanotechnology on the instrumentation and other research infrastructure, as well as scientific research at universities (see also Darby and Zucker, 2003). However, the higher than average concentration of nanotechnology patenting is also partly due to small number of patents based on which the index values are calculated.

More insights can be gained when considering the distribution of patents accumulated during 2003-05 across the top 20 regions, in Table 4 . These top 20 regions account for as much as $44 \%$ of total nanotechnology patents during this period (by the definition used 228 regions are listed as locations for nanotechnology patents). As could be expected the overwhelming majority of these regions are traditional high-technology hotspots in the United States, followed by the greater Tokyo area in Japan, some specific regions in France, and the United Kingdom (in these latter two countries the geographic concentration index is higher than average) ${ }^{11}$.

Table 4. Nanotechnology patenting by region, 2003-05

\begin{tabular}{llcc}
\hline Region & Country & $\begin{array}{c}\text { No. of nanotech } \\
\text { patents }\end{array}$ & $\begin{array}{c}\text { \% of nanotech } \\
\text { patents }\end{array}$ \\
\hline San Jose-San Francisco-Oakland & United States & 285 & 6.8 \\
Tokyo & Japan & 226 & 5.4 \\
Boston-Worcester-Manchester & United States & 217 & 5.2 \\
Kanagawa & Japan & 114 & 2.7 \\
New York-Newark-Bridgeport & United States & 109 & 2.6 \\
Los Angeles-Long Beach-Riverside & United States & 109 & 2.6 \\
Capital region & Korea & 72 & 1.7 \\
Noord-Brabant & Netherlands & 72 & 1.7 \\
Minneapolis-St. Paul-St. Cloud & United States & 70 & 1.7 \\
Austin-Round Rock & United States & 67 & 1.6 \\
Rhône-Alpes & France & 61 & 1.5 \\
Île de France & France & 58 & 1.4 \\
Ibaraki & Japan & 57 & 1.4 \\
Osaka & Japan & 57 & 1.4 \\
Philadelphia-Camden-Vineland & United States & 56 & 1.3 \\
Israel & Israel & 55 & 1.3 \\
Washington-Baltimore-Northern Virginia & United States & 49 & 1.2 \\
San Diego-Carlsbad-San Marcos & United States & 44 & 1.1 \\
Chicago-Naperville-Michigan City & United States & 43 & 1.0 \\
South East England & United Kingdom & 42 & 1.0 \\
\hline
\end{tabular}

The Figure includes the top 20 regions by the number of patents 2003-2005.

Source: OECD Patent database, January 2008.

For comparison it should be noted that the share of the top 20 regions of all patenting is $35 \%$, although these are the same regions that rank high in nanotechnology patenting. Further support for this finding can be found in Youtie and Shapira (2008) for the case of the United States. These two studies conclude that agglomeration in nanotechnology patenting occurs in regions which have experience in other emerging technologies (mainly ICT or biotechnology). In other cases, new research institutions/centres may explain regional agglomeration: the case of Minatec in the Rhône-Alps area of France and MESA+ in

11. As Israel is considered as one region by itself, this country also ranks high in the Table. 
the Netherlands are good examples of this (see Robinson et al., 2007). Figures 17-19 illustrate the regional concentration of nanotechnology patenting during 2003-07 across the United States, Europe, Japan and Korea.

Figure 17. Number of nanotechnology patents across regions in the United States, until 2005

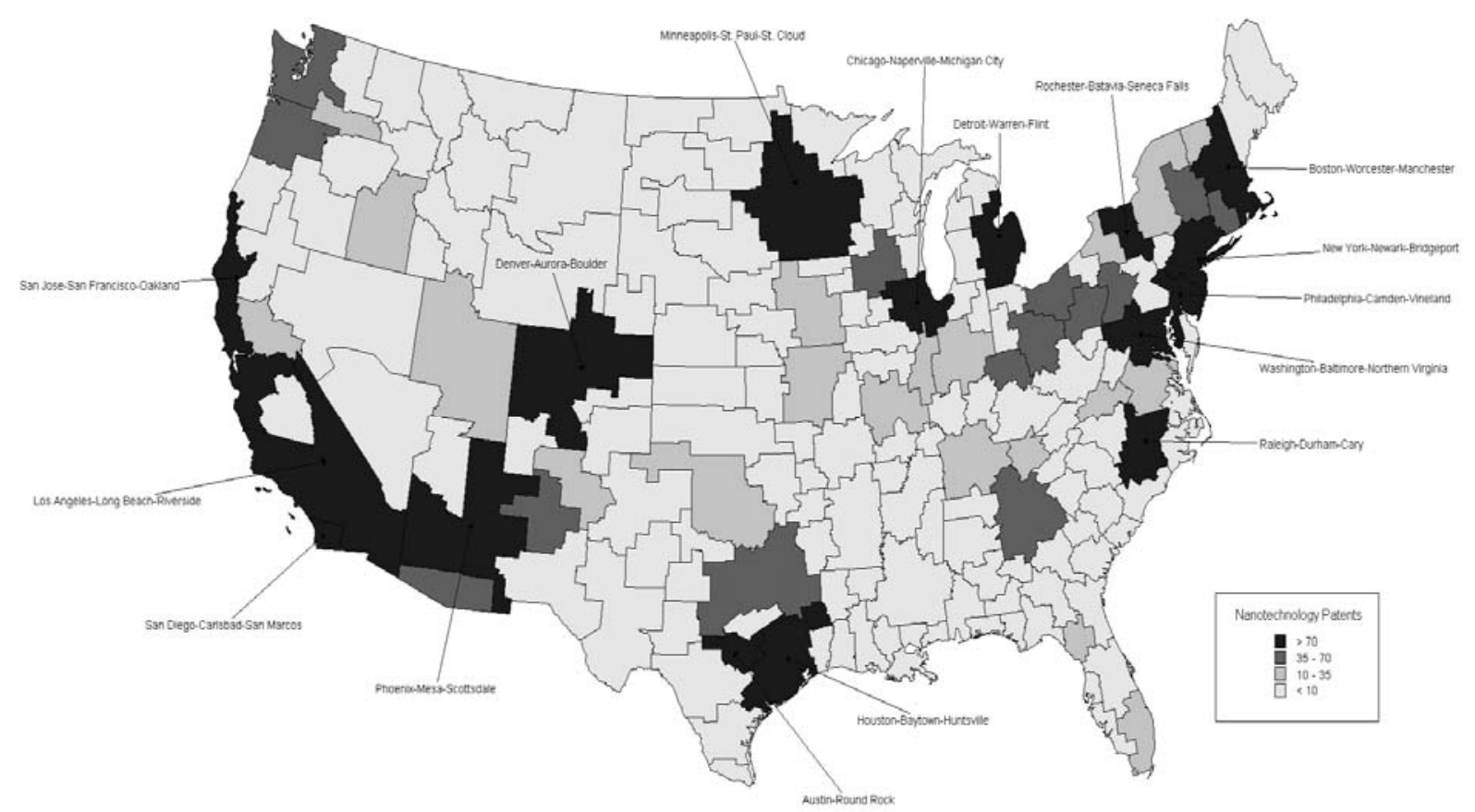

Source: OECD Patent database, January 2008. 
Figure 18. Number of nanotechnology patents across regions in Europe, until 2005

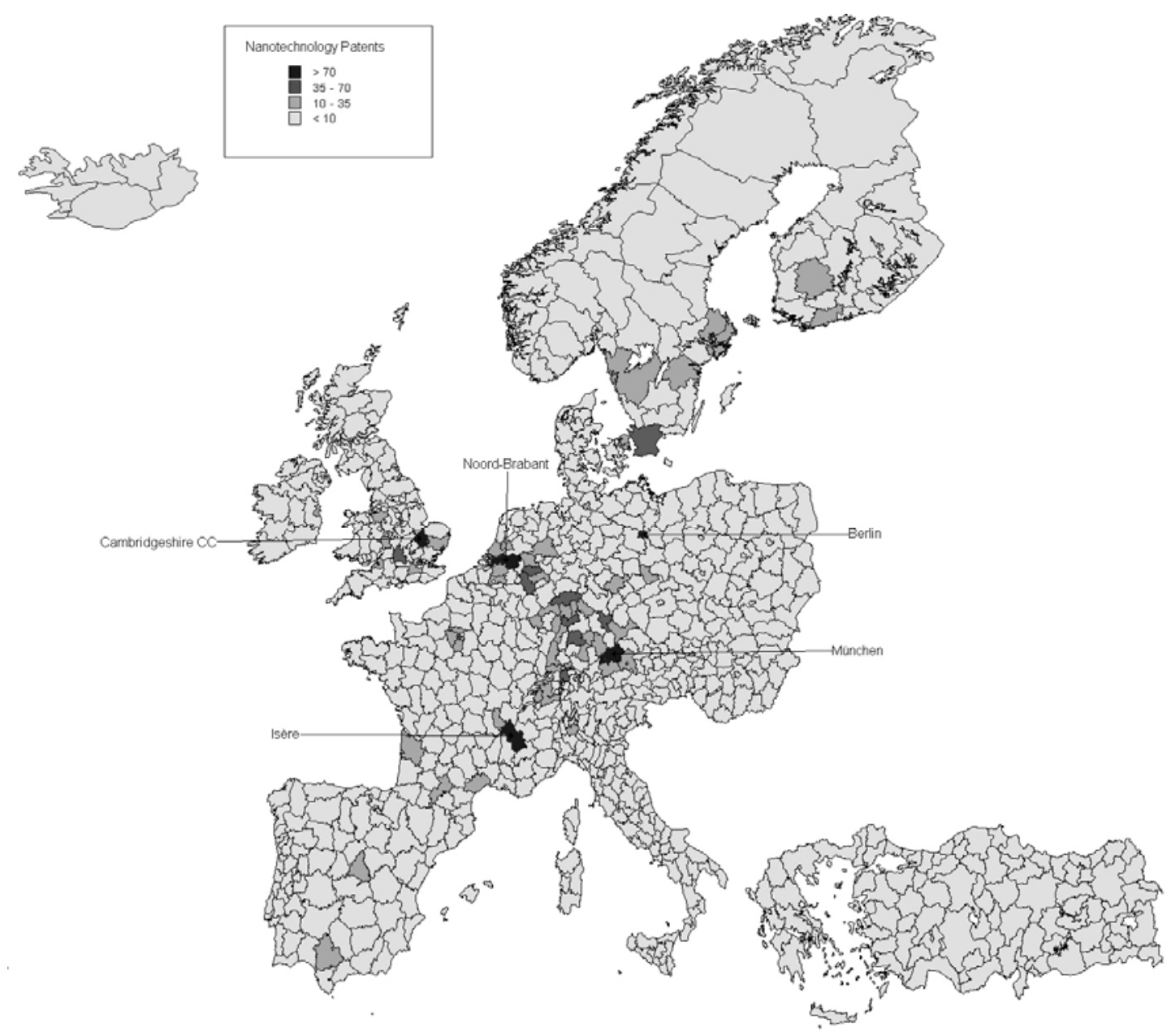

Source: OECD Patent database, January 2008. 
Figure 19. Number of nanotechnology patents across regions in Japan and Korea, until 2005

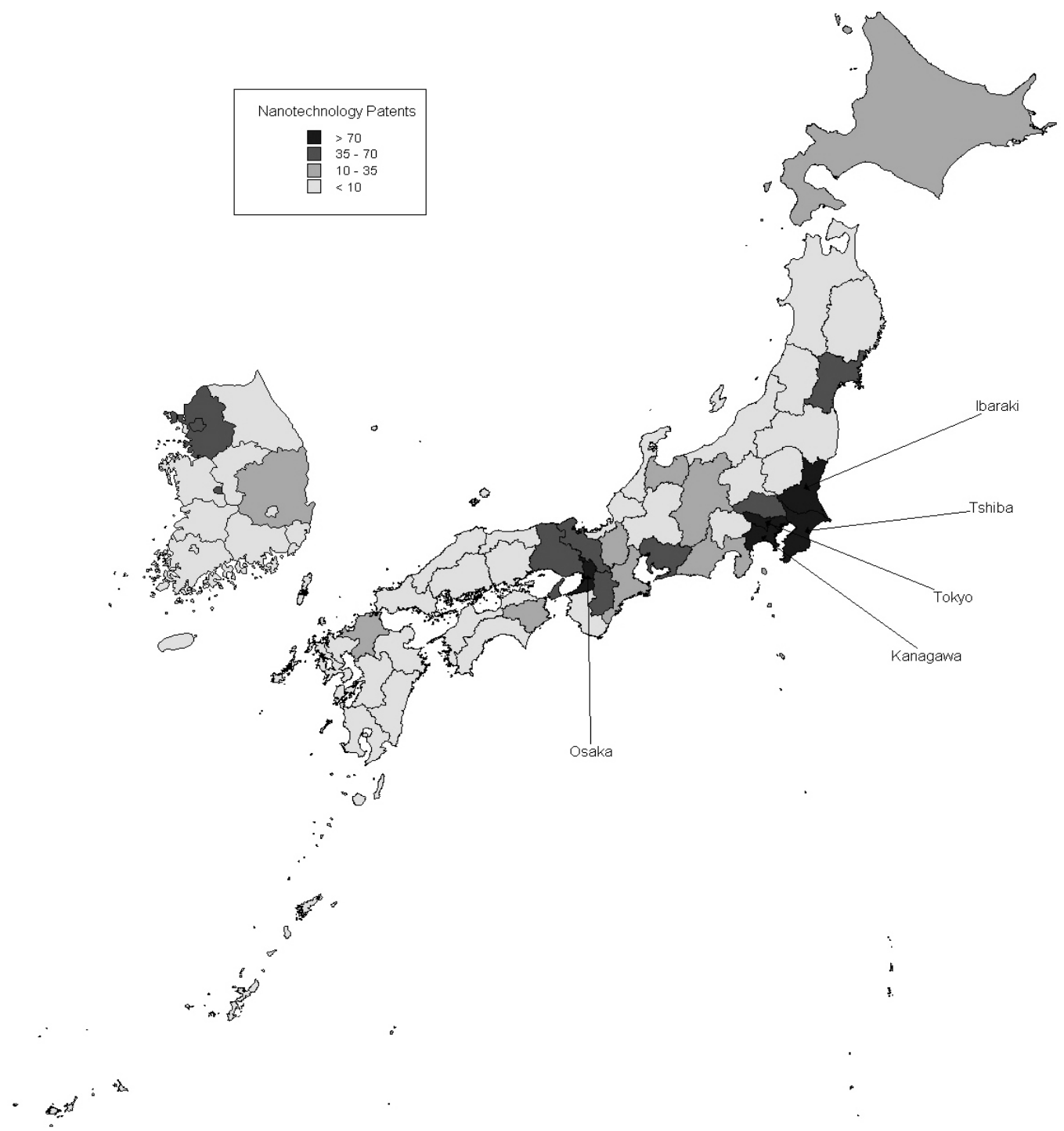

Source: OECD Patent database, January 2008. 
DSTI/DOC(2009)7

\section{Relationships between publications and patents: non-patent literature citations}

The analysis of publications highlighted the broad scientific base of nanotechnology and its interdisciplinary nature. In practice research and development activities span from basic to applied research along a continuum whereby it is practically impossible to delimit where basic science ends and applied research begins. Patent data does, however, also contain information about citations that individual patents make to both previous patents and scientific publications. These citations are often used as indicators of the nature and dependency of research and development activities on scientific and technological knowledge (see Box 11).

\section{Box 11. Considerations when analysing patent citations}

An increasing number of applicants file patents under PCT before entering the EPO process in the regional phase. However, if EPO has acted as the international search authority and undertaken the international search, then most citations will appear in the international document rather than the EPO document. In order to count citations in a European patent application correctly, information from both the international and the European searches need to be combined. PCT and EPO publications include information for five different types of citations: $i$ ) added by examiners during the search (whether or not provided by the applicant); ii) provided by the applicant but not used in the search report, iii) added during examination; iv) provided during opposition proceedings; and v) other. Most citations in PCT and EPO publications (about 95\%) are added by examiners in the search report. Non-patent literature (NPL) consists not only of peer-reviewed scientific papers but also includes conference proceedings, databases (DNA structures, gene sequences, chemical compounds etc.) and other relevant literature. However, previous studies have found that total NPL is a good proxy for scientific papers in similar types of analysis.

Source: OECD Patent Manual 2008.

Of interest is to consider the dependency of nanotechnology patenting on citations to the non-patent literature (NPL) as an indication of the strength of the interrelationships between the application of nanotechnology and basic scientific research. Figure 20 gives this share for nanotechnology patents across countries when compared with the corresponding share of all patents. This indicator confirms further the science-based nature of nanotechnology when compared with patents in general across almost all countries (differences across countries may reflect specific features of their R\&D system). Similar results emerge in more detailed studies of nanotechnology patents (see e.g. Meyer, 2000). 
Figure 20. Share of NPL citations: nanotechnology versus all patents by country, until 2006

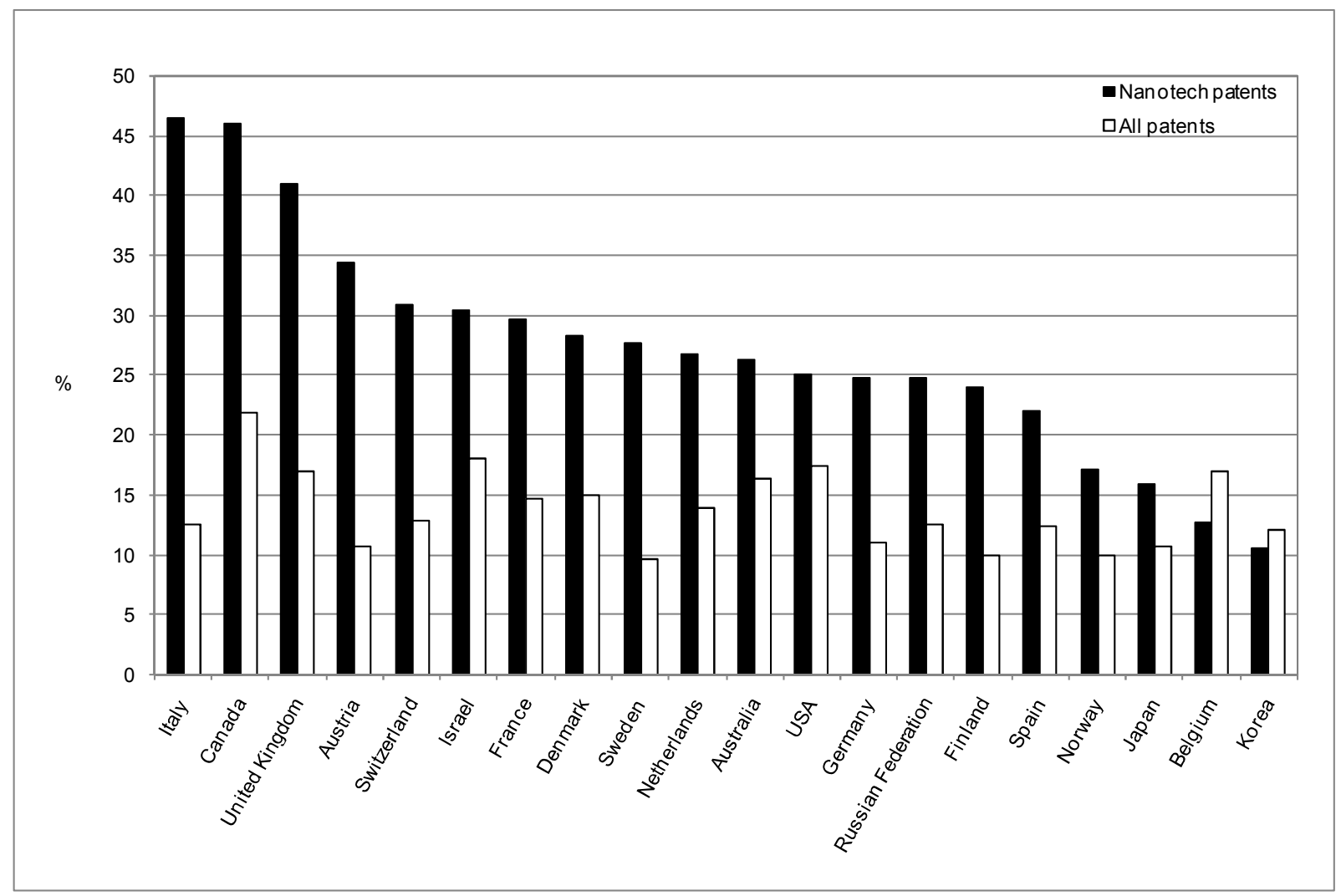

Source: OECD Patent database, December 2006

Igami and Okazaki (2007) provide further analysis of NPL citations of nanotechnology patents. They note that the share of NPLs has declined continuously since the early 1990s while the corresponding share of total patents has remained constant. Hence, it appears that research and development in this field increasingly draws on more applied research, perhaps in the wake of certain key scientific advances earlier on. They also find that as many as $50 \%$ of nanotechnology patents do not contain any NPL citations. Thus, nanotechnology appears as both science-based and technology-driven in so far as publication and patent data can capture distinctions between basic and more applied research. This observation is also in line with the notion of 'top-down' and 'bottom-up' nanoscale engineering, of which the latter appears to be more science-based.

\section{Summary}

- According to data on R\&D investments, the United States, the European Union and Japan are the main countries/regions for research and development activity in nanotechnology. When considering relative figures, adjusted for the size of countries, some smaller countries can also be highlighted. Estimations prior to the unfolding economic crisis suggest that R\&D investment was set to increase during 20082010 in most countries.

- Data on publications and patents provide further insights into the nature of $R \& D$ during emerging phases in the development of new technologies. As is often the case for such technologies the number of publications exceeds by far the number of patents; this observation also holds for nanotechnology. Further, the rate of growth of nanotechnology-related publications and patents clearly exceeds that of publications and patents more generally. 
- The main countries in terms of R\&D investments - the United States, Japan and the large European Union countries - also dominate in publication activity. However, the number of Chinese publications has grown rapidly in recent years, while also being increasingly visible in the pool of highly cited publications. Some other "newcomer" countries (Korea, India, Chinese Taipei and Singapore) also show impressive growth rates although from low starting levels. The publications draw on a broad range of scientific disciplines and involve interdisciplinarity.

- When looking at nanotechnology patenting, the United States has a clear lead with a few geographic regions accounting for a very large share of these patents. The large European countries and Japan follow while the remaining countries individually account for less than $5 \%$ of all these patents. Patenting started to accelerate some 12-13 years after key enabling inventions in instrumentation, bearing some resemblance to patenting trends in biotechnology.

- This section also considered non-patent literature citations as an indicator for the degree of dependency of technology on sciences. On the one hand, nanotechnology patents are characterised by an above-average share of citations to the scientific literature as further evidence on the scienceoriented nature of developments to date in this field. On the other, such citations are concentrated in a subset of patents, while their share has declined over time. 
DSTI/DOC(2009)7

\section{APPLICATION AREAS AND INSTITUTIONAL SECTORS}

\section{Introduction}

Researchers and analysts have suggested that nanotechnology may evolve into the next general purpose technology, implying that it is likely that nanotechnology will develop rapidly to be used for various different purposes in a whole range of application areas and industries (see e.g. Lipsey et al. 2005; Youtie et al.,2007). Such suggestions seem viable due to the ability of nanotechnology to contribute to a better understanding and control of matter at the fundamental level of atoms and molecules as the basic building blocks of manufacturing processes in almost all types of industries.

A definitive assessment of whether nanotechnology really could live up to the characteristics of a general purpose technology is outside the scope of this overview. Such assessments will, among other things, also depend on whether complementary technologies, innovations and institutions will emerge, and how debates and initiatives related to EHS and ethical, legal and social (ELS) issues unfold. However, patent data can provide some further insights into nanotechnology developments by application areas as an illustration of the pathways through which this emerging technology may affect industrial dynamics and structural change of economies. Specifically, patent data contain information on the intended industrial use of inventions based on a very detailed technology classification system, the most common of these being the International Patent Classification (IPC).

The use of Euro-PCT patent data in this report enables the breakdown of patents by both nanotechnology sub-areas, based on the tagging activity of EPO, and more broadly defined technology fields based on aggregations of the IPC system. The EPO classification highlights developments across specific nanotechnology sub-areas, while the classification of broader technology fields enables a classification of these patents by intended applications further downstream. In addition, the classification of nanotechnology patents by these application fields enables a comparison of nanotechnology developments with patenting in general.

Another viewpoint on the use and application of nanotechnology is to trace the institutional sectors of patents by the patent assignee. While the name and residence of the inventors of patents indicate the location of $R \& D$ activities, the assignee is the holder of the legal rights over commercial exploitation. Accordingly the assignee will indicate the institutional context for the commercialisation of nanotechnology, although this may also involve the transfer of the legal rights to the invention to other entities through trade sales, licensing etc.

\section{Patenting by nanotechnology sub-area}

The distribution of the patents by nanotechnology sub-areas is illustrated in Figure 21 (see Appendix 1 for the classification of nanotechnology sub-areas). Of all nanotechnology patents identified for this overview the largest share is classified to the sub-areas of nanomaterials and nanoelectronics. Nanobiotechnology patents also constitute a noteworthy share followed by instruments and measurement, optics and magnetics. 
Figure 21. Share of patents by nanotechnology sub-areas, 1995-2005

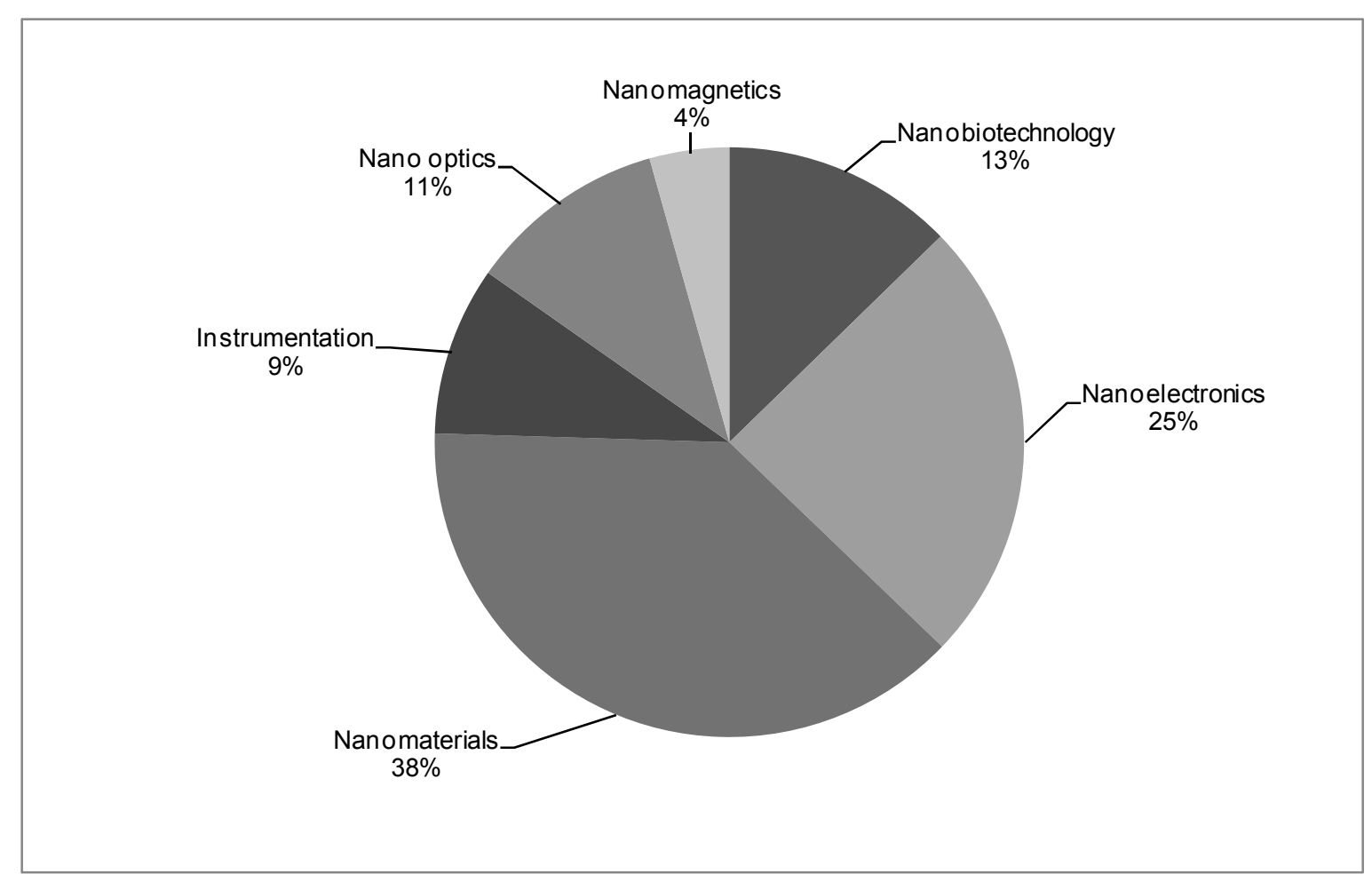

Source: OECD Patent database, January 2008.

When considering developments over time, most growth in patenting occurs in nanoelectronics followed by nanomaterials, nanomagnetics and nano-optics. The remaining sub-areas have experienced relatively constant number of patents over time. The modest growth of nanobiotechnology patents is somewhat surprising given the high prospects that have been assigned to this sub-area. These developments are shown in Figure 22. 
Figure 22. Number of patents by nanotechnology sub-area

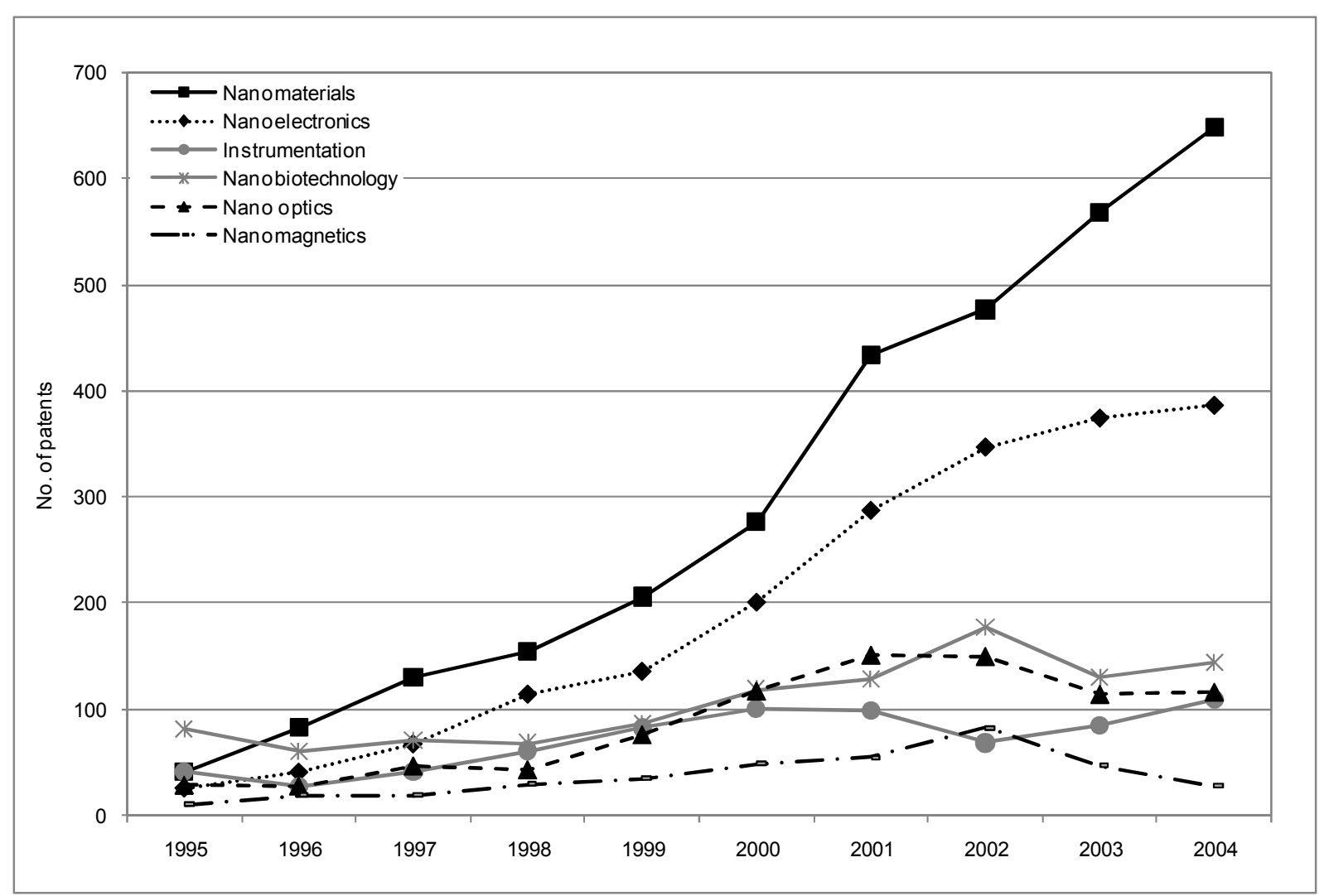

Source: OECD Patent database, January 2008.

Before proceeding it makes sense to consider how nanotechnology sub-areas relate to the broader technology fields. Figure 23 cross-tabulates the distribution of nanotechnology-dedicated sub-areas by technology fields, aggregated to a classification of seven main fields. 


\section{DSTI/DOC(2009)7}

Figure 23. Share of patents in nanotechnology sub-areas by main application field, until 2005

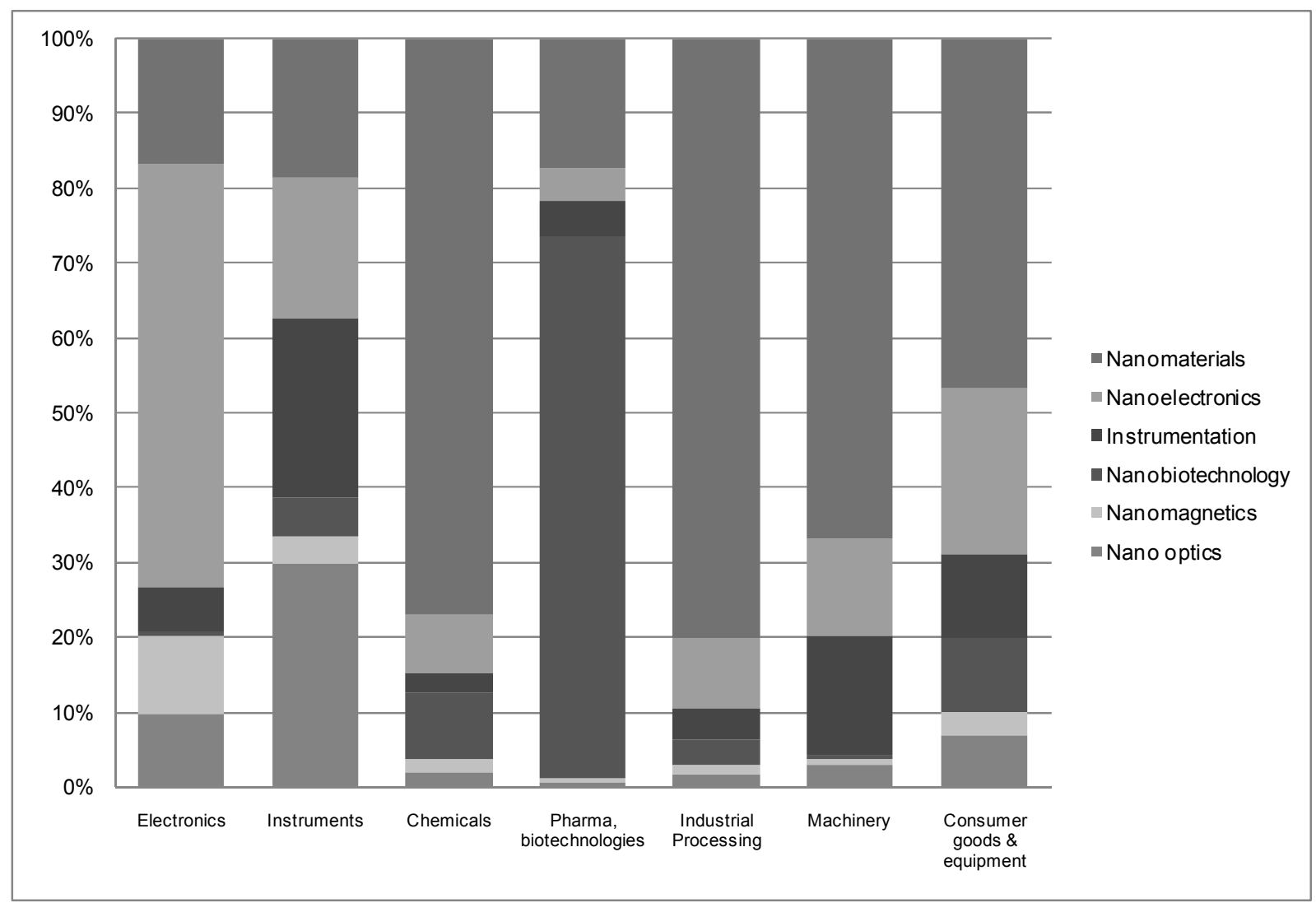

Source: OECD Patent database, January 2008.

Patents classified to the sub-area of nanoelectronics are found in the application fields of electronics, consumer goods and equipment. Nanobiotechnology patents are almost exclusively found in pharmaceuticals and biotechnology, while nanomaterials patents also are found in the application fields of chemistry and materials, industrial processing, machinery, mechanics and transports. Overall, the sub-areas nanomaterials and instruments are finding use in all application fields as an indication of their generic nature.

\section{Patenting by application field}

Turning to nanotechnology patenting by applications fields, in Figure 24, the significance of nanoelectronics and the rapid growth of patenting related to applications in electronics are evident, along with patenting in the field of chemicals and instruments (see Appendix 2 for the classification of patents by application fields). Patenting in pharmaceuticals, biotechnologies and industrial processing follow while applications intended for the fields of mechanical engineering, machinery, consumer goods and equipment have advanced less rapidly. Nonetheless, it should be borne in mind that the economic potentials of patents may vary significantly; e.g. nanobiotechnology and its application in the pharmaceuticals industry may lead to unexpected breakthroughs also in the shorter term. 
Figure 24. Number of nanotechnology patents by application field

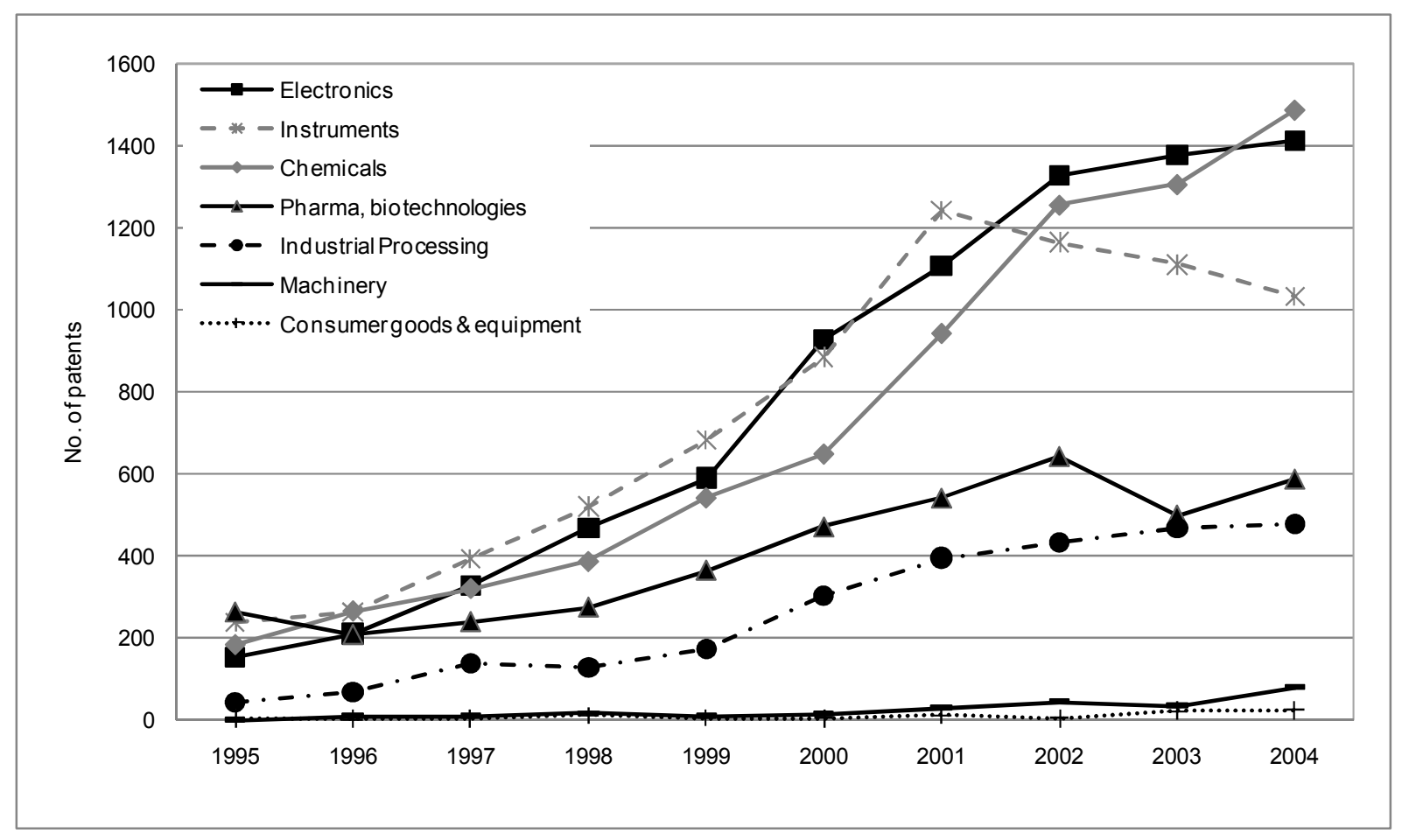

Source: OECD Patent database, January 2008.

To trace developments in fields that contain a significant number of patents (electronics, instrumentation, chemistry and materials, pharmaceuticals, biotechnology and industrial processing) the seven main areas are disaggregated further. Figure 25 shows the average annual growth rates of patenting across disaggregated sub-fields while also comparing to the corresponding growth rate for all patenting in these same fields. The rapid growth of patenting in information technology (IT) and semiconductors explains the overall significance of nanoelectronics, while electrical devices, telecommunications and audiovisual technology have experienced far lower growth. These latter sub-fields have also witnessed quite high growth rates generally and thus do not appear peculiar to nanotechnology. 


\section{DSTI/DOC(2009)7}

Figure 25. Average annual growth rates of nanotechnology and all patents across application fields, 1995-2004

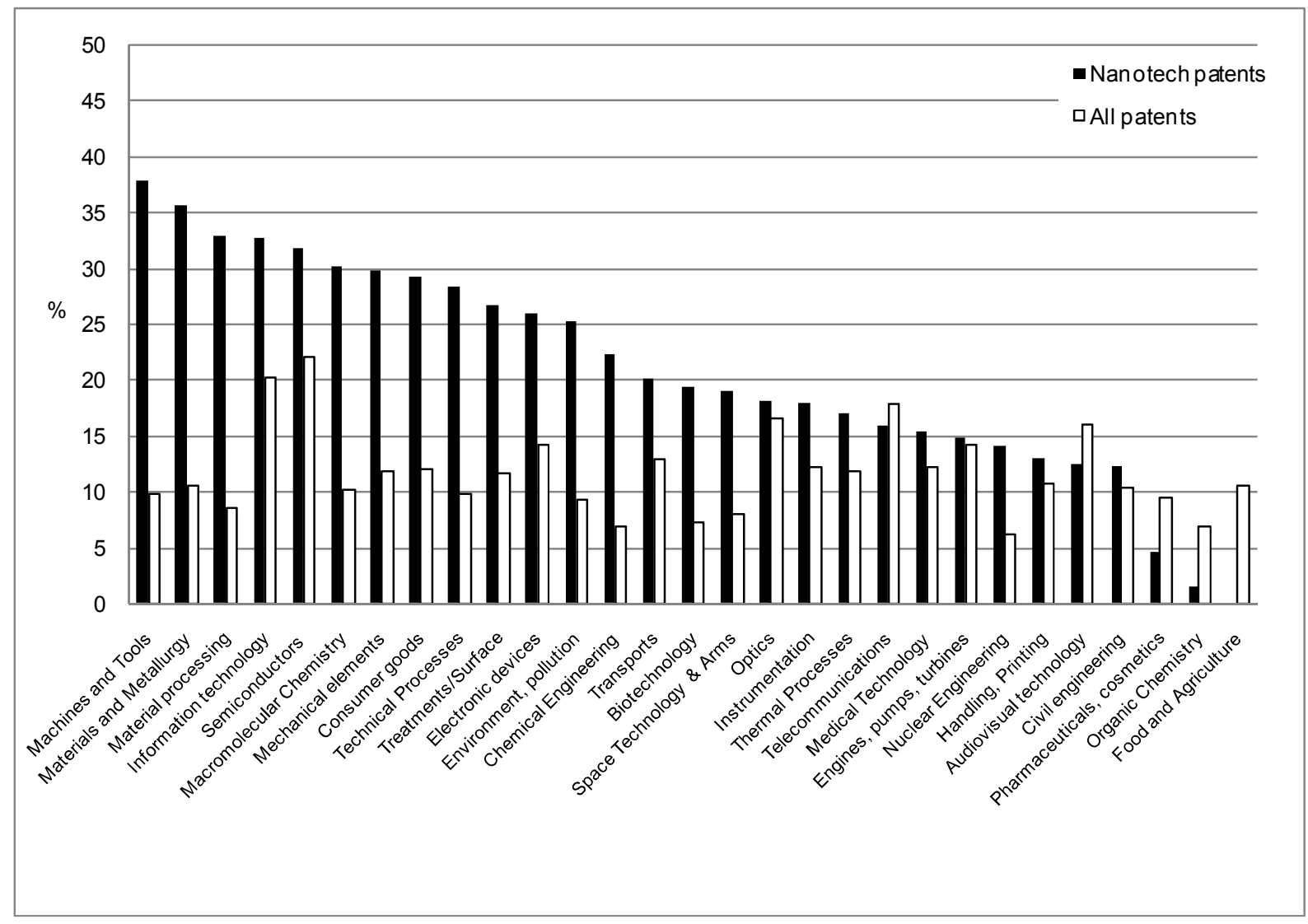

Patents 1995-2004.

Source: OECD Patent database, January 2008.

Nanotechnology patenting in the sub-fields of IT and semiconductors is in line with roadmaps that these industries have commissioned. In particular, it is believed that top-down nanoscale engineering may sustain capacity increases related to microprocessors developments. Reference is commonly made to the so-called Moore's Law that predicts a biannual doubling of the number of transistors that can inexpensively be placed on an integrated circuit, and which has provided the foundation for revenues in the semiconductor industries. The possibility of nanotechnology to sustain, or even move beyond, this law is hence a major incentive for $\mathrm{R} \& \mathrm{D}$ in this particular sub-field.

The bottom-up approach to nanoscale engineering may be more discontinuous and science-oriented. It concerns the synthesis, characterisation and modelling of individual atoms and molecules to construct larger entities. It is often considered the facilitating factor behind the possible convergence between nanoand biotechnology. Bottom-up approaches may also require more interdisciplinary collaboration between physics, chemistry and biology. In this context it is interesting to note that nanotechnology patenting in the sub-fields of macromolecular chemistry, chemical engineering and biotechnology also show high growth rates.

The sub-fields of materials and metallurgy and materials processing are also characterised by rapid growth that is outpacing patenting in general in these sub-fields. Finally, the sub-fields of environment and pollution stand out with a rapid growth rate, especially for the nanotechnology-related patents. However, a small number of patents in many of these sub-fields make growth rates difficult to interpret. 


\section{Patenting by institutional sectors}

The identification of institutional sectors of patents relies on information about the assignee of patents, enabling a distinction between individuals, private companies, governments, universities, hospitals and private non-profit (PNP) organisations (see Box 12). Figure 26 presents the shares of nanotechnology patents by these institutional sectors. While a majority of nanotechnology patents are assigned to companies this share is still lower when compared with the share of companies as assignees to all patents (for example, in $2005,82 \%$ of all PCT applications were assigned to companies followed by $5 \%$ to universities and $3 \%$ to governments). Accordingly, the impression is that nanotechnology R\&D is relatively much more frequently going to be commercialised in a university setting compared to inventions in generally.

\section{Box 12. Classification of patents by institutional sectors}

Methods for allocating an institutional sector to patents were developed in a recent project led by Eurostat, in line with the Frascati Manual (2002). These methods consist mainly of analysing a set of keywords in the name of the patent applicant. However, the matching of name characteristics to different categories is not clear-cut for certain types of organisations and some countries. The algorithm for sector attribution enables allocating patent documents to individuals, private enterprises, government, universities, hospitals or private non-profit (PNP) organisations. A separate category for hospitals was included, as the governance structure under which they operate is not always straightforward.

Source: OECD Patent Manual 2008.

Figure 26. Nanotechnology patenting by institutional sector, until 2005

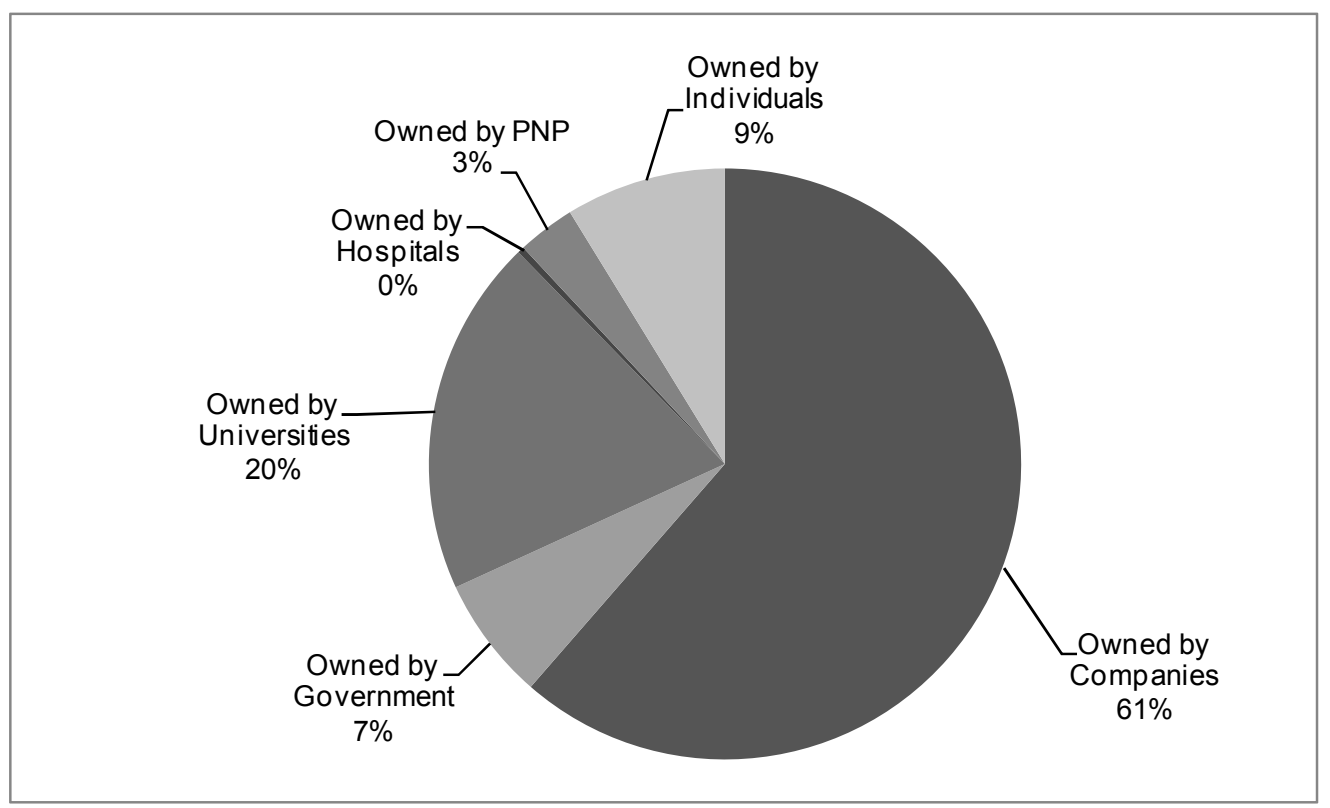

Source: OECD Patent database, January 2008.

While only slight variations are detected in the institutional sectors of nanotechnology across main application fields, these variations are quite significant by country (Figure 27). At one extreme, in the case of Japan, close to $75 \%$ of these nanotechnology patents are assigned to companies compared with $66 \%$ for EU27 and $61 \%$ for the United States. The Netherlands and Sweden stand out with shares of company 
assignees closer to $90 \%$, while Israel, China and Spain have a much larger share of nanotechnology-related patents assigned to universities. In terms of government assigned patents France stands out with a 26\% share (compared with 5\% for all PCT applications). The results concerning public sector institutions mainly reflect variations in the structure of public R\&D systems across countries and may not be specific to nanotechnology, apart from the case of France where government research organisations and laboratories play an especially important role.

Figure 27. Share of nanotechnology patents by institutional sources, until 2005

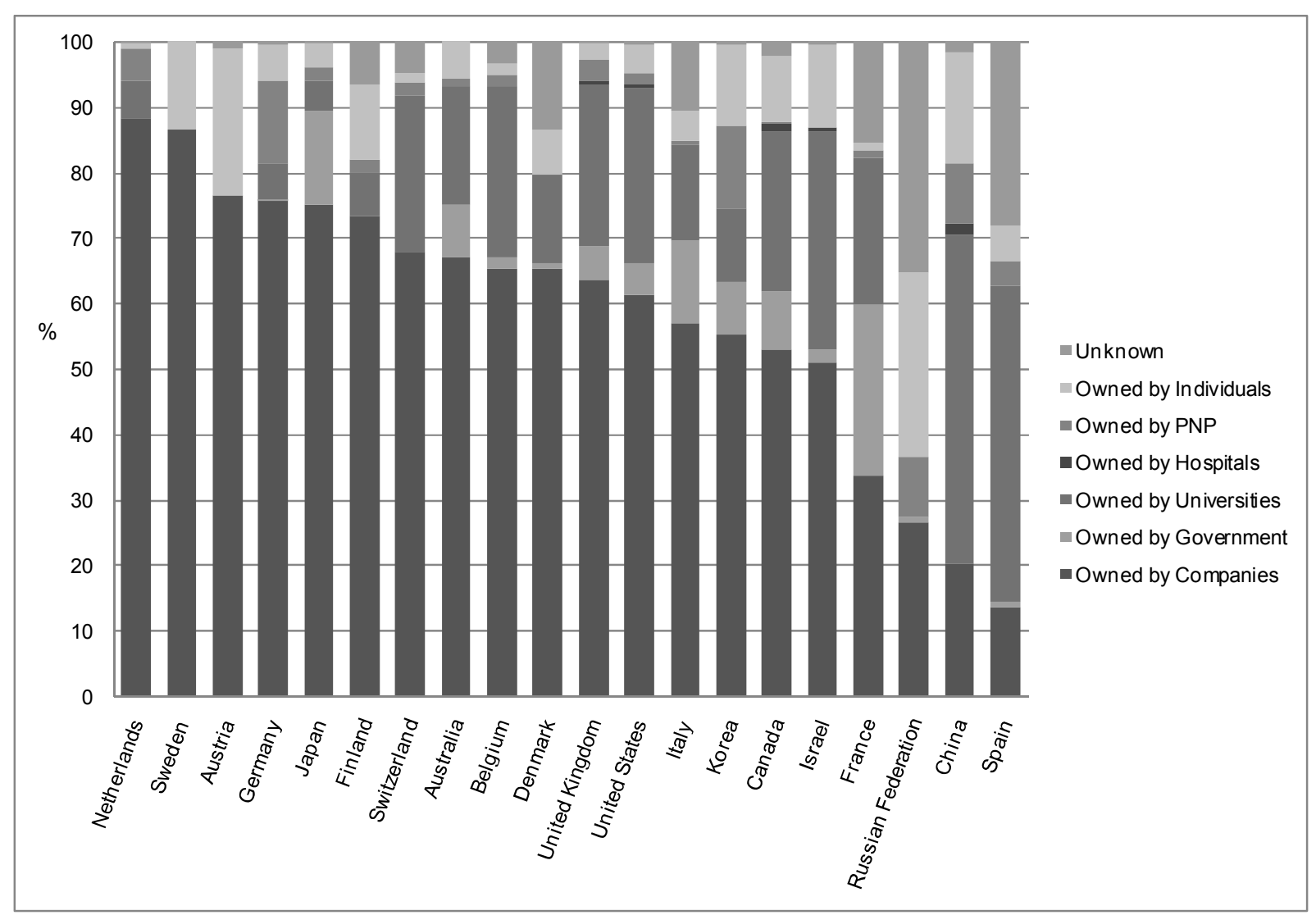

The Figure includes the top 20 countries by the number of nanotechnology patents

Source: OECD Patent database, January 2008.

Table 5 lists the top 30 assignees by their name; i.e. the name of companies, universities or research institutes and other organisations that own the patents. As expected the list is dominated by multinational enterprises (MNEs) based in the United States and Japan and Europe such as Phillips, Hewlett-Packard, NEC, Intel, 3M, Matsushita, Canon, IBM and the Eastman Kodak Company. All of these are major players in the electronics industry in which top-down approaches to nanoscale engineering have been used already for some time. Nonetheless, smaller companies such as Nantero and Nanosys in the United States, Evonik and Infineon Technologies in Germany, also show up on the list along with significant United States and Japanese universities or public research institutes. 
Table 5. Top 30 assignees to nanotechnology patents, 2003-05

\begin{tabular}{|c|c|}
\hline Assignee & $\begin{array}{l}\text { No. of nanotech } \\
\text { patents }\end{array}$ \\
\hline Philips Electronics & 85 \\
\hline Japan Science and Technology Agency & 82 \\
\hline The Regents of the University of California & 81 \\
\hline Hewlett-Packard Development Company & 69 \\
\hline Commissariat a l'energie atomique (CEA) & 52 \\
\hline NEC Corporatiom & 41 \\
\hline Intel Corporation & 39 \\
\hline Massachusetts Institute of Technology (MIT) & 39 \\
\hline 3M Innovative Properties Company & 36 \\
\hline National Institute of Advanced Industrial Science and Technology & 32 \\
\hline Nantero, Inc. & 32 \\
\hline William Marsh Rice University & 32 \\
\hline Matshushita Electric Industrial Corporation & 31 \\
\hline International Business Machines Corporation (IBM) & 29 \\
\hline Canon & 27 \\
\hline Esatman Kodak Company & 27 \\
\hline TDK Corporation & 25 \\
\hline Agency for Science, Technology and Research & 25 \\
\hline CNRS & 24 \\
\hline Evonik Degussa GmbH & 23 \\
\hline California Institute of Technology & 23 \\
\hline Molecular Imprints & 22 \\
\hline Nanosys, Inc. & 21 \\
\hline Du Pont de Nemours and Company & 20 \\
\hline Infineon Technologies & 19 \\
\hline Kyoto University & 19 \\
\hline Pioneer Corporation & 19 \\
\hline Philips Intellectual Property \& Standards $\mathrm{GmbH}$ & 18 \\
\hline Bussan Nanotech Research Institute Inc. & 18 \\
\hline
\end{tabular}

The Table includes the top 30 patent assignees by the number of nanotechnology patents 2003-2005.

Source: OECD Patent database, January 2008.

\section{Summary}

- Nanotechnology is a broad term for R\&D in various sub-areas and application fields. Most patenting occurs in the sub-areas of nanomaterials and nanoelectronics; nanomaterials are generic in nature and enable applications in a broad range of fields further downstream while nanoelectronics primarily is confined to electronics, machinery and consumer goods applications.

- Nanotechnology patenting in the application fields of electronics, chemicals and instruments show the highest growth; sub-fields with above average growth rates include machines and tools, materials and 
metallurgy, and materials processing, information technology and semiconductors. The rapid growth of these latter fields may relate to "top-down" nanoscale engineering in the electronics industry. "Bottom-up" approaches are less visible in patent data.

- While a majority of nanotechnology patents are assigned to companies, universities figure relatively more frequently as owners of patents when compared with patenting in general. Hence, technology transfer from universities to companies may be a key issue in the commercialisation of nanotechnology.

- The ranking of assignees of nanotechnology patents is dominated largely by the United States, Japan and European MNEs; many of these companies are major players in the electronics industry. However, a few smaller European companies also rank high, along with US and Japanese universities and public research institutes. 
DSTI/DOC(2009)7

\section{POSITION AND SPECIALISATION OF COUNTRIES}

\section{Introduction}

The broad range of potential nanotechnology applications implies that priority-setting in R\&D investments is an important issue. Countries may aim for application fields with high forecasted growth rates. They may seek to benefit from nanotechnology by strengthening existing industries or by supporting new ones through the technological diversification of companies, and entrepreneurship. The different approaches that countries take will be influenced, among other things, by their present specialisation patterns. Nanotechnology may introduce incremental innovation in existing areas of specialisation and industrial strongholds. But nanotechnology may also provide a platform for discontinuous innovation and the gradual emergence of new fields of specialisation.

The analysis of nanotechnology patenting can be extended to consider the position and specialisation pattern of countries across the technology areas in which nanotechnology is finding applications. In this context the most frequently used indicator is called the "Revealed Technological Advantage" (RTA) index and various modifications thereof. In its simplest form the RTA index calculates the ratio of the share of patenting of a country in a particular application field, and the corresponding share for patenting globally. RTA indexes can be calculated over time and against different benchmarks depending on the perspective taken. Their origin is in international trade theory where they have been used extensively to trace the competitive advantage and specialisation of countries by their exports.

Drawbacks in using RTA indexes as indicators include situations in which all other countries than the one being examined, increase their patent activity in an emerging field. In these situations the specialisation index of the country in the specific field will appear to be declining while this may not be the case in reality. The index is also sensitive to a small number of patents at the country level when the benchmark is set to global patenting. Despite these caveats the RTA indexes provide interesting insights as one basis for a discussion also about the international division of labour in nanotechnology $\mathrm{R} \& \mathrm{D}$ and innovation.

\section{Country patenting by nanotechnology sub-area and application field}

Figure 28 presents the distribution of patents across nanotechnology sub-areas by country. While most countries are involved in a majority of the sub-areas, the Netherlands and Austria stand out with a higher share of patents in nanoelectronics. Korea, Belgium, China and Finland have a higher share in nanomaterials. Beyond this no clear patterns emerge. 
Figure 28. Share of patents across nanotechnology sub-areas by country, until 2005

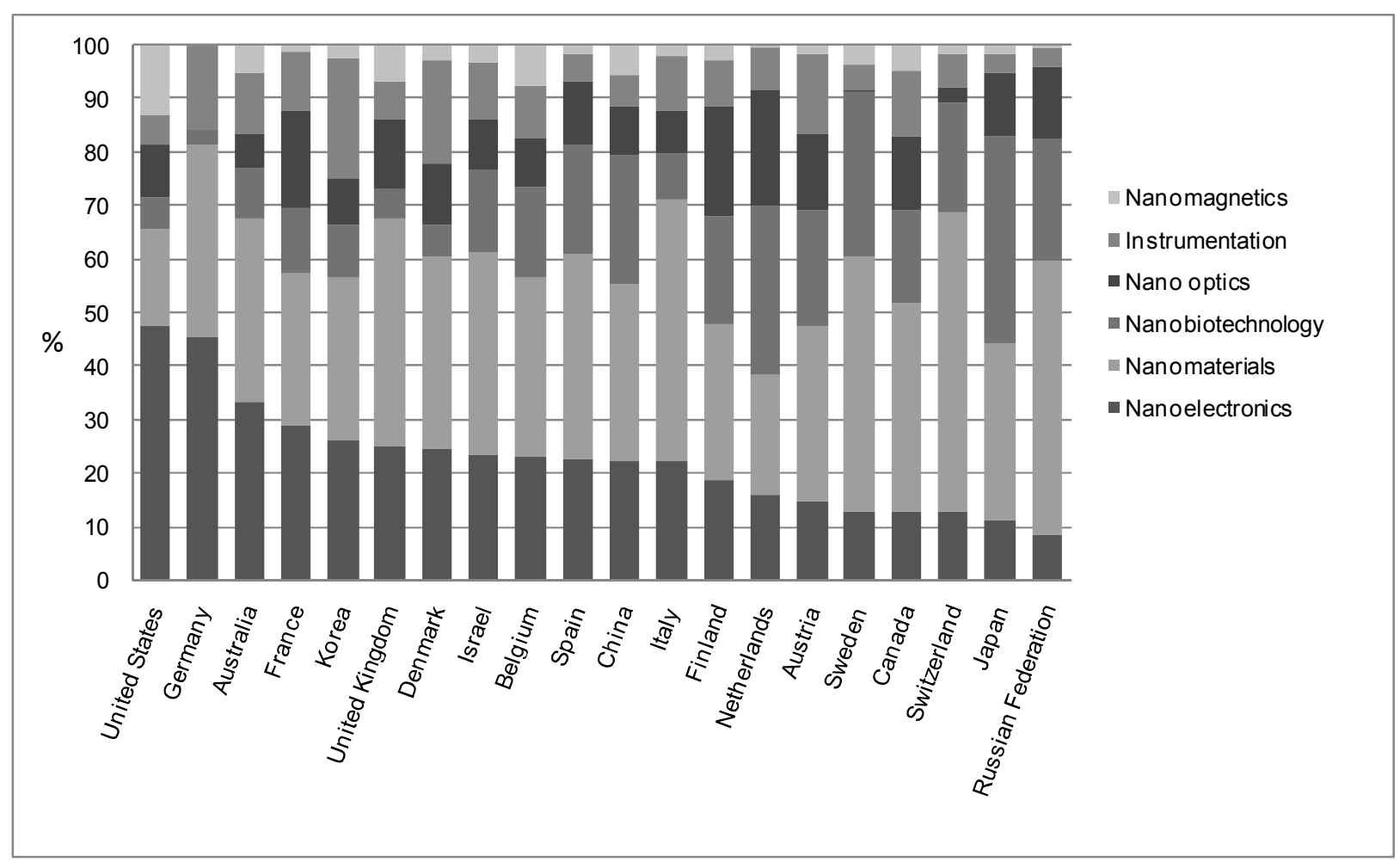

The Figure includes the top 20 countries by the number of nanotechnology patents accumulated by 2005 .

Source: OECD Patent database, January 2008.

Figure 29 shows the distribution of nanotechnology patents by application field across the same countries. The United States, Japan, the United Kingdom, Netherlands, Canada, Switzerland, Sweden, Israel, the Russian Federation and Austria appear to apply nanotechnology mainly in the high growth fields of electronics and instruments. France, Australia, Italy, China, Belgium and Finland do so in the fields of chemicals, materials, pharmaceuticals and biotechnology, some of which are characterised by lower growth rates. Germany, Korea, Israel, Denmark and Spain occupy the middle ground with a fairly equal distribution of patents across all application fields. The Figure also indicates that no country appears particularly active in the application fields of machinery, mechanics, transportation, consumer goods and equipment. Hence these fields can be excluded from the analysis which follows. 
Figure 29. Share of nanotechnology patents across application fields by country, until 2005

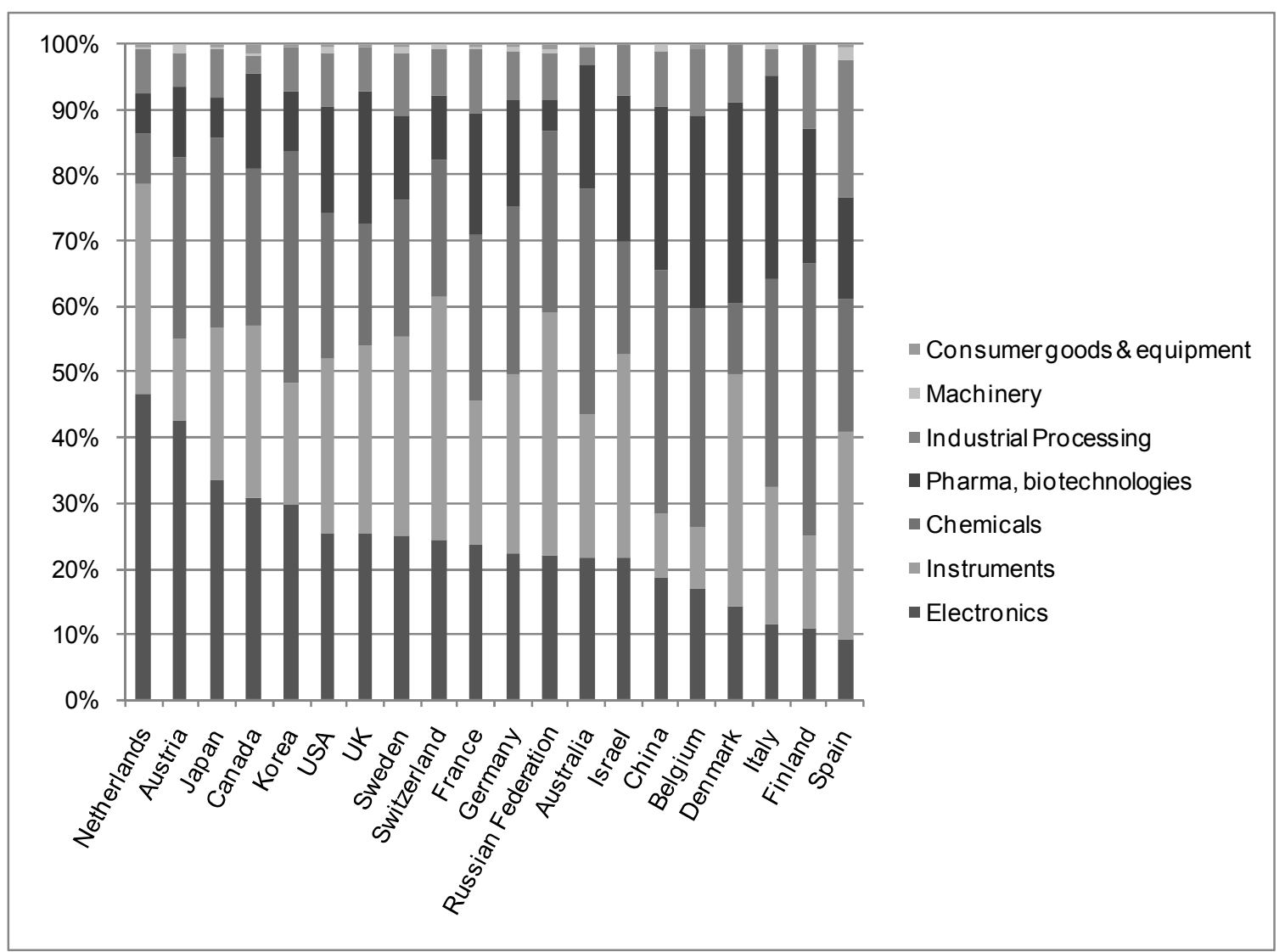

The Figure includes the top 20 countries by the number of nanotechnology patents accumulated by 2005 .

Source: OECD Patent database, January 2008.

\section{Specialisation of countries by application field}

Regarding the RTA indexes, two different benchmarks are used to identify specialisation patterns. In the first standard case, the benchmark is global patenting in nanotechnology by the main application fields. This gives an indication of the specialisation of the country, or economic region, relative to all other countries. In the second case the benchmark is all patenting by the country in the same application fields. This second modified index gives an indication of the degree to which nanotechnology patenting of the country is similar or different compared with the overall technological specialisation of the country; it is here referred to as the revealed technological compatibility index. ${ }^{12}$

12. This modified index is inspired by the use of a similar approach in Nikulainen (2007). 


\section{Box 13. RTA indexes}

Revealed Technological Advantage (RTA) - indices have been derived from corresponding indices used to assess the export specialisation profiles of countries. In this context RTA indexes are used as an approximation of the relative advantages of countries in certain technology fields. They consist of the ratio of the share of patents of a country in a particular technological sub-area (in this case a nanotechnology application field), divided by the total share of patents in this same sub-area globally. Formally, the RTA index for country $i$ and sub-area $d$ can be defined as follows:

$$
R T A=\frac{\left(P_{d, i} / \sum_{d} P_{d, i}\right)}{\left(\sum_{d i} P_{d, i} / \sum_{d, i} P_{d, i}\right)}
$$

By definition, this index equals 1 if the country holds the same share of patents in a given technology sub-area as total patenting in that sub-area globally, and is below (above) 1 if there is a relative weakness (strength). This allows cross-sectional as well as longitudinal comparison of relative technological strengths and weaknesses of countries.

Source: DSTI/EAS/STP/NESTI(2008)12: OECD Patent Manual 2008

\section{Specialisation across nanotechnology application fields}

For the sake of clarity the standard RTA indexes are illustrated in Figure 30 only for the United States, Japan, European Union (all 27 EU member states) and BRIC countries (Brazil, Russian Federation, India and China). It is clear that both the United States and European Union are similarly and broadly specialised across all the main application fields even though the European Union appears slightly more specialised in pharmaceuticals and biotechnology when compared with the United States and especially with Japan. In contrast, Japan distinguishes itself from the United States and European Union with a higher specialisation in electronics and chemicals (excluding pharmaceuticals). The BRIC countries appear more specialised in pharmaceuticals and biotechnologies, and chemicals, compared to the United States, Japan and European Union, while being less specialised in the other application fields. 
Figure 30. Specialisation across nanotechnology application fields: the US, Japan, EU and BRIC countries, until 2005

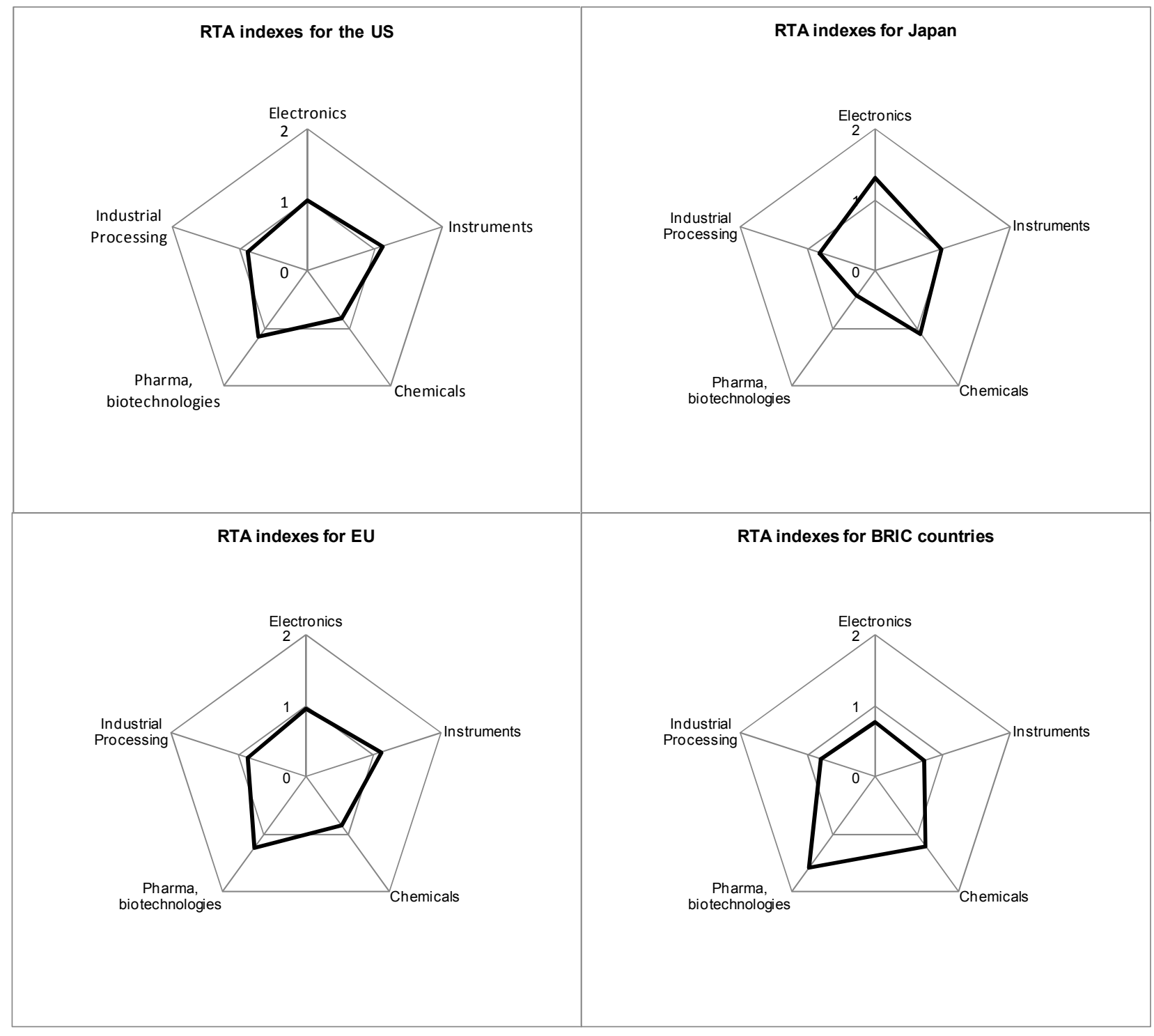

Note: RTA indexes over 1 indicate a higher relative specialisation.

Source: OECD Patent database, January 2008.

Considering briefly the specialisation pattern of the remaining top ranked countries in Table 6, the Netherlands, Korea, Canada and Austria are more specialised in electronics compared to all other countries. In contrast, Germany, France, Italy, China, Denmark, Belgium, Spain and Finland appear to lean relatively more on applications in pharmaceuticals and biotechnologies. Even though far-reaching interpretations should be made with care, the overall pattern that emerges is one in which smaller or nonEuropean countries, as mentioned above, specialise in electronics applications, while many of the more active EU countries are embarking on a trajectory of specialisation in pharmaceuticals and biotechnology. It is also interesting to note that the majority of countries appear specialised in the application field of instruments. 
DSTI/DOC(2009)7

Table 6. Specialisation across nanotechnology application fields by country, until 2005

\begin{tabular}{|c|c|c|c|c|c|}
\hline & Electronics & Instruments & Chemicals & $\begin{array}{c}\text { Pharmaceuticals, } \\
\text { biotech }\end{array}$ & $\begin{array}{l}\text { Industrial } \\
\text { Processing }\end{array}$ \\
\hline$\overline{U S A}$ & 1.01 & 1.11 & 0.83 & 1.15 & 0.88 \\
\hline Japan & 1.32 & 0.99 & 1.09 & 0.43 & 0.82 \\
\hline Germany & 0.88 & 1.15 & 0.95 & 1.15 & 0.82 \\
\hline UK & 1.01 & 1.22 & 0.69 & 0.94 & 0.73 \\
\hline France & 0.94 & 0.93 & 0.94 & 1.32 & 1.06 \\
\hline Netherlands & 1.84 & 1.36 & 0.29 & 0.44 & 0.71 \\
\hline Korea & 1.18 & 0.79 & 1.32 & 0.66 & 0.74 \\
\hline Canada & 1.22 & 1.11 & 0.89 & 1.03 & 0.30 \\
\hline Switzerland & 0.96 & 1.58 & 0.78 & 0.70 & 0.78 \\
\hline Sweden & 0.98 & 1.28 & 0.77 & 0.92 & 1.01 \\
\hline Israel & 0.86 & 1.32 & 0.65 & 1.59 & 0.84 \\
\hline Australia & 0.86 & 0.93 & 1.29 & 1.34 & 0.31 \\
\hline Italy & 0.45 & 0.88 & 1.16 & 2.20 & 0.45 \\
\hline China & 0.74 & 0.41 & 1.38 & 1.79 & 0.93 \\
\hline Russian Federation & 0.87 & 1.59 & 1.03 & 0.34 & 0.80 \\
\hline Denmark & 0.57 & 1.50 & 0.40 & 2.20 & 0.96 \\
\hline Belgium & 0.67 & 0.39 & 1.26 & 2.10 & 1.11 \\
\hline Spain & 0.36 & 1.34 & 0.76 & 1.13 & 2.29 \\
\hline Finland & 0.43 & 0.60 & 1.54 & 1.47 & 1.42 \\
\hline Austria & 1.69 & 0.53 & 1.03 & 0.79 & 0.55 \\
\hline
\end{tabular}

Note: RTA indexes over 1 indicate a higher relative specialisation. The Figure includes the top 20 countries by the number of nanotechnology patents accumulated by 2005.

Source: OECD Patent database, January 2008.

\section{Compatibility between nanotechnology and existing application fields}

Figure 31 shows to what degree nanotechnology patenting across application fields in the United States, European Union, Japan and the BRIC countries is similar or different when compared with their overall technological specialisation profile (the revealed technological compatibility index). The interpretation of the Figure should that an index value close to 1 for an application field is taken as an indicator of a specialisation profile in nanotechnology application fields that is close to the overall specialisation profile of the country or economic region, while deviating values indicate deviations from this overall profile. 
Figure 31. Compatibility of nanotechnology application fields: the US, Japan, EU and BRIC countries, until 2005

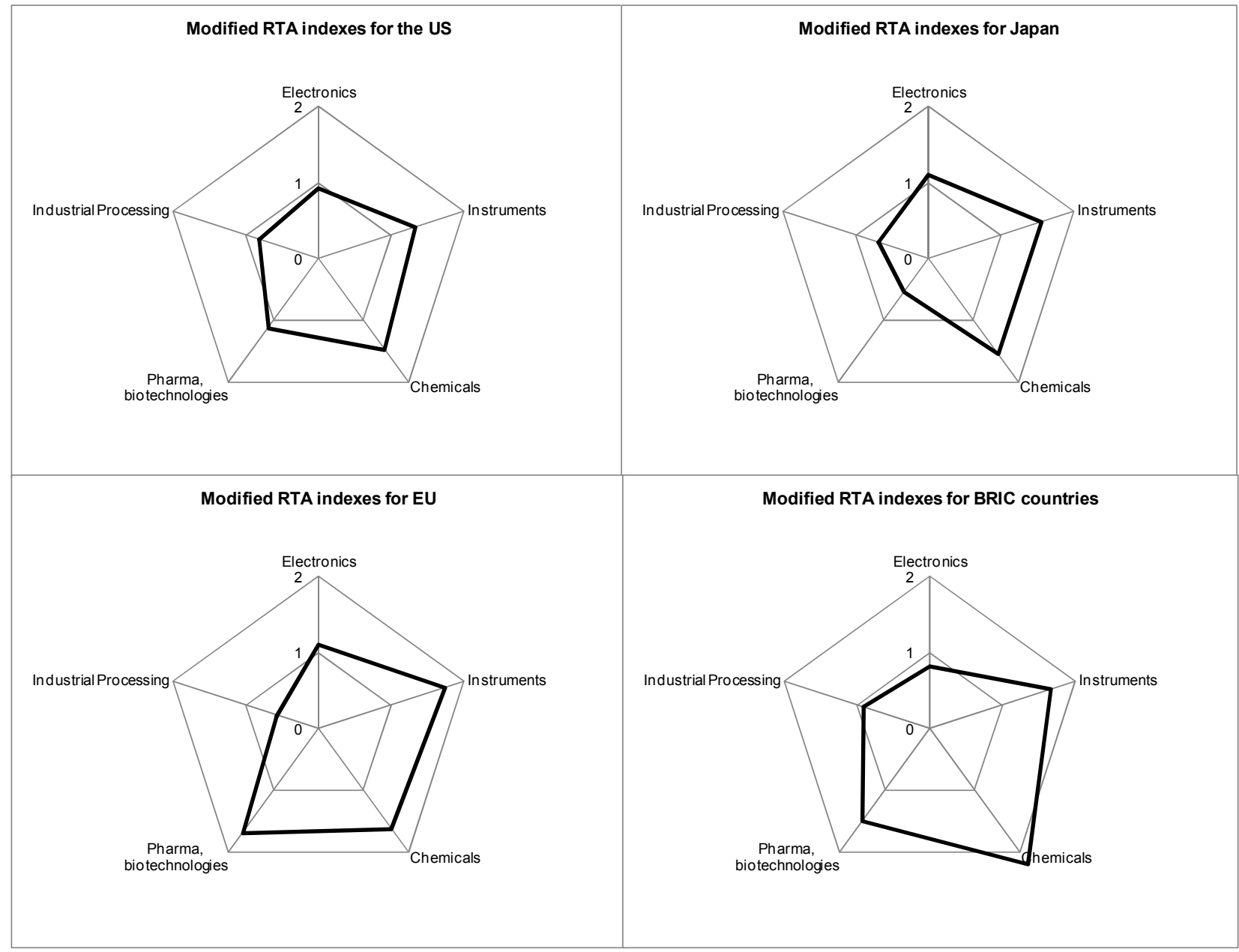

Note: RTA indexes close to 1 indicate a technological compatibility between nanotechnology and overall specialisation. The Figure includes patents accumulated by 2005 .

Source: OECD Patent database, January 2008.

This Figure suggests that the specialisation of all of these countries/regions in nanotechnology applications fields related to pharmaceuticals and biotechnology, chemicals, as well as instruments, represent new fields relative to their overall specialisation profiles (based on patenting in general). Conversely, especially electronics appears as a nanotechnology application field that matches the overall specialisation of these countries/regions. Further, the relatively broad specialisation profile of the United States in nanotechnology applications is compatible with the overall, broad, technological specialisation pattern of this country. 
DSTI/DOC(2009)7

Table 7. Compatibility of nanotechnology application fields by country, until 2005

\begin{tabular}{lccccc}
\hline & Electronics & Instruments & Chemicals & $\begin{array}{c}\text { Pharmaceuticals, } \\
\text { biotech }\end{array}$ & $\begin{array}{c}\text { Industrial } \\
\text { Processing }\end{array}$ \\
\hline USA & 0.92 & 1.34 & 1.47 & 1.12 & 0.82 \\
Japan & 1.09 & 1.56 & 1.55 & 0.55 & 0.69 \\
Germany & 1.12 & 1.84 & 1.61 & 1.99 & 0.57 \\
UK & 1.26 & 1.60 & 1.28 & 1.52 & 0.54 \\
France & 1.14 & 1.39 & 1.83 & 1.43 & 0.76 \\
Netherlands & 1.06 & 2.38 & 0.70 & 0.74 & 0.58 \\
Korea & 0.75 & 1.83 & 3.15 & 1.00 & 0.79 \\
Canada & 1.19 & 1.72 & 1.94 & 0.94 & 0.25 \\
Switzerland & 1.82 & 1.82 & 1.32 & 0.85 & 0.45 \\
Sweden & 0.97 & 1.88 & 2.99 & 1.96 & 0.56 \\
Israel & 0.65 & 1.14 & 2.09 & 1.61 & 1.19 \\
Australia & 1.37 & 1.37 & 3.59 & 1.75 & 0.18 \\
Italy & 0.95 & 1.53 & 2.13 & 2.56 & 0.21 \\
China & 0.47 & 1.13 & 3.29 & 1.55 & 1.29 \\
Russian Federation & 1.30 & 1.87 & 1.80 & 0.53 & 0.56 \\
Denmark & 1.09 & 2.18 & 0.95 & 1.54 & 0.63 \\
Belgium & 1.55 & 0.78 & 1.17 & 1.80 & 0.64 \\
Spain & 0.73 & 2.63 & 1.54 & 1.05 & 1.28 \\
Finland & 0.26 & 1.39 & 5.72 & 4.20 & 0.67 \\
Austria & 2.11 & 1.03 & 2.27 & 1.49 & 0.32 \\
\hline & & & & & \\
\hline
\end{tabular}

Note: RTA indexes over 1 indicate a higher relative technological compatibility. The Figure includes the top 20 countries by the number of nanotechnology patents accumulated by 2005.

Source: OECD Patent database, January 2008.

When considering briefly the modified RTA indexes across the remaining countries in Table 7 less clear distinctions emerge. Only Korea and Switzerland are countries in which the specialisation in nanotechnology application fields relatively well matches their overall specialisation profile. For Korea this concerns electronics, pharmaceuticals and biotechnologies; for Switzerland this concerns chemicals, pharmaceuticals and biotechnologies. The remaining countries have a mixed profile of both compatible and incompatible specialisation. Again the small number of observations for some countries should be noted as a limiting factor in this type of analysis.

\section{Overall position and specialisation of countries}

For an overall summary Appendix 3 presents scatter plots to illustrate the position of countries by both the standard and modified RTA indexes. These scatter plots give a overall indication of the degree of specialisation of countries in nanotechnology application fields, as well as the degree to which these specialisation profiles represent a departure from their technological profiles in general. The scatter plots provide the bigger picture while less attention should be given to the position of individual countries.

In electronics, the specialisation of countries appears to cluster in the centre of the figure. This indicates a moderate specialisation in nanotechnology application for electronics that is compatible with the overall specialisation profile of a majority of these countries. Accordingly, it seems that electronics is an application field in which many countries are drawing on existing technological competences. The scatter plots for instruments, pharmaceuticals and biotechnologies, and chemicals look clearly different. In these fields countries generally appear more specialised in nanotechnology applications compared to their overall specialisation profile in the respective fields. The overall impression is that these are application 
fields towards which much new activity is directed, with a lesser association with traditional areas of strength.

An interesting question is whether these specialisation profiles and trajectories can be related to the more fundamental distinction between top-down and bottom-up approaches to nanoscale engineering. The prevalence of the more incremental top-down approach in electronics may explain why a majority of countries in this application field appear to be adhering to their present fields of strength. In contrast, the bottom-up approach draws to a greater extent on new developments in chemistry and biology (including biotechnology). In so far as this approach is more important in the application fields of chemicals and materials, pharmaceuticals and biotechnologies, it may explain the lesser resemblance between the nanotechnology application and overall specialisation profiles of the majority of countries in these fields.

Finally, the application field of industrial processing is strikingly different when compared with all the other. The majority of countries tend to be far less specialised in this field compared with their overall specialisation profile. Patenting in industrial processing covers a number of heterogeneous sub-fields, ranging from materials and surface processing to petrol processing, environment and pollution. Some of these sub-fields are more traditional application areas for new technologies, which may explain the higher specialisation outside nanotechnology that appears to be characteristic in the majority of countries.

\section{Summary}

- Countries are positioned and specialised in nanotechnology and its application fields in different ways, partly also reflecting their overall specialisation patterns. Most countries covered by patent data are involved in multiple nanotechnology sub-areas; this is also reflected in the relatively similar distribution of patents across these sub-areas in the United States, Japan and the European Union.

- When considering the distribution of nanotechnology patents by application fields more variations can be detected; countries tend to either patent relatively more either in the field of electronics, or in the fields of chemicals, pharmaceuticals and biotechnology, while only a few countries are diversifying across all application fields.

- Using indexes of revealed technological advantages clearer specialisation patterns emerge. The United States and European Union are relatively more diversified across the main nanotechnology application fields. Japan has a higher degree of specialisation in electronics while the BRIC countries lean relatively more on applications in pharmaceuticals and biotechnologies. Further, both the European Union and Japan are specialising in application fields where there has been lesser overall specialisation in the past. In contrast, the diversified profile of the United States in nanotechnology applications is compatible with its broader overall specialisation pattern.

- Electronics appears to be a nanotechnology application field in which most countries have previous strengths. Instruments, chemicals, pharmaceuticals and biotechnologies appear to represent application fields towards which nanotechnology is enabling diversification beyond fields of previous specialisation. These findings may reflect the significance of incremental top-down nanoscale engineering in electronics, on the one hand, and the more discontinuous nature of bottom-up approaches on the other, e.g. pharmaceuticals and nanobiotechnology. 


\section{INSIGHTS FROM COMPANY SURVEYS}

\section{Introduction}

The indicators and statistics included so for in this report have covered global developments based on data sources that enable comparisons across countries. To counter-balance the abundant use of publication and patent data this section focuses on company surveys that have been undertaken in a few countries. Even though these surveys are not comparable in a strict sense they are based on similar definitions and methodologies, and can therefore provide some scope for generalisation. The majority of these surveys address at least some common issues of relevance, and all of them have been commissioned by agencies involved in the design or implementation of science, technology and innovation (STI) policies in the field.

Company surveys have been undertaken in the United States, Canada, Germany, Finland and Australia. A common challenge when undertaking these surveys has been the identification of nanotechnology companies. Nanotechnology covers a rare population of companies which is not tagged in regular company registers or industrial classifications, while a common statistical definition is missing. The identification of small nanotechnology-dedicated companies is somewhat easier as many of these more actively promote their nanotechnology activities. However, in larger companies nanotechnology is usually only one technology of many that feed into research and development, production and innovation activities, whereby identification is harder.

Company surveys undertaken in the countries mentioned above therefore were reviewed and synthesized in so far as their results have been made publicly available. Each of the reviews described below highlights some survey practicalities and the basic characteristics of the company sample. Beyond this the selection of issues addressed is based on subjective judgement in order to identify at least some common results across all of them. Whenever possible the raw data (Figure 1 and Table 1) have been requested from the original sources together with their approval of the reviews and synthesis of this material.

\section{The NCMS Surveys of Industry in the United States}

\section{Survey practicalities and company sample}

In the United States, the National Science Foundation (NSF) has funded three consecutive company surveys undertaken by the An Arbor-based National Centre for Manufacturing Sciences (NCMS) in 2003 and 2005 (with a new follow-up survey planned in 2008-2009) of which the 2005 survey will be reviewed here as it has been reported extensively. The objective of these surveys was to understand and benchmark the efforts within existing industries towards development and commercialisation of nanomanufacturing technologies, with a specific focus on determining whether the senior company executives treat nanotechnology differently from any other generation of advanced science and technology. The methodological approach is interesting as it identifies a large number of senior-level executives in leading US companies with assumed responsibility in management, technology or R\&D in nanotechnology-related fields. The list of senior executives was obtained from a listing of Small Times Magazine's nanotechnology-identified subscribers. As a consequence problems in identifying nanotechnology companies were avoided although the definition proposed by NNI was used in engaging survey 
participants and in differentiating between their areas of nanotechnology to solicit and differentiate survey participants.

In the 2005 survey, an electronic questionnaire was sent out to 6000 senior executives with an attained response rate of $10 \%$ or 595 completed responses. As such it probably represents the largest crossindustry survey commissioned by a public agency and can thus provide important insights, although the focus on existing industries in the US context has to be borne in mind when considering the results. Details of the background, methodologies and results of the survey are reported in NCMS and NSF (2006). The survey covered the following issues of which emphasis will be given, i.e. the organisational, infrastructural and managerial capabilities relating to nanotechnology; partnering and their drivers; timeliness and nature of products, as well as challenges related to manufacturing and commercialisation.

As the survey targeted senior executives, rather than companies, exact information on the number and basic characteristics of the companies that were indirectly covered is lacking. Overall $80 \%$ of the responding executives are affiliated with smaller companies with less than 20 employees. The data contains information about the geographical distribution of the respondents, the position of respective companies along the value chain, and the envisioned main application areas. Predictably, the Pacific regions of the US (including California) represented the largest share of respondents $(20 \%)$ considering that the electronics and semiconductor industry have been at the cutting edge in applying nanotechnology already for several years. Other significant concentrations of senior executives related to nanotechnology include Illinois, Wisconsin, Indiana, Michigan and Ohio (13\%), New York, Pennsylvania, New Jersey, and Connecticut (13\%) and South Atlantic states such as Georgia, Virginia, Maryland, Delaware, Washington DC, the Carolinas and Florida (15\%).

Figure 32 gives the breakdown by the position of companies in the value chain and the envisioned application areas. Nearly half of the respondents to this survey indicated their companies are involved in nanomanufacturing (31\%) comprised of manufacturers, integrators and component suppliers, vendors of nanotechnology products and equipment. This is followed by university-based developers, service suppliers and researchers (rather than executives) in both public and private R\&D laboratories. Regarding application areas, these comprise a broad range of different industries with relatively equal shares of respondents for electronics and semiconductors, ICT, aerospace, automotive, chemicals and process industries. The single most important application area is equipment, logistics and distribution according to $52 \%$ of all respondents. 
Figure 32. Position of US nanotech companies in value chains and application areas

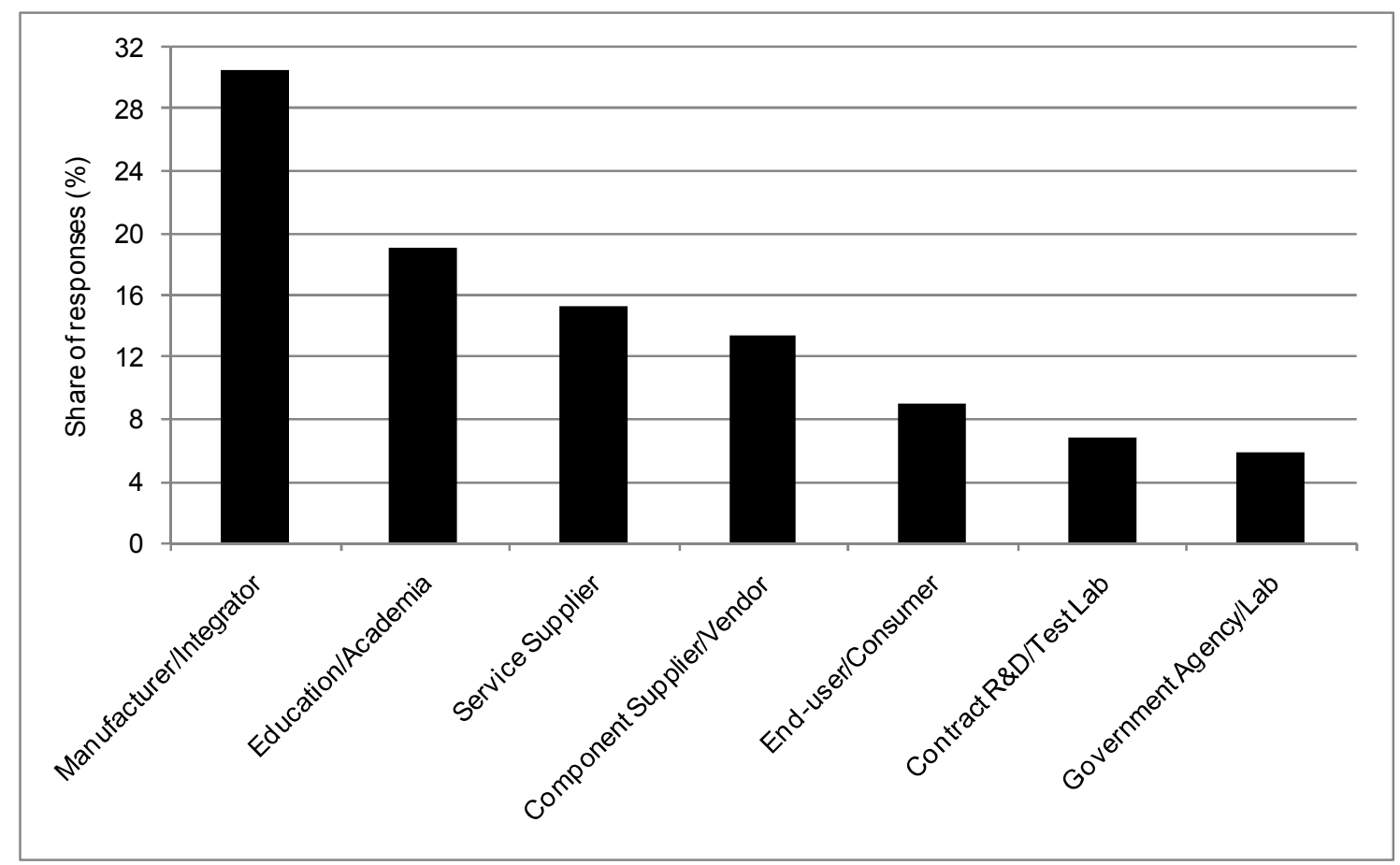

Source: NCMS and NSF (2006).

\section{Managerial and organisational capacities}

The first part of the NCMS survey was dedicated to managerial and organisational capacities that nanotechnology developments require for their manufacturing and commercialisation. On a five-point scale from high to low priority, $52 \%$ of the respondents stated that nanomanufacturing is considered a high priority for their companies while about $20 \%$ considered it a low priority. In terms of company size, responding executives from larger companies with over 100 employees tended to assign a large share of responses to high priority compared with those from smaller companies. Overall $46 \%$ of all respondents stated that their companies are coping relatively well with strategy, resources and market changes related to nanotechnology, which was unchanged when compared with the 2003 NCMS survey. However, as organisation size decreases the share of respondents indicating difficulty in managerial adaptability increases (Figure 33). The report suggests that this may be due to small companies investing scarce resources in the development of speciality products, often for niche or underdeveloped markets where uncertainty is higher. 
Figure 33. Managerial capacity amongst US nanotechnology companies

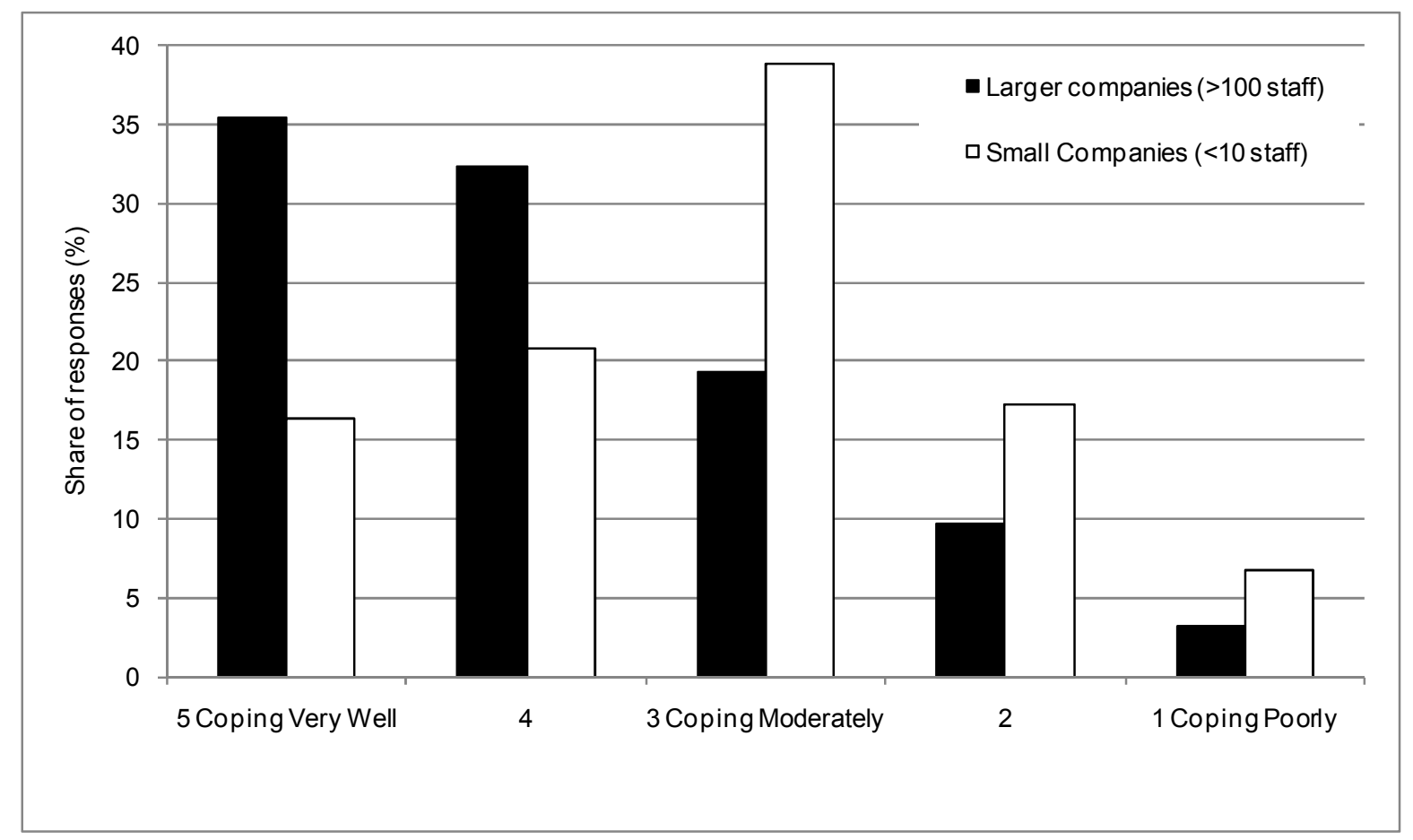

Source: NCMS and NSF (2006).

In the survey managerial abilities cover the ability of companies to build relationships with academic researchers, national laboratories and centres of excellence, as well as execute changes in strategies with respect to the interdisciplinary nature of nanotechnology, intellectual property rights, the handling of societal and environmental issues. The survey also considers organisational capacity to access capital, manpower, talent and research or production infrastructures for developing nanotechnology products. Overall as many as $70 \%$ of all respondents reported medium to high levels of organisational capacities along a five point scale, representing a significant improvement compared with the 2005 NCMS survey. Again smaller company size increases the share of respondents indicating difficulty in capacities (Figure 34). 
Figure 34. Organisational capacity amongst US nanotechnology companies

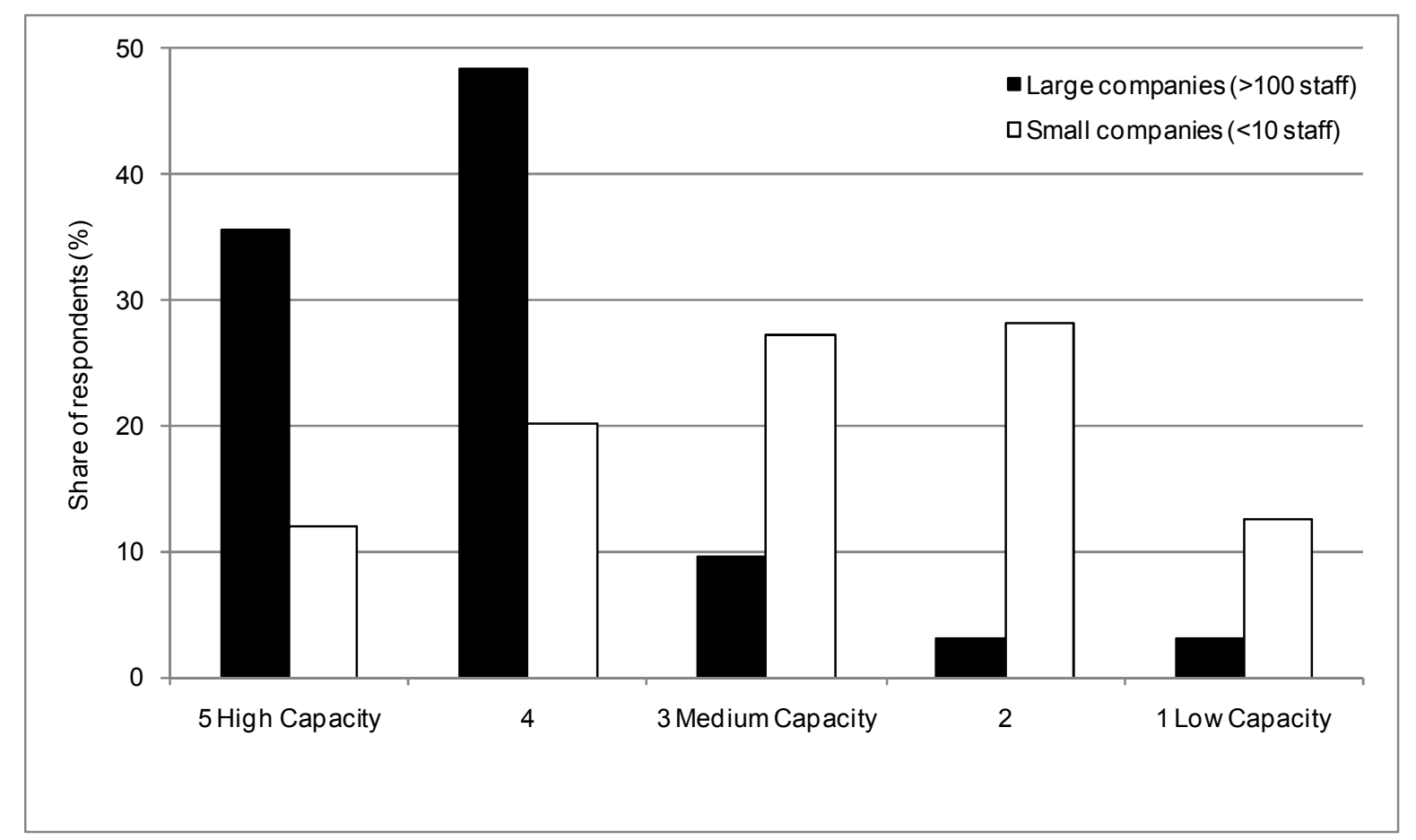

Source: NCMS and NSF (2006).

\section{Challenges to manufacturing and commercialisation}

The overall aim of the NCMS survey was to determine whether the surveyed executives perceived and treated nanotechnology differently from any other generation of advanced science and technology. The barriers and challenges to nanomanufacturing and commercialisation were particularly important issues and they are discussed in greater length in the report, also based on complementary interviews with some executives. The survey suggested 18 key challenges along with an open-ended response alternative. The complete ranking of these challenges is illustrated in Figure 35. 
Figure 35. Challenges in manufacturing and commercialisation amongst US nanotechnology companies

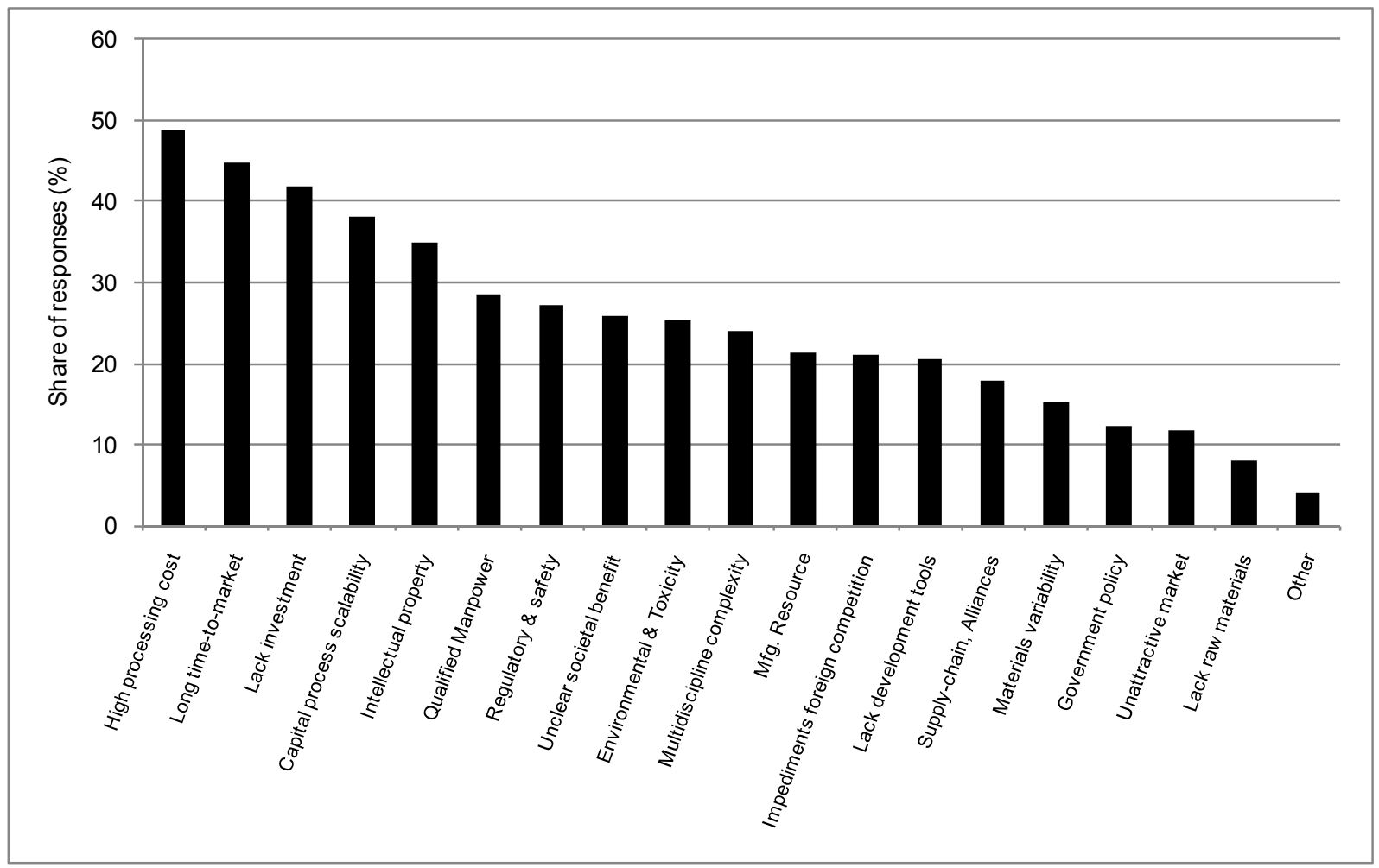

Source: NCMS and NSF (2006).

Overall the respondents expressed consensus around the key challenges to nanotechnology commercialisation, namely high processing costs, followed by lengthy times to market, insufficient investment capital, process scalability and intellectual property issues. These main challenges were also identified in the 2003 NCMS survey, and thus appear consistent over time. However, environmental, regulatory and safety concerns were more pronounced in the latest survey from 2005 . Further, the report notes some important differences in the results when analysed across application industries. For example, foreign competition appears as a much larger challenge in certain of these application industries compared with the others, such as the energy, semiconductors, aerospace and chemicals industries.

The five main challenges, along with regulatory and safety concerns, are discussed at some greater length in the report with the intention of pin-pointing issues of specific relevance to nanotechnology. Regarding high processing costs for nanotechnology products, this challenge is taken as an indication that the nanomanufacturing industry is still in its infancy and characterised by few early adopter applications, fragmented markets, lack of infrastructure equipment for nanomanufacturing, and few efficient manufacturing methods especially in bottom-up approaches to nanoscale engineering. As a consequence, companies need to innovate and improve ways to deliver exact products at prices competitive with those of mass production. The standardisation of macro- and nano- scale parts, equipment, tooling, interfaces and product offerings would be one way forward to lowering processing costs.

The lack of investment capital is highlighted as a challenge in numerous other company surveys on innovation and commercialisation of emerging technologies. In the NCMS report, it is suggested that the high costs of building and maintaining processing facilities while trying, at the same time, to develop viable business models, products or processes, is a specific challenge related to nanotechnology that may 
be pronounced for smaller companies. Further, many academic entrepreneurs with a background in natural sciences (physics, chemistry, biology) tend to lack the critical business and entrepreneurial skills, and thus, may not be capable of explaining the value proposition of their nanotechnology products to potential investors or customers. Lengthy times to market of nanotechnology products, combined with public perceptions of environmental, regulatory, health and safety concerns may compound the situation. According to the NCMS report there is thus a strong case for sustained government funding of long-term $\mathrm{R} \& \mathrm{D}$ in this field.

Lack of process scalability is also considered as a challenge specific to nanotechnology. The upgrading of nanotechnology processes and the integration of nanoparticles into other dissimilar materials with reproducible performance and properties, are highlighted as important technically challenging issues, especially in the converging nano- and biotechnology areas where breakthroughs would be needed to make the transition from lab-scale to pilot-and prototype-nanomanufacturing. The high degree of variability of nanomaterials and associated Lack of scalability of nanomanufacturing processes points to the need for further R\&D, and the increase of public-private resources and investment in supporting infrastructures and processes related to such structurally complex materials.

Finally, regarding regulatory and safety concerns the report suggests that these span several key areas, such as the handling and industrial use of nanoparticles, coatings, nanoadditives and nanotubes. The key challenges identified include the development and demonstration of targeted applications for societal benefits, while addressing the safety and regulatory issues associated with these types of products.

\section{Timeliness and nature of products}

Against the backdrop of very optimistic market forecasts for nanotechnology products the NCMS survey also included questions on commercialisation timelines and types of nanotechnology products that are being developed in the US manufacturing industries. Although very little comparable data is available (for the case of Finnish nanotechnology products see below) the overall results suggest that nanotechnology commercialisation is developing rapidly due to urgent societal concerns in energy generation, environment, defence and biomedicine. The survey found that $18 \%$ of respondents indicated the commercial availability of nanotechnology products, while $40 \%$ were expected to reach the market within three years. The remaining $40 \%$ of respondents indicated that commercialisation was beyond three years (see Figure 36). 
Figure 36. Timeliness of commercialisation amongst US nanotechnology companies

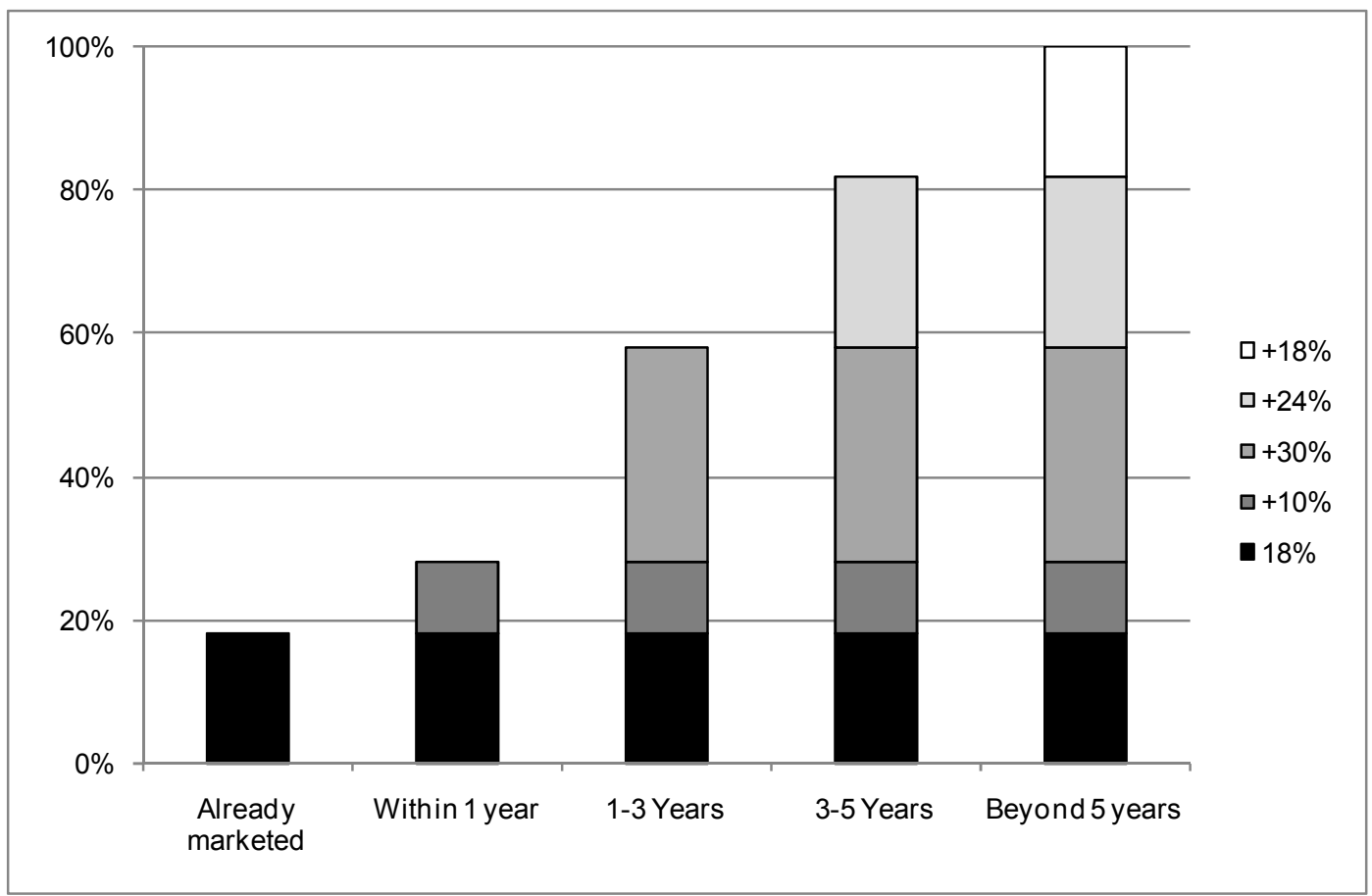

Source: NCMS and NSF (2006).

Questions about the types of nanotechnology products that were being commercialised in the United States were cross-tabulated with timelines of commercialisation. According to the survey the top five nanotechnology products that were already commercially available in the US manufacturing industry were the following:

- Semiconductors, nanowires, lithography and print products

- Nanostructured particulates and nanotubes

- Coatings, paints, thin films, and nanoparticles

- Defence, security and protection gear

- Telecommunications, displays and optoelectronic products

In the timeline of 3-5 years, nanotechnology products entering the market include a larger portion of biomedical, nano-biotechnology and energy-related products:

- Environmental, sensing and remediation products

- Drug delivery, medical diagnostics and implant systems

- Nano-biotechnology, nanofluidics and tissue engineering products

- Energy-related battery materials, catalysts, fuel cell components and filtration products

\section{The Canadian pilot survey on nanotechnology}

\section{Survey practicalities and company sample}

Statistics Canada has been among the pioneers in surveying nanotechnology through company surveys. The approach eliminates some of the problems in identifying nanotechnology companies by surveying a large population through a so-called Emerging Technology Survey (ETS). In 2005, this survey 
was mailed to all firms in whose industry codes nanotechnology had been observed, or where there was a possibility of nanotechnology activities. This resulted in a list of potential respondents that to whom the Biotechnology Use and Development Survey, which contained the pilot survey on nanotechnologies was sent. The Biotechnology Use and Development Survey from 2005 contained a dedicated nanotechnology section that asked basic questions of firms that has been identified as being active in nanotechnology. The main findings of this survey are reported here.

In 2005, 88 companies reported involvement in nanotechnology; the vast majority (91\%) were active in research and development $(\mathrm{R} \& \mathrm{D})$ and $27 \%$ reported that they were in the production/or marketing stage. Companies reported the greatest involvement in nanomaterials $(43 \%)$ and nanobiotechnology (42\%), followed by nanomedicine, nanophotonics and nanoelectronics. Some firms reported activity, primarily research and development, in more than one category. Small firms accounted for $82 \%$ of all respondents, with medium and large firms accounting for $8 \%$ and $10 \%$ of firms respectively. The provincial distribution of the firms found Ontario with 30 firms (34\%), followed by Quebec with $25(28 \%)$, British Columbia with $19(21 \%)$ and Alberta with 12 (14\%) firms. The remaining companies are spread across Canada. The size distribution and provincial distribution stage of development and nanotechnology category followed similar patterns as Canada as a whole, the latter distribution of which is shown in Figure 37.

Figure 37. Distribution of companies by nanotechnology activity

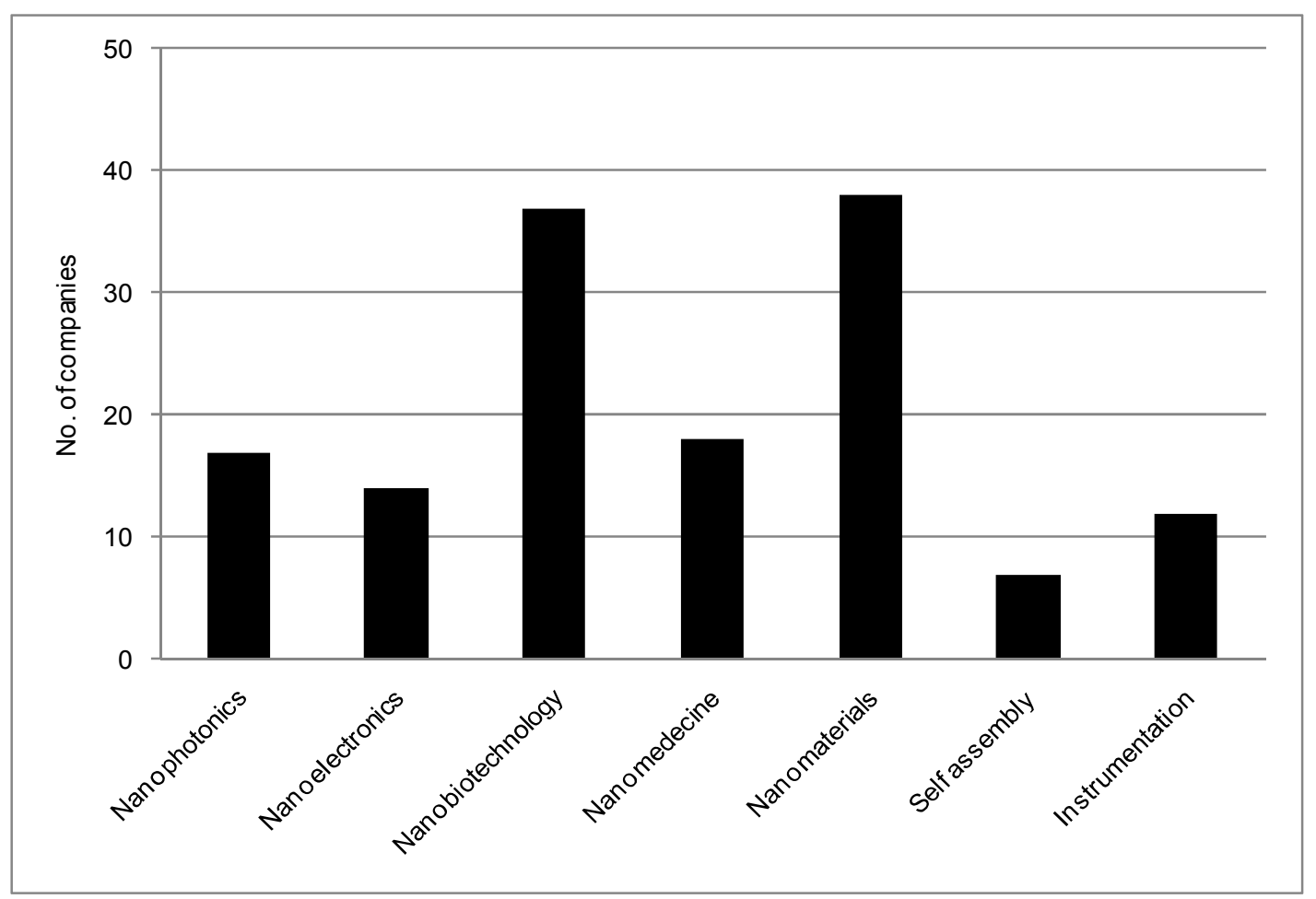

Source: Statistics Canada (2006).

The Canadian survey had as its main aim to quantify the size of nanotechnology through company information, whereby most questions dealt with the financials of nanotechnology activities in the company (revenues, R\&D investments, external support, imports and exports) including the extent of IPR activities. Nonetheless, the survey also included a few questions on human resources, alliances and collaboration that enable comparisons with some of the other surveys referred to later in this section. 
DSTI/DOC(2009)7

\section{Nanotechnology revenues and investments}

The Canadian companies covered by the survey reported USD 28 million in nanotechnology revenues in 2005, an increase of $19 \%$ over 2004 revenues. However, this is far less than the nearly doubling of revenues to USD 55.8 million forecast by respondents for the year 2007. Quebec accounted for the majority of revenues with $52 \%$, with Ontario following at $22 \%$, British Columbia at just under $14 \%$ and Alberta at $12 \%$. Financial data for the rest of the provinces is not available due to the small number of respondents in those provinces. The 72 small firms earned $88 \%$ of all nanotechnology revenues in 2005 .

Nanotechnology R\&D expenditures totalled just over USD 40 million in Canada, a $12 \%$ increase from 2004. Again Ontario leads the provinces with $38 \%$ of nanotechnology-related R\&D, followed closely by British Columbia at 35\%, Quebec at 22\%, and Alberta at just under 5\%. Total Canadian nanotechnology R\&D expenditures rose $12 \%$ between 2004 and 2005, with firms forecasting expenditures of an additional USD 18 million a year by 2007 . R\&D contracted out makes up about $6 \%$ of total nanotechnology R\&D expenditure in 2005 , with the forecast this will increase by $136 \%$ in 2007 at which time it will almost double to fewer than $10 \%$ of nanotechnology R\&D spending. Not surprising is the fact that $93 \%$ of nanotechnology R\&D is undertaken by small firms, as they account for $82 \%$ of all firms.

In 2005, 22 firms attempted to raise capital for nanotechnology related activities. Of these only eight small firms were successful in raising just over 16.5 million USD. This demonstrates a fairly significant failure rate and could be of importance for the future growth of the nanotechnology sector and of concern to stakeholders. Surprisingly, given the early stage of development of the nanotechnology sector, 34 firms reported a total of 559 intellectual property instruments in 2005. Patents made up $60 \%$ of the total and pending patents comprised $28 \%$, followed by technology transfer agreements at $26 \%$ of the IP activity, licensing agreements made up $20 \%$ with the balance comprised of the 'other' category. The majority of firms were in Quebec with 14 firms reporting 112 IP instruments, almost all were patents or pending patents. In Ontario, 13 firms reported 226 IP instruments, of which 56\% were patents or pending patents. Four British Columbia firms reported 177 IP instruments of which $77 \%$ were patents and an additional $15 \%$ were pending patents. Other provincial data are unavailable.

The unexpectedly high number of patents has been investigated and verified. The survey question only asks the number of patents and other IP instruments without geographic parameters. Therefore it is possible that double counting has occurred, raising the total number reported. These patents also may not be unique to Canada.

\section{Human resources and collaboration}

The number of nanotechnology employees is small, with $88 \%$ of the 380 total nanotechnology employees found in small nanotechnology firms. The majority (76\%) have full time duties as nanotechnology employees and the remaining $25 \%$ were employees with part time nanotechnology duties. Ontario leads with 36\% of nanotechnology employees, followed by Quebec with 32\%, British Columbia with $22 \%$ and finally Alberta with just over $8 \%$. Overall $15 \%$ of firms, virtually all small firms, reported difficulty in attracting nanotechnology employees, with scientists and technical staff the most commonly cited areas of difficulty. Provincial data availability is limited but $40 \%$ of firms in British Columbia reported difficulty finding nanotechnology staff, more than double the percentage of the next highest province, Quebec, at $19 \%$ and Canada as a whole.

A total of 55 firms entered into 107 collaborative arrangements for nanotechnology purposes, meaning many firms entered into 2 or more arrangements. University collaborations made up $65 \%$ of the total, followed by other firms at 38\%, other nanotechnology firms with $35 \%$ of the collaborations and government partners in $25 \%$ of arrangements. 


\section{DSTI/DOC(2009)7}

\section{The German survey on the Economic Potential of Nanotechnology}

\section{Survey practicalities and company sample}

The German survey was directed at companies in order to better understand the developments and economic impacts of nanotechnology. The methodologies and main finding of this project are reported at greater length in Malanowksi et al. (2006), which is the basis for this review. The project was set against the backdrop of the large socio-economic expectations and optimistic market forecasts that characterise nanotechnology and had the objective of clarifying the German situation. The survey has also been used to critically assess the available market. The project was a joint effort of analysts at VDI Technology Centre, HfB Business School of Finance and Management, and Nano \& Micro Technology Consulting.

The survey was undertaken in 2003 and addressed to 800 companies of which 450 most probably were active in nanotechnology. The definition of the survey population was based on company lists compiled by various organisations monitoring nanotechnology in Germany, including VDI technology Centre as the primary source. Depending on the definition of the sample, for example when considering the degree of involvement of the companies in nanotechnology, the response rate was in the range of $13-15 \%$, resulting in 107 responses.

The majority of the surveyed companies (70\%) were founded in the period 1980-2002 with particularly many start-ups during the 1990s. The size distribution of companies is dominated by small and medium-sized firms with about $35 \%$ of the companies having less than 20 employees. A large majority of the companies are situated in the chemicals and instruments industries, followed by various manufacturing industries of both high-technology and a more traditional nature (Figure 38). The primary markets of these companies were in the European Union and United States followed by Japan and other Asian countries.

Figure 38. Main industries of German nanotechnology companies

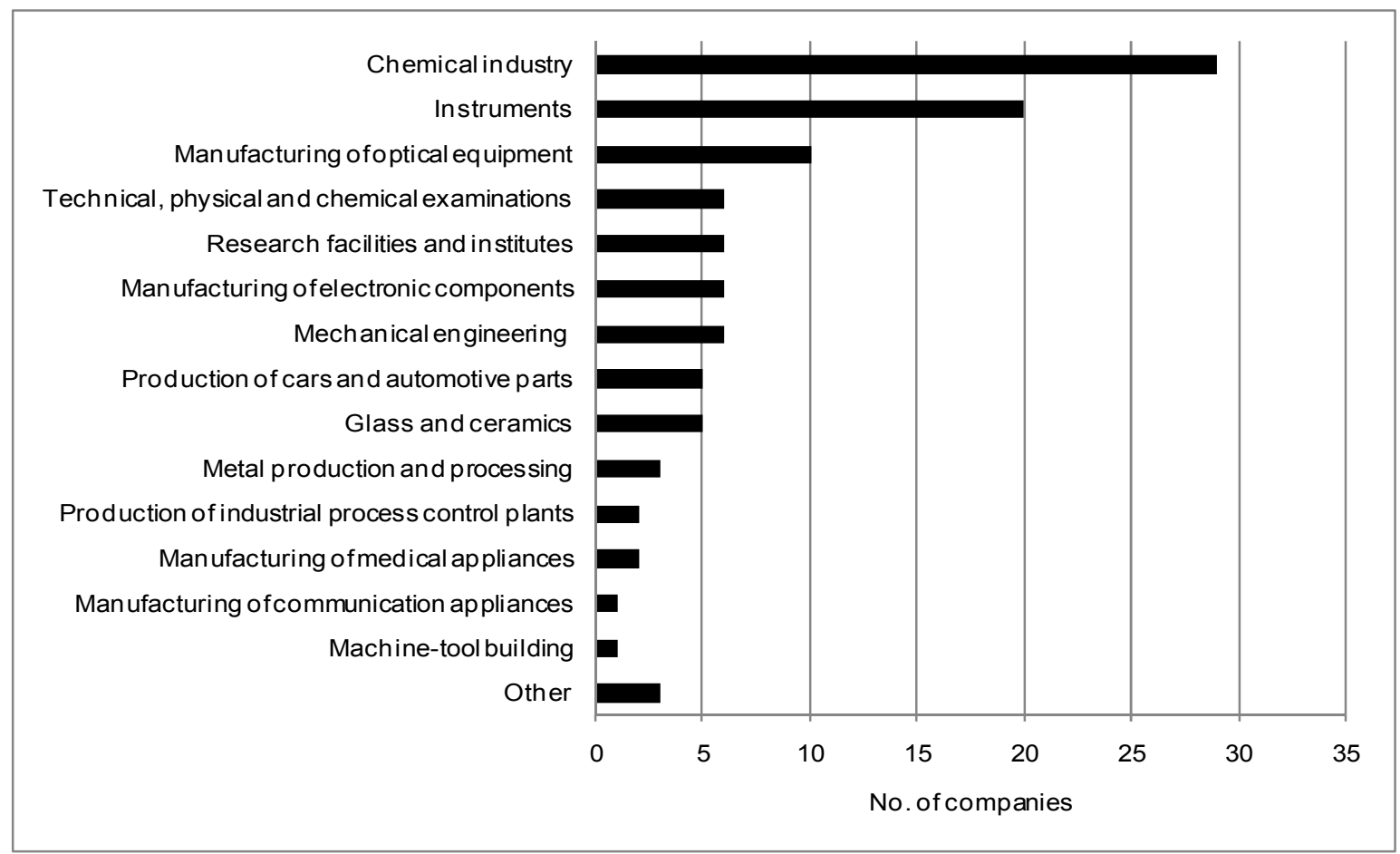

Source: Malanowski et al. (2006). 


\section{Importance, impacts and future developments of nanotechnology}

The emphasis of the project on the economic impacts of nanotechnology in Germany implied that a large part of the survey focused on estimated future developments with a specific relevance for this country. Nonetheless, some of the results provide insights into similar issues addressed by the other company surveys reviewed here. In particular, when asked about their degree of involvement in nanotechnology, $66 \%$ of the companies described themselves as manufacturers while $29 \%$ regarded themselves as users of externally developed technologies related to this field. Based on benchmarking of shares of nanotechnology sales in 1996 the survey also indicates that the number of companies manufacturing nanotechnology products, and receiving sales revenues from there, has increased.

On a 5 point scale more than $75 \%$ stated that nanotechnology will enable their company to open up new markets while more than $60 \%$ expect increased competitiveness in traditional markets (Figure 39). Overall over $60 \%$ of these surveyed companies believed that nanotechnology know-how will be a decisive competitive factor. When asked about the location of major competitors, US companies were mentioned with the highest frequency followed by other companies in Germany. Some $10 \%$ mentioned either Japanese companies or companies elsewhere in Europe. At this stage these German companies did not consider other Asian companies as a noteworthy competitive threat.

Figure 39. Relevance of nanotechnology for competitive position of German companies

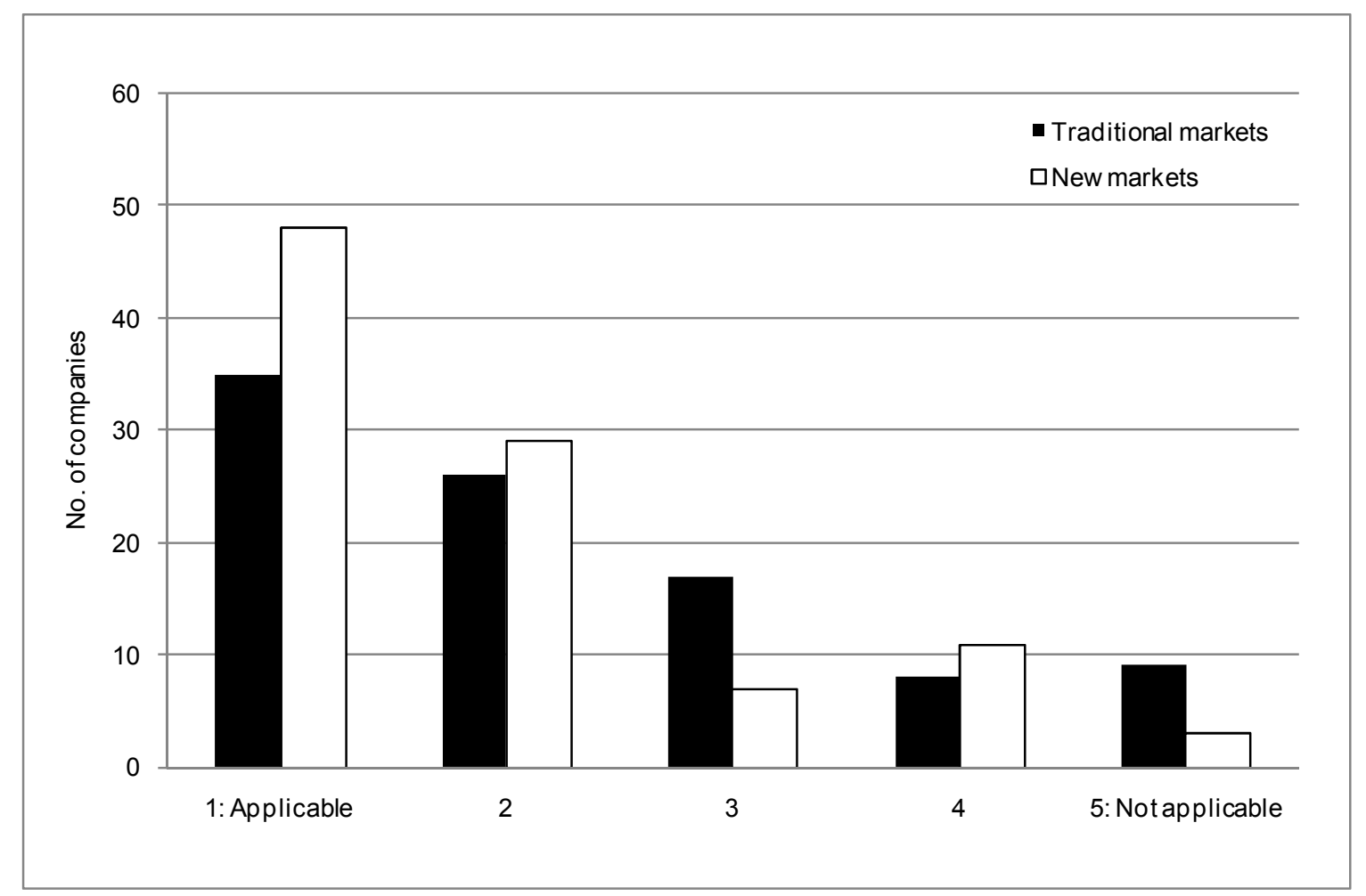

Source: Malanowksi et al. (2006).

Regarding the future prospects of nanotechnology, almost $90 \%$ of the companies reported plans to increase activities, accompanied also by an increase in employment. The predicted increase in staff was especially clear amongst the small and medium-sized companies. The respondents were also asked to rank the three most potential application fields for the future. Information and communications applications was perceived as the most important one followed by chemistry, materials and process engineering, medicine 
and life sciences, and measurement technologies (instruments). More traditional areas, such as energy, construction, food and its processing received lower scores in this ranking.

In order to gain even further insights into the future developments the respondents were asked about the functional elements that nanotechnology could realise. Overall there was an emphasis on surface functionalisation, optical effects, improved material properties, analytical/diagnosis, sensor technology and nanobiological functions. When these functionalities are cross-tabulated with the application field some further indication of future developments could be gained.

In the field of information and communications the central functional elements were data processing and storage, displays and optical effects. According to the report this can be explained by the growing demand on the performance of IT hardware (compare with the discussion about Moore's law) and software along with that of light-weight and robust high-resolution user interfaces. In chemistry, materials and process engineering the central functional elements were improved material properties and surface functionalisation, followed by protection functions and optical effects. Finally, in medicine and life sciences these were nanobiological properties and analysis/diagnostics, as could be expected.

\section{Barriers to nanotechnology innovation and application}

The German Survey also addressed the planned next steps for the realisation of nanotechnology projects within the companies. Overall some $45 \%$ report that they are in the product development phase. Nonetheless, when asked about the next steps the provision of research staff and co-operation partners, the initiation of research projects and fixed investments emerged at the top while the development of intellectual property and distribution networks - that assumedly would relate to rapid commercialisation have very low response frequencies. This leads the report to conclude that the main concentration of these companies is on the research side while product development and innovation are still in an early phase.

An important policy issue concerns the barriers to innovation, an issue that was addressed also in this German context (Figure 40). The respondents were asked for the relevance of 9 barriers to innovation on a four point scale. In the German context investment costs and funding issues emerge as the main barriers. Funding issues are followed by the lack of skilled personnel and co-operation partners, while the availability of information on nanotechnology and markets was of lesser importance. The findings suggest that legislation is a far lesser barrier than could have been expected. 
Figure 40. Barriers to innovation amongst German nanotechnology companies

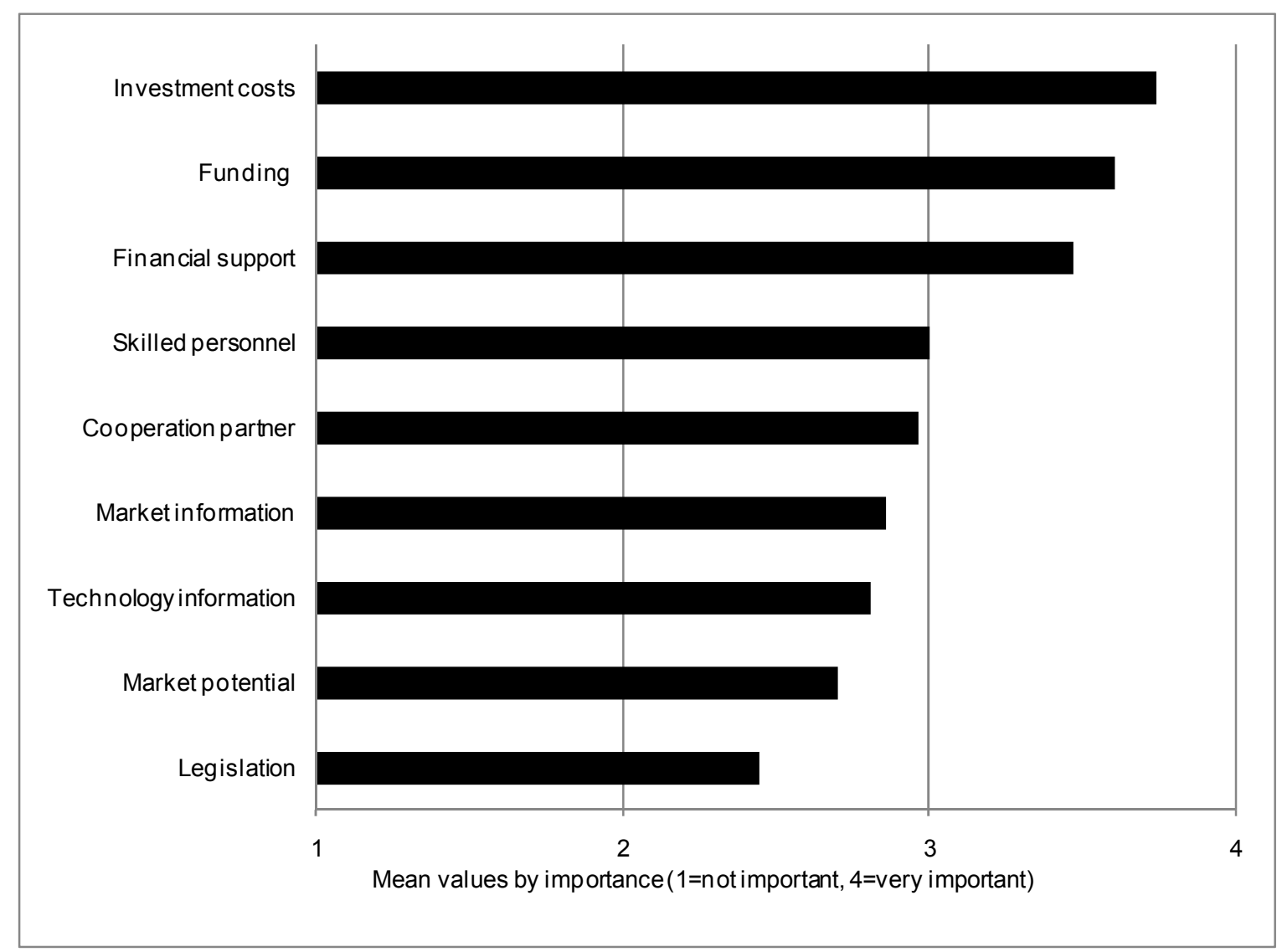

Source: Malanowksi et al. (2006).

The survey found that the barriers to innovation show significant variability by the size of the surveyed companies. Small and medium-sized companies indicated a higher tendency to stress fundingrelated issues as barriers while larger companies cited these much less frequently. The report concludes that access to capital markets, the availability of market information and the attractiveness for regional partners appears to grow with company size. However, it remains unclear whether these barriers are specific to nanotechnology.

\section{The Finnish industry and nanotechnology researcher surveys}

\section{Survey practicalities}

In Finland the consultancy company Spinverse has undertaken company surveys in 2004 and 2006 with a third one forthcoming. The aim of these surveys has been to provide background information for the design and implementation of the national FinNano technology programs commissioned by the Finnish Funding Agency for Technology and Innovation (Tekes). The latest survey from 2006 will be reviewed here while reference will also be made to findings of the previous surveys when relevant. The company sample of these surveys was identified through registers of companies involved in the FinNano program, expert opinion and other sources. Most of these identified companies are located in close vicinity of major cities and technical universities, namely Helsinki, Tampere and Turku. 


\section{DSTI/DOC(2009)7}

In 2006, the survey identified 134 companies, compared with 61 in 2004. Out of these 134 companies 93 completed responses were received. The sample was relatively evenly distributed across companies of different sizes and covering different industries (see Figure 41). Roughly one-third were large companies while another third were small companies and the remaining third were either micro- or medium-sized ones. When comparing with the sample from 2004, the number of companies increased relatively more in the small and medium sized categories. The largest number of companies was found in the electronics, chemicals and materials industries both in 2004 and 2006. Life sciences, forest products and other industries accounted for lower numbers while new companies entered the instruments and tools industry in 2006.

Figure 41. Distribution of Finnish nanotechnology companies by industry

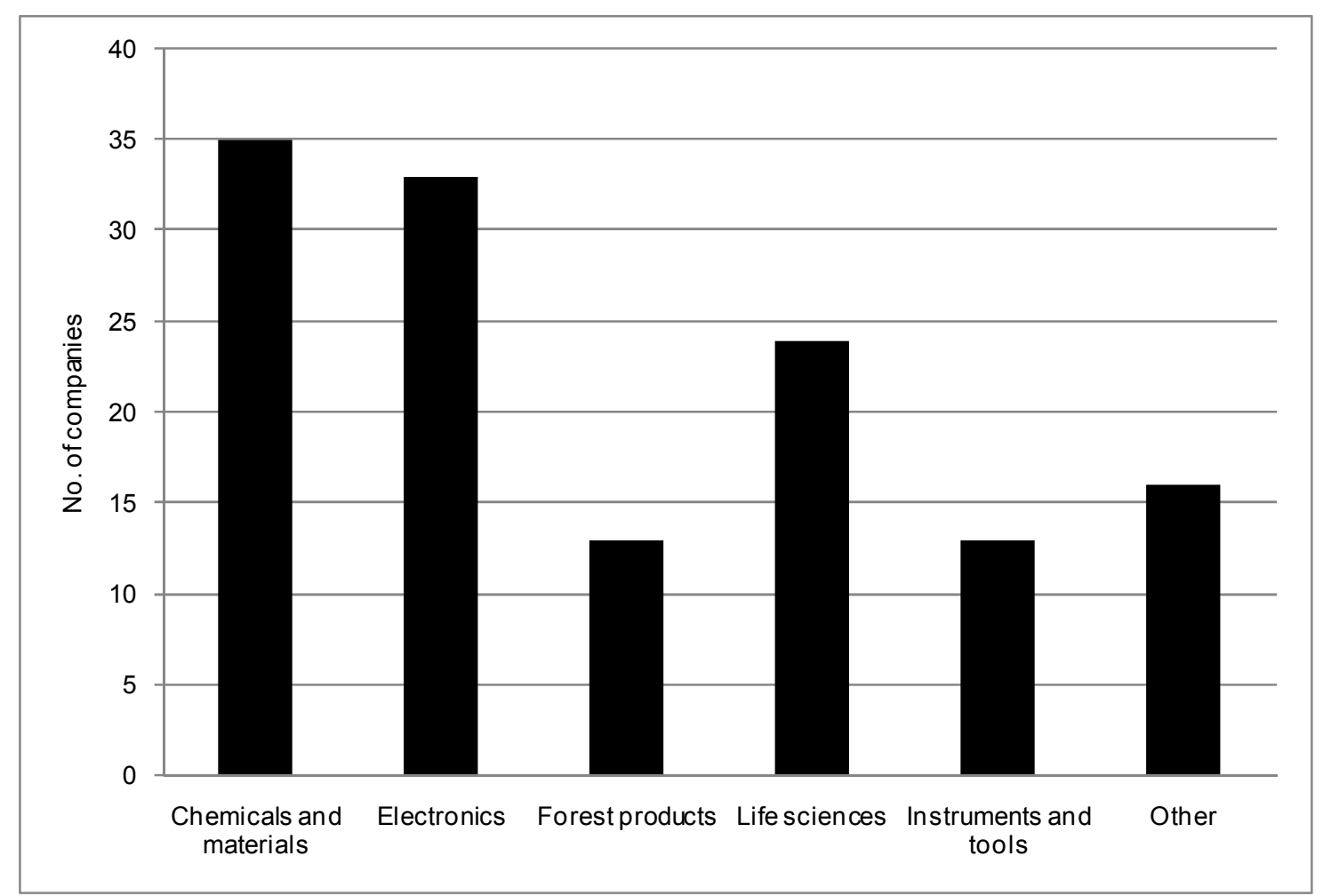

Source: Spinverse (2008).

An important part of the survey sought to trace developments in companies and industries from the early stages of idea-generation through research, product development and to the commercialisation of nanotechnology. This has enabled a monitoring of nanotechnology developments by stages of commercialisation across Finnish industries. In addition, the survey also addressed challenges during commercialisation, the role of public funding and participation in R\&D programme, collaboration, as well as human resource issues; the commercialisation challenges and human resource issues will be highlighted here. Similar issues also have been addressed in a large and complementary Finnish survey directed to individual researchers and inventors and undertaken by the Research Institute of the Finnish Economy (ETLA) (see Palmberg and Nikulainen, 2008). 


\section{Nanotechnology commercialisation duration and stages}

When considering the stage of nanotechnology commercialisation in Finland, the Spinverse survey from 2004 indicated that a majority of the covered companies were already offering commercial products or undertaking product development in the field. In 2006, as a large number of companies were identified, a relatively high number of new companies also in the earlier research stages of nanotechnology commercialisation could be detected. Most of the companies included in the 2006 survey estimated a time to market duration of nanotechnology research in the range of 2-4 years. Figure 42 these estimates differed relatively significantly across industries with shorter time to market durations expected in the more traditional chemicals and materials, and forest products industries, while longer ones were expected in the high-technology industries electronics and life sciences.

Figure 42. Time to market duration of research amongst Finnish nanotechnology companies

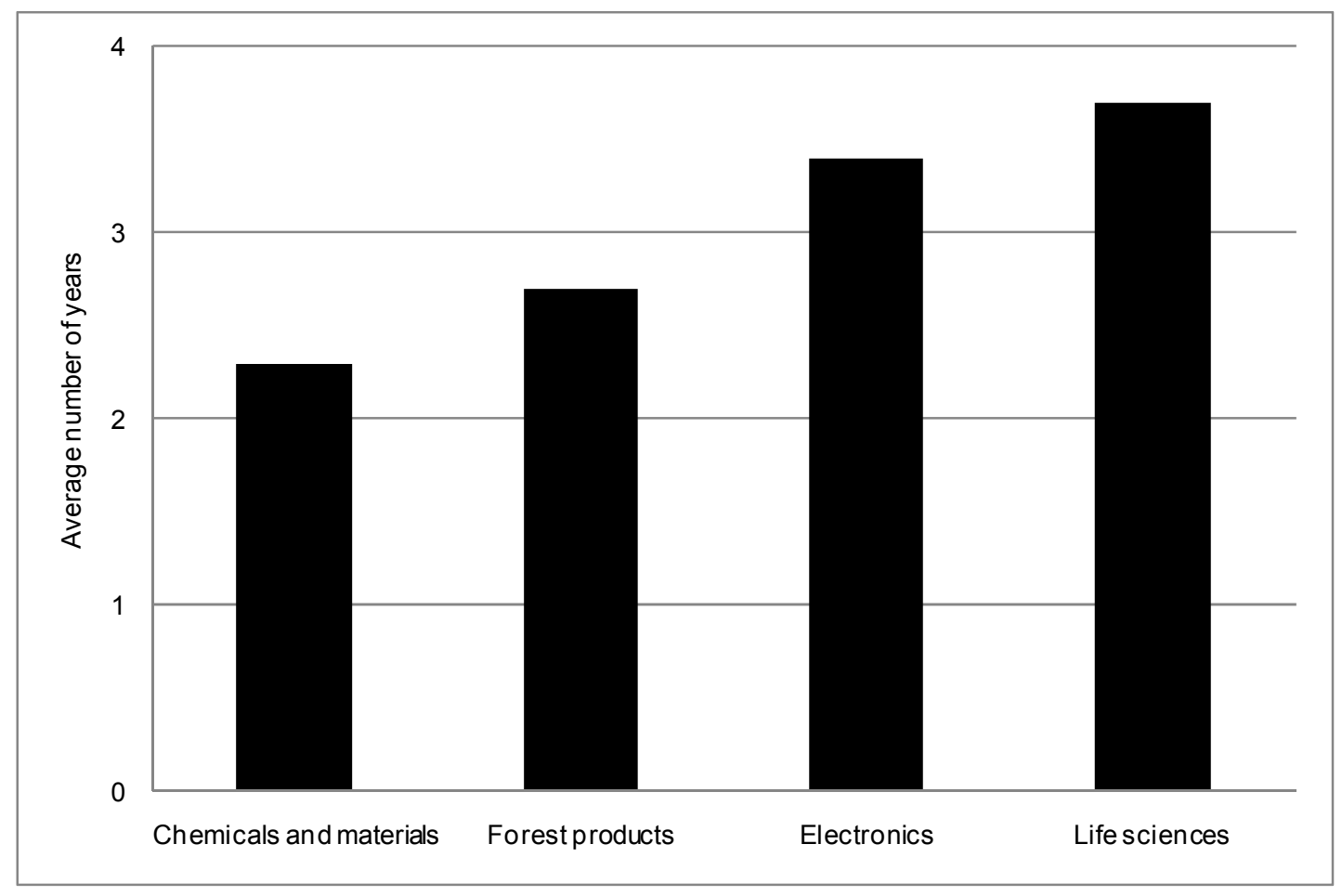

Source: Spinverse (2008).

The researcher and inventor survey undertaken by ETLA covered responses from 397 university researchers involved in nanotechnology (the survey also covers 116 researchers at research institutes and 79 at companies). When asked about their estimations of nanotechnology commercialisation durations, similar findings emerge. These durations are expected to be longer in high-technology industries, in particular related to the life sciences, while they are expected to be shorter in many of the more traditional industries such as metals and engineering, pulp \& paper, energy and construction. The longer expected durations in life sciences industries (mainly pharmaceuticals) may reflect the necessity of clinical research. The shorter expected durations in traditional industries may be due to the existence of large and R\&Dintensive companies in these industries in Finland (Palmberg and Nikulainen, 2008).

The Spinverse surveys have been used to map research and commercialisation pipelines across Finnish industries, of which chemicals and materials as well as electronics appear to be the most established and coherent. In the Finnish chemicals and materials industries nanotechnology research is 
contributing to various types of innovative coatings, new materials and nanoparticles. Product development covers improved catalyst materials, mineral Sol-Gel binders, anti-fingerprint room temperature curing, nanocomposite coatings, nanopowder synthesis, metal-based nanoparticles and coil-coated sheet metals. The following types of products are in the commercialisation phase:

- Gas catalyst materials

- Nanoactive porous structures

- UV-TiO2 nanoparticle retention systems

- Self-cleaning facades

- Ceramic powders for thermal spraying

- Carbon-based nanomaterials

- Conducting polymers

- Nanocomposites

The electronics industry is of key importance in Finland following breakthroughs especially in mobile telecommunications, but also in a range of other adjacent product groups. In the Finnish electronics industry nanotechnology research is contributing with new types of sensors, manufacturing processes, lasers and optics and a range of other types of components. Examples of product development projects include nanoimprint materials, diffractive optics, conductive transparent thin film for displays, nanoprojectors, EPIDS particle sensors and functional coatings on plastics. The following types of products are in the commercialisation phase, mainly within smaller companies:

- Semiconductor materials

- Sensors

- Lasers

- Fotomasks

- Optics

- Fibres

\section{Commercialisation challenges}

The Spinverse survey asked companies about challenges in the commercialisation of nanotechnologybased items on a set of pre-defined items (Figure 43). Of these items 'challenges in identifying commercial applications during collaboration with universities', 'difficulties in achieving reliable mass production, and the 'shortage of funding' stand out as the most widespread ones. Overall, amongst these companies, universities in Finland constitute the main collaborative partner in the sourcing of knowledge, underlying once more the science-based nature of nanotechnology developments that this report has discussed earlier. Difficulties in achieving mass production was also clearly highlighted by the NCMS survey in the United States as a challenge specific to nanotechnology, while the shortage of funding may be a challenge common to small companies in science-based technologies. 
Figure 43. Challenges in commercialisation amongst Finnish nanotechnology companies

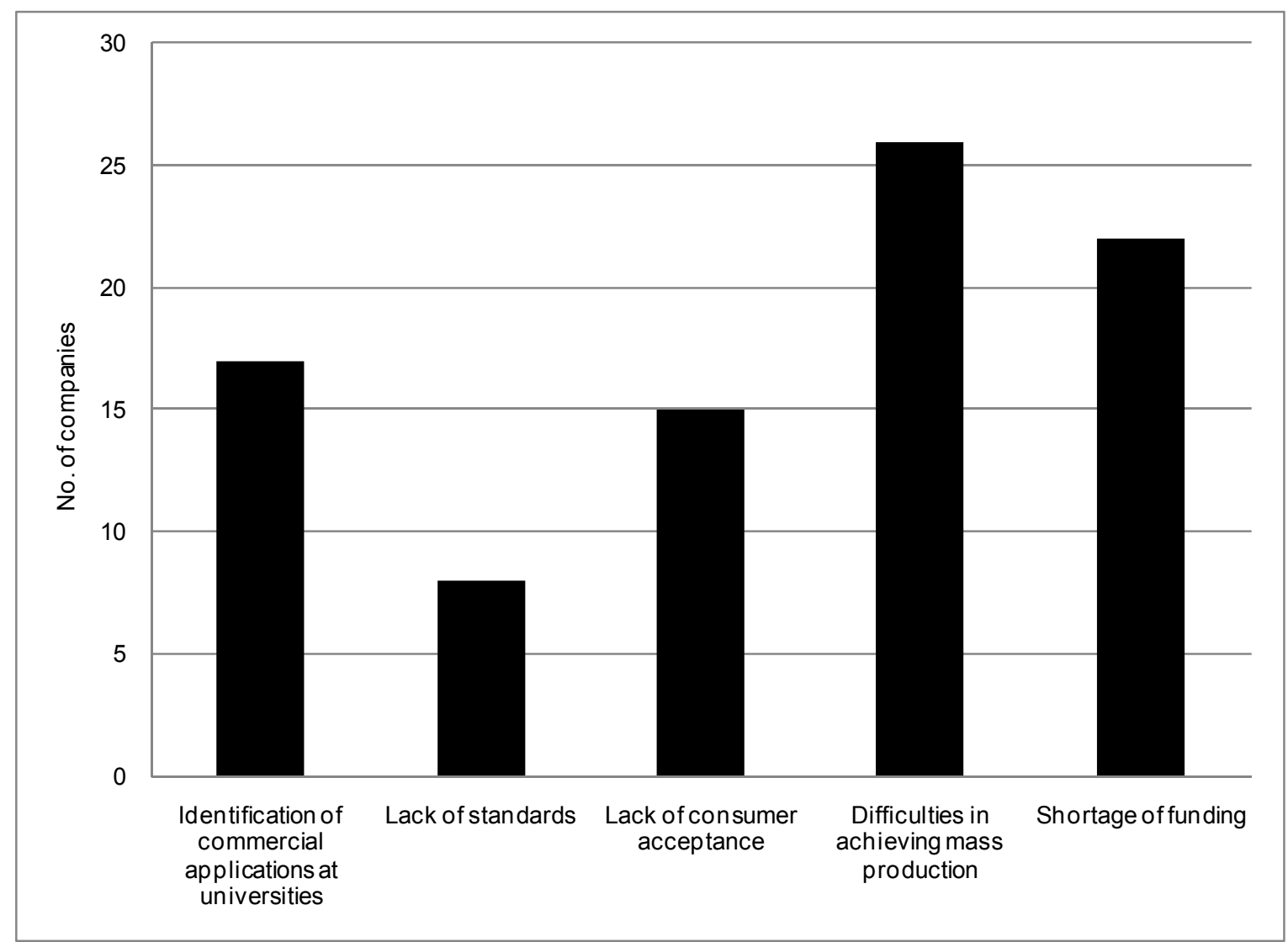

Source: Spinverse (2008).

The challenges that these Finnish companies are experiencing in collaborating with universities were highlighted in greater detail by the researcher and inventor survey undertaken by ETLA (Figure 44). In particular, researchers at universities identified the basic research-orientation of their nanotechnologyrelated field as a key challenge in transferring knowledge from universities to companies, followed by difficulties in identifying commercial opportunities of their research, as well as their lack of business skills.

When researchers at companies were asked to consider these same challenges they considered difficulties in identifying commercial opportunities of research as the main challenge, followed by the lack of business skills of university researchers and the underdeveloped nature of production technologies. IPR issues were not considered as major challenges even though researchers from companies tended to view this as more significant when compared with university researchers (Palmberg, 2008). 
DSTI/DOC(2009)7

Figure 44. Challenges in commercialisation amongst Finnish nanotechnology researchers

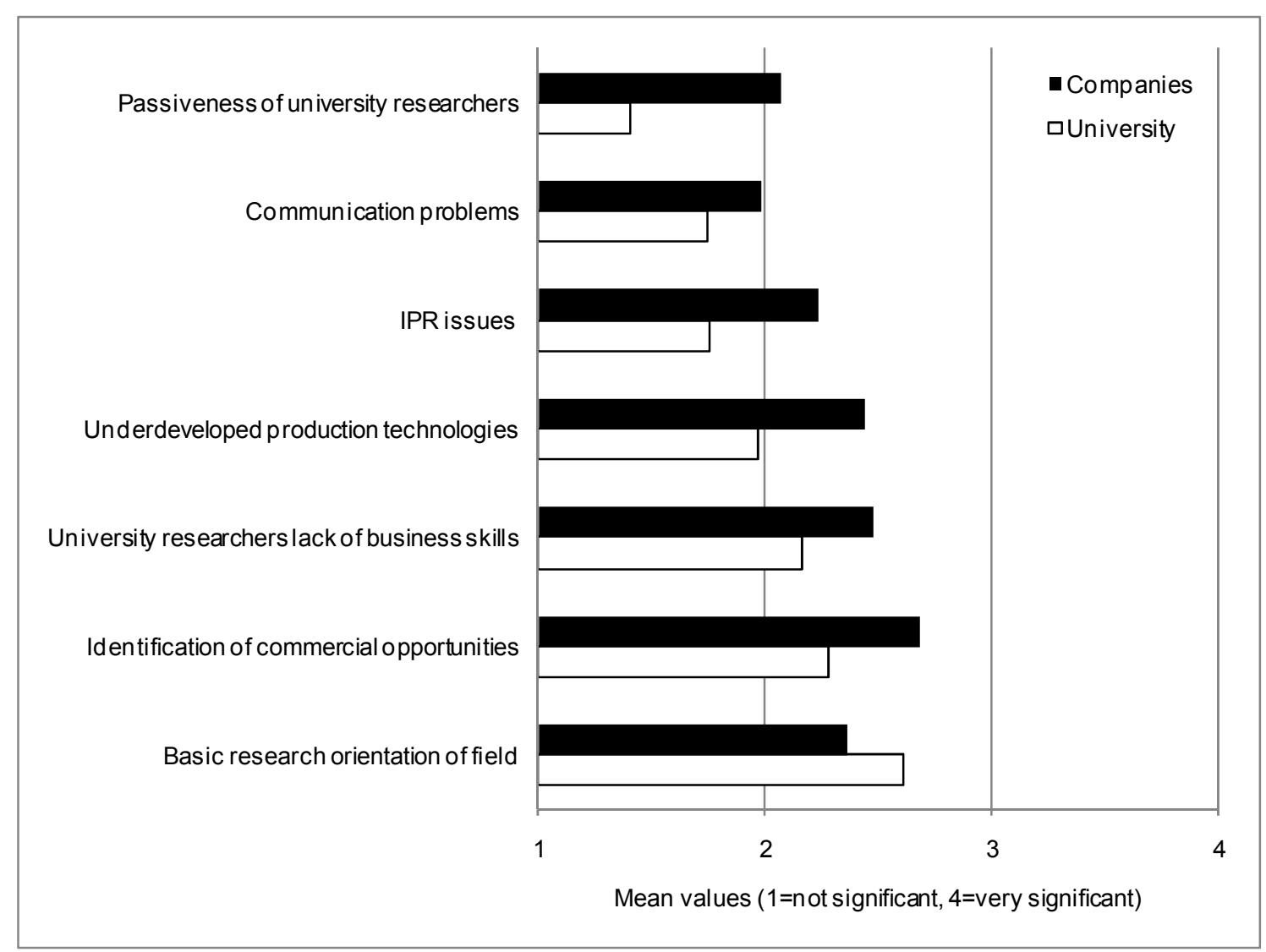

Source: Palmberg (2008).

\section{Human resources}

The effects of nanotechnology on the labour market may potentially be very large in so far as some of the more optimistic job forecasts, referred to in this report, indeed are correct. The Spinverse survey asked whether the companies had found it easy or difficult to recruit skilled people in areas connected to nanotechnology (Figure 45). 44\% of the surveyed Finnish companies did indicate that the recruiting of skilled people has been 'difficult' or 'very difficult'. Forthcoming analysis will consider whether particular sectors in Finland are affected as well as which skills are in most demand. 
Figure 45. Extent of difficulties in recruiting skilled people according to Finnish companies

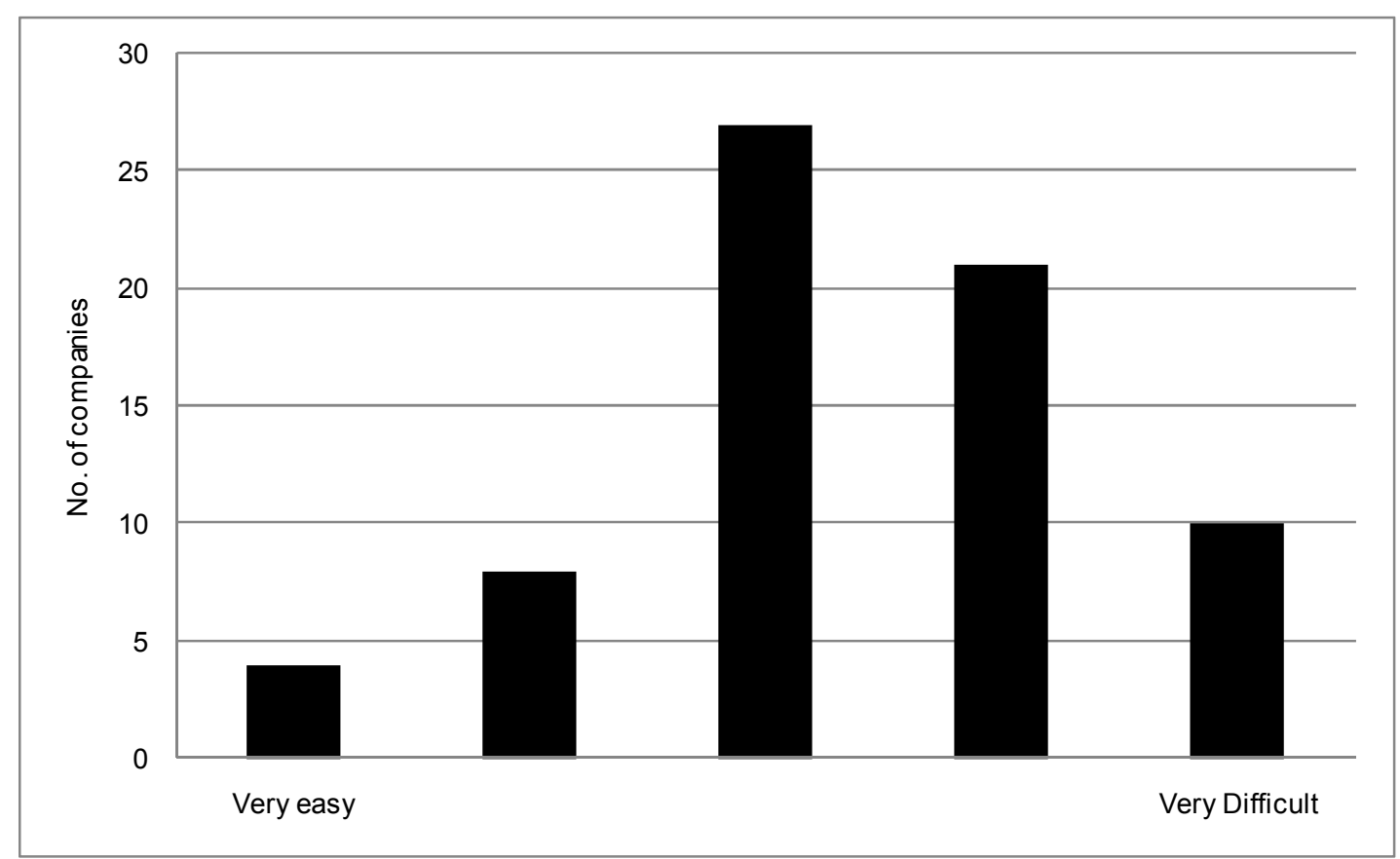

Source: Spinverse (2008).

This result is broadly in line with another larger survey addressed to various types of organisations in Europe (universities, research institutes, companies) which also highlighted human resource challenges (Kshitij and Singh, 2007). This survey received 179 responses and indicated that $42 \%$ of these organisations have had difficulties with recruitment related to nanotechnology, particularly relating to technical support and specific expertise. Further, it found that a wide variety of skills are required although $\mathrm{PhD}$ qualifications are most highly valued. On-the-job training was seen as the most popular method to maintain skills and nanotechnology-related training levels of employees.

\section{The Australian nanotechnology business survey}

\section{Survey practicalities and company sample}

In Australia the Department of Industry, Tourism and Resources (DITR), together with Nanotechnology Victoria, commissioned two surveys in 2005 and 2006 entitled the "Nanotechnology Business Surveys". The objectives of these surveys were to explore investments in and attitudes towards nanotechnology, thereby identifying potential barriers to promoting nanotechnology. The methodological approach was to draw a random sample from a population of identified companies interested in nanotechnology that was defined through industry associations and supplemented by additional lists. While the familiarity of companies with nanotechnology was assessed, no pre-defined definition of this field was used.

The survey undertaken in 2006 was based on computer-assisted telephone interviews covering a sample of 134 companies. The questions included in the survey were the same as for 2005 , with some additions. Details of the background, methodologies and results of the survey are reported in Dandolopartners (2006), as the source for this overview. The survey covered a broad range of issues: emphasis here will be given to the degree of engagement, investments, areas of use and perceived impacts, 
as well as barriers to investments in nanotechnology, and regulatory and environmental issues related to nanotechnology.

A large share (35\%) of the companies in the sample were small, with less than 20 employees, while large companies with over 1000 employees accounted for $19 \%$. Figure 46 shows the principal industry of the companies. The clear majority are involved in manufacturing $(49 \%)$, while materials $(63 \%)$, chemicals $(43 \%)$, as well as nanotechnology (42\%), are the three main scientific fields that constitute their knowledge base. Accordingly this randomised sample seems to be relatively representative of Australian companies involved in nanotechnology manufacturing although nanotechnology only constitutes one among many other sciences/technologies that these companies draw on. The large share mentioning biotechnology $(29 \%)$ is also noteworthy. Similarly to the NCMS survey in the United States these companies tend to be relatively small and concentrated in the main areas of technology-based industries in the respective countries.

Figure 46. Australian nanotechnology companies by principal industry

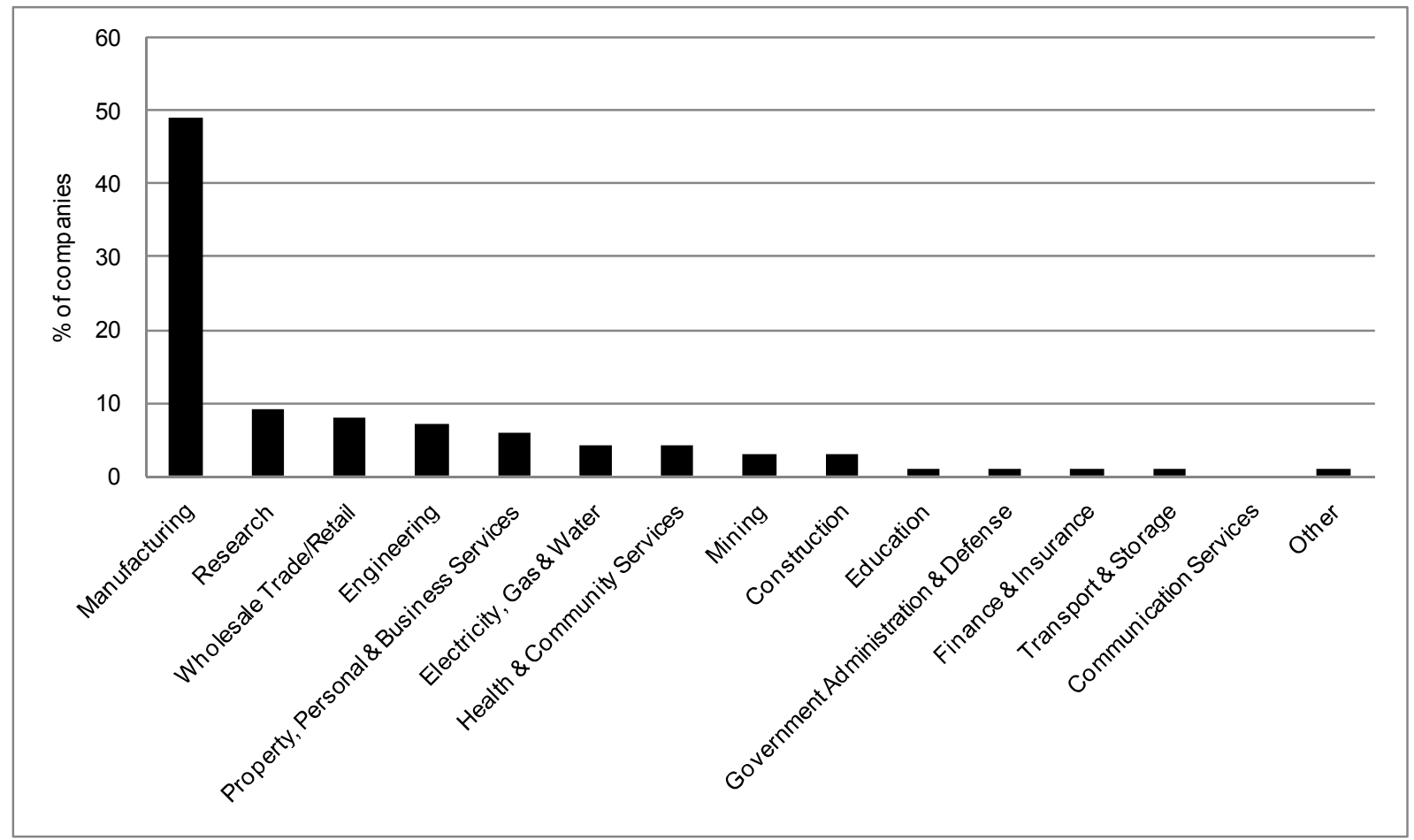

Source: dandolopartners (2006).

\section{Investments, use and future importance of nanotechnology}

Overall the awareness of nanotechnology amongst this sample of companies was high and had increased since the first Australian company survey undertaken in 2005; 69\% of all respondents "knew in detail what nanotechnology means and how it works" compared to $43 \%$ in 2005 . Only $10 \%$ reported having heard about the term without knowing the details. This high degree of awareness was also reflected in relatively high investments in nanotechnology with $40 \%$ of the companies reporting this, likewise a significant increase compared with 2005. Figure 47 presents the share of companies investing in nanotechnology by main industry type and company size. Again the concentration in manufacturing and the materials industries and smaller companies, is clear. 
Figure 47. Nanotechnology investments amongst Australian companies by industry and size

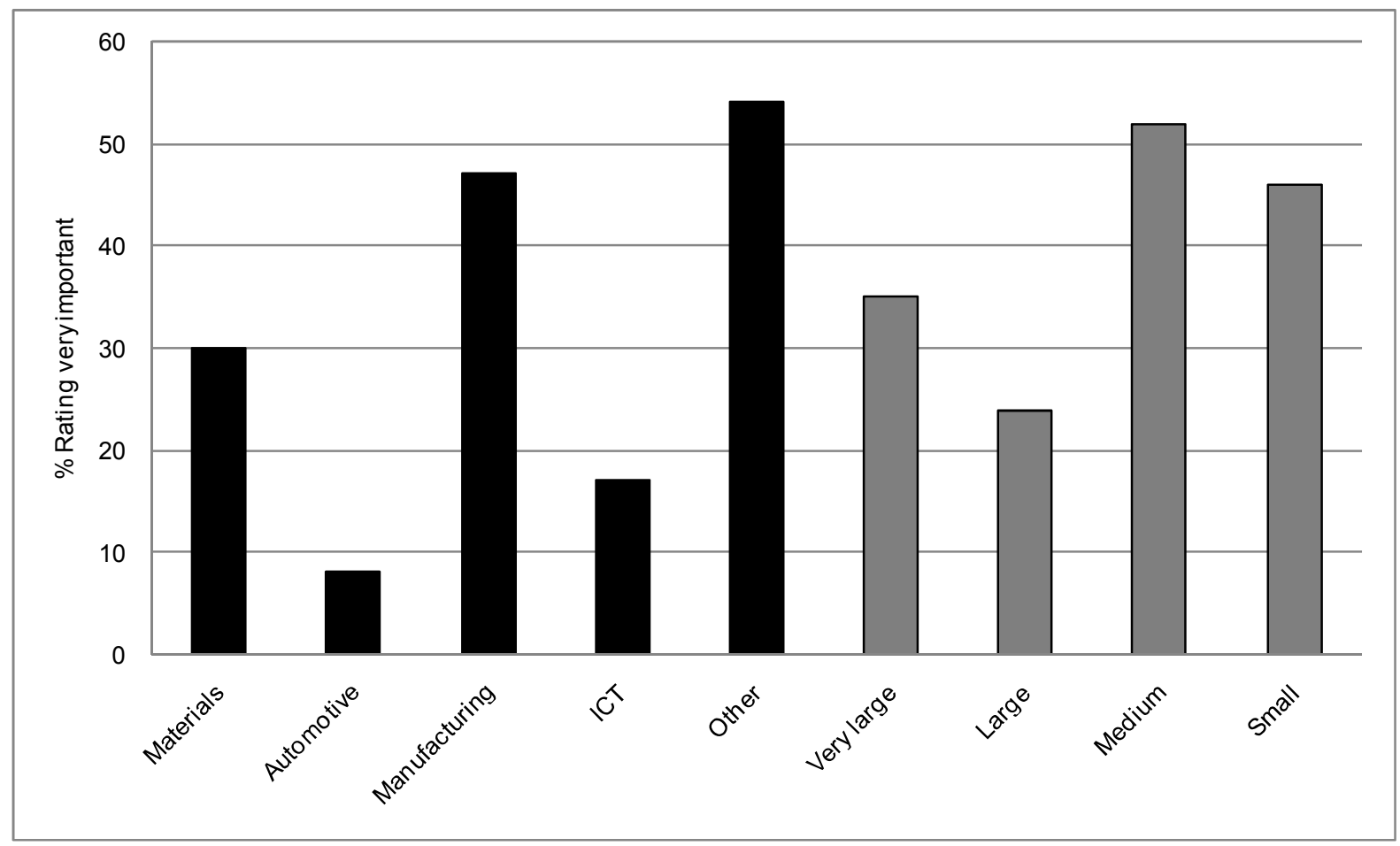

Source: Dandolopartners (2006).

Companies may approach nanotechnology by developing new nanotechnology-enabled products or processes themselves or by using those developed by others. The Australian nanotechnology business surveys indicate a clear increase in the share of companies who are engaged in the development of nanotechnology products, reaching 33\% in 2006. Correspondingly the share of companies which use those products developed elsewhere has declined. The report also notes that the developers of nanotechnology products tend to view science as important to their future success and logically also suggest a higher awareness of nanotechnology and its details.

When questioned about the perceived importance of nanotechnology to the companies in the next five years, $57 \%$ reported high importance while $15 \%$ reported no importance, with a tendency towards higher perceived importance for 2006 compared with 2005. Those companies that had a higher tendency to rate nanotechnology as very important were developers rather than users of nanotechnology products, and they were also currently investing in the field and had a high degree of awareness of nanotechnology. Further, a large share of these companies are classified in the manufacturing industries and tend to be smaller in size (Figure 48). 
Figure 48. Importance of nanotechnology amongst Australian companies by industry and size

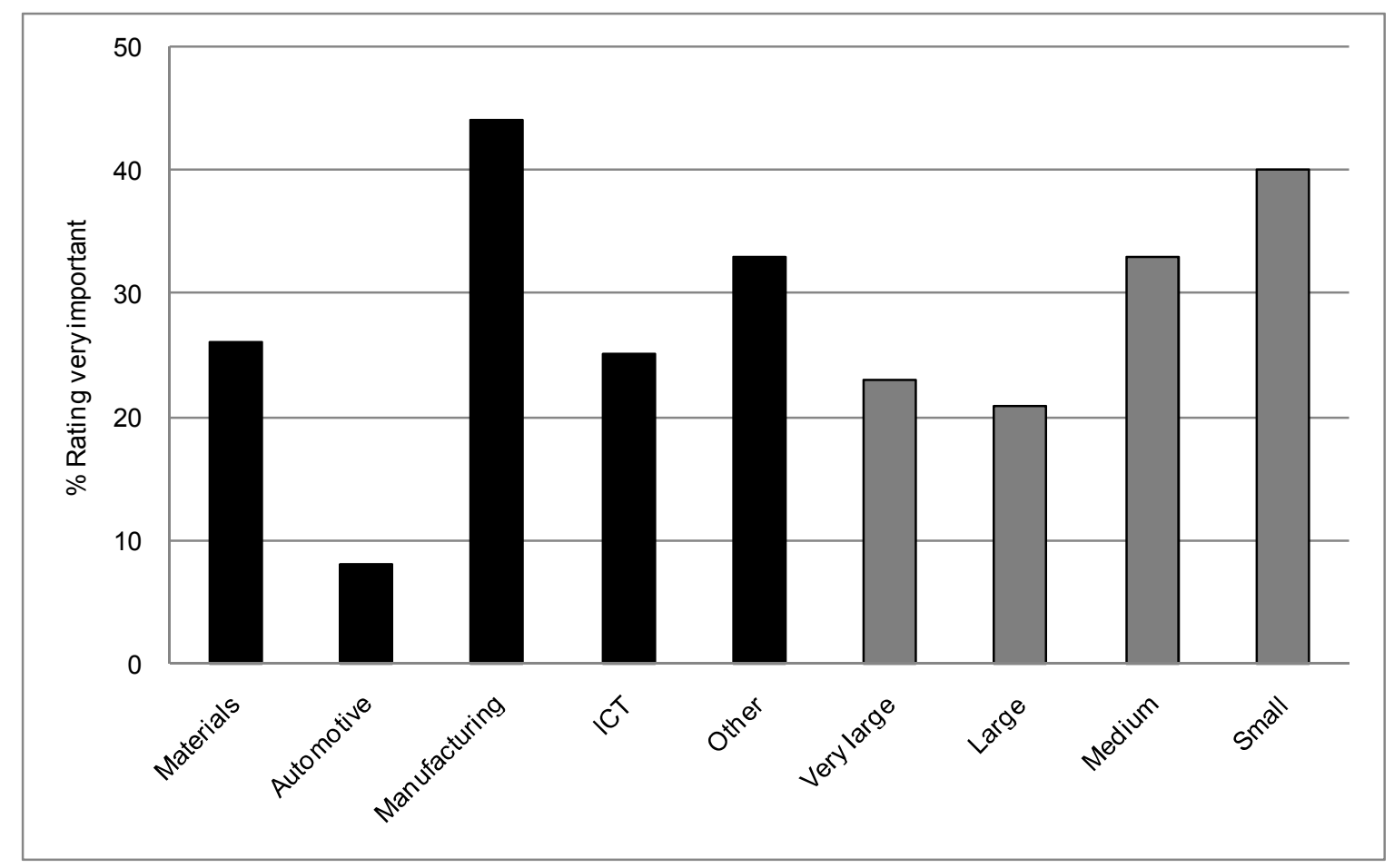

Source: Dandolopartners (2006).

The issue of timelines for developments was covered, this time through a question about the point in time when decisions related to investing in nanotechnology will be made. Again the impression is that developments are rapid. Of all respondents $13 \%$ had already made a decision to invest in nanotechnology in 2006 while $19 \%$ would do so within five years.

\section{Perceived impacts, investment barriers and challenges}

Investments in nanotechnology will depend on how companies view its impact, while company perceptions of the impacts are important for policy considerations. The Australian Nanotechnology Business Survey provides some interesting insights into the areas that companies view as having potentially the greatest positive impacts in terms of product and process innovation, and also addresses barriers to investments and specific challenges related to regulatory and environmental issues. On impacts the survey highlighted the following items: creating new products; improving current products; creating a competitive edge more generally; improving current processes and reducing costs.

Figure 49 gives the share of respondents highlighting each of the impacts. The "creation of new products" was the most important perceived impact, although closely followed by "improving current products" and "creating a competitive edge". Even though the possibilities of nanotechnology to reduce production costs have been discussed extensively this items appears less significant, as does the item "improving current processes". Perhaps these results again point to the infancy of nanomanufacturing at this point in time, as well as to some barriers that would need further policy attention. Overall the spread of responses across these impact types is consistent with common understanding of the general purpose nature of nanotechnology. The report also notes that respondents to the 2006 survey nominated a higher number of different types of impacts than the 2005 survey. 
Figure 49. Areas of greatest impact of nanotechnology amongst Australian companies

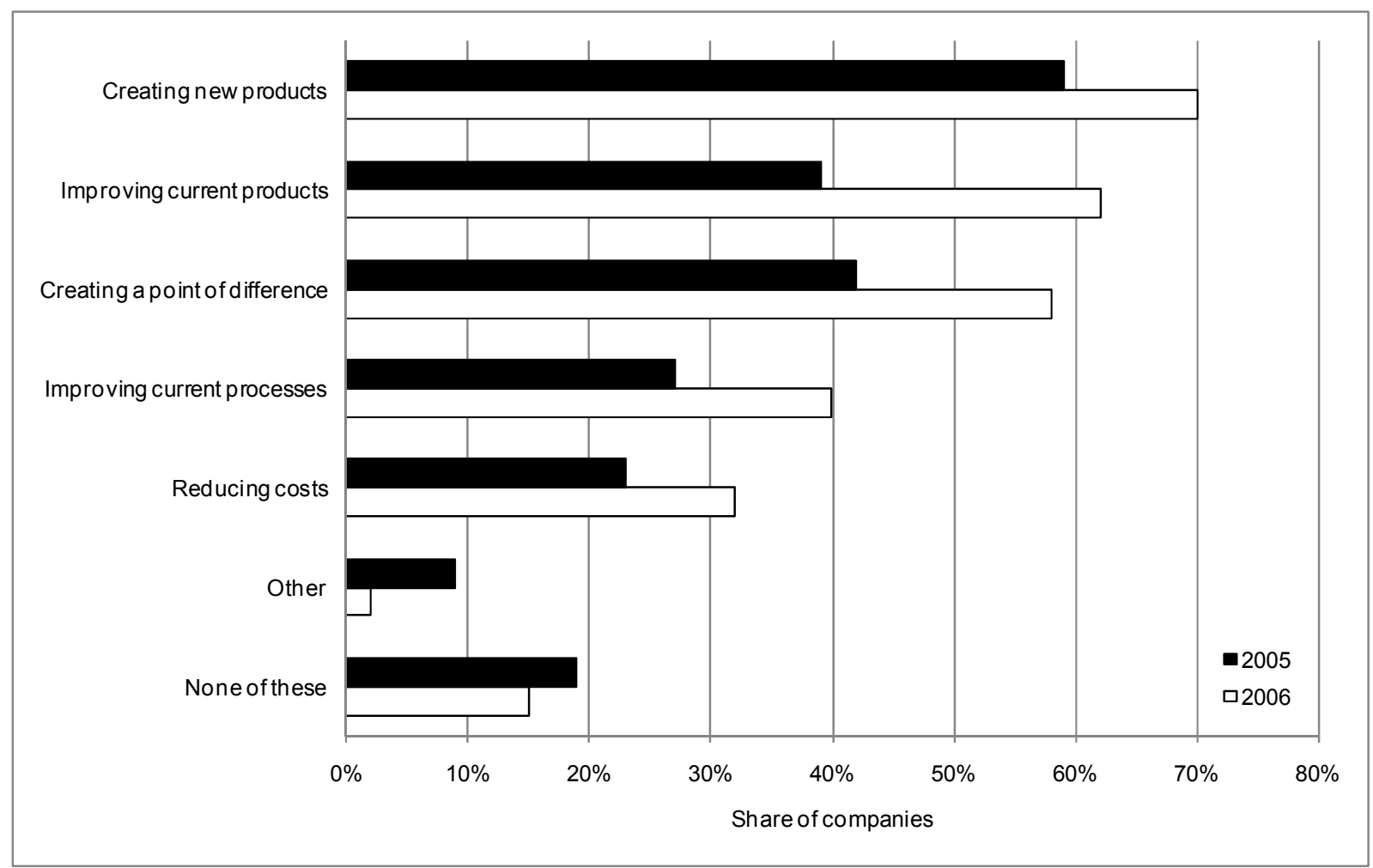

Source: Dandolopartners (2006)

Regarding barriers these were considered in the context of elements preventing investments in nanotechnology rather than barriers or challenges related to nanomanufacturing and commercialisation. Altogether 10 barriers were suggested for rating by the respondents on a four point scale from very likely to unlikely. The share of respondents rating each of the items as very likely is displayed in Figure 50. "The lack of customers who demand nanotechnology products" is rated as the primary barrier to investing in nanotechnology followed by "difficulty in securing the right skills in-house to manage developments". These two barriers were also highlighted in the Australian nanotechnology business survey from 2005 and thus appear consistent also over time. The remaining barriers score similar shares in the range of 13-19\% with "the lack of current information about current research in nanotechnology" being the least likely barrier. 
Figure 50. Barriers for nanotechnology investments amongst Australian companies

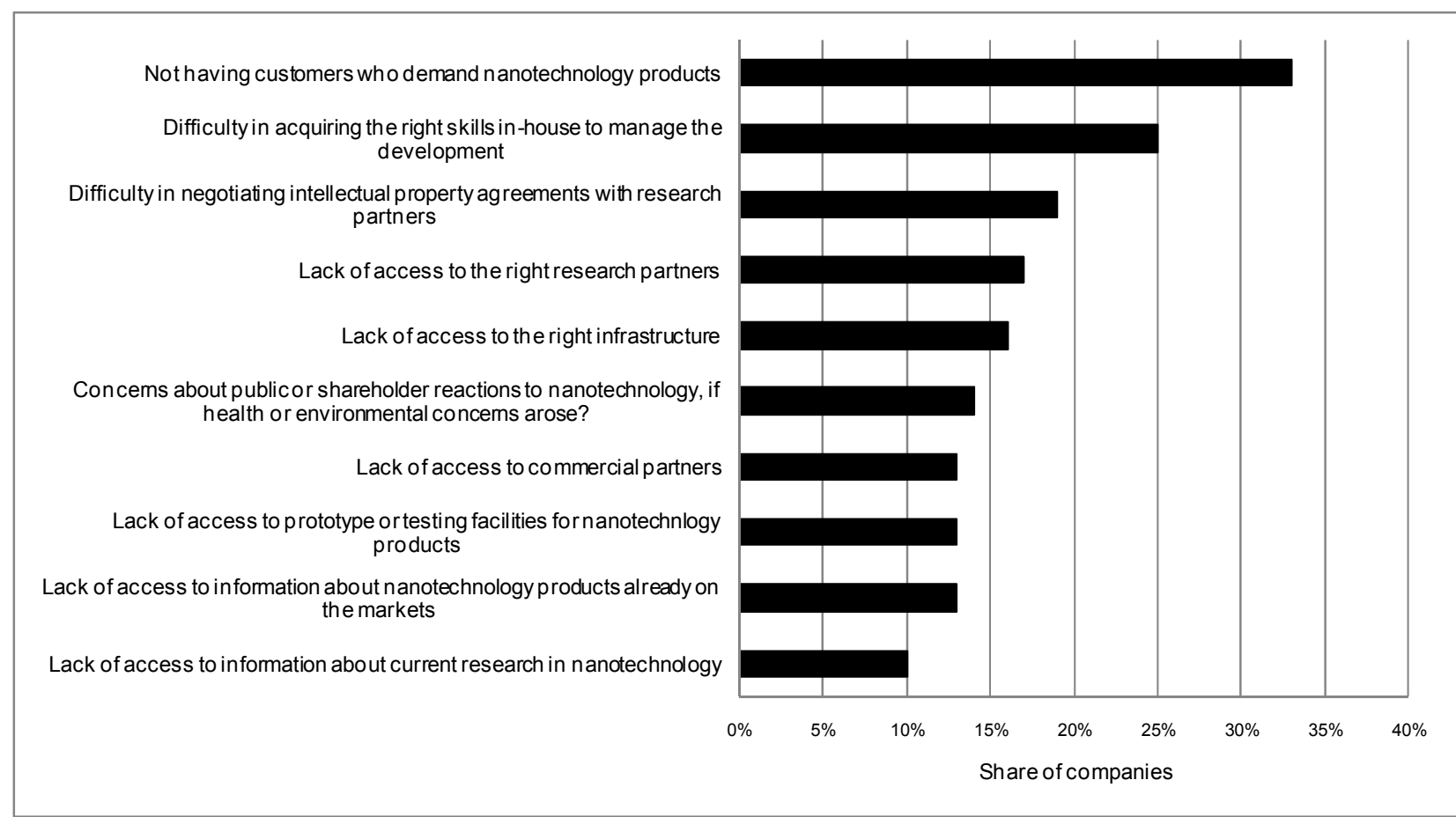

Source: Dandolopartners (2006).

The significance of lacking customers and in-house skills as barriers could reflect the infant stage of nanotechnology commercialisation, similar to the findings of the NCMS survey in the United States. However, specificities of markets, the industrial structure and infrastructures of the Australian nanotechnology business environment may also play a role in interpreting this result. The lack of in-house skills primarily related to manufacturing equipment/facilities, testing machines/analytical tools, scientific personnel, surface characterisation instruments, upgraded laboratories, electron microscope/advanced microscopes and prototype testing facilities.

The share of respondents highlighting "concerns about health and environment" is low while these issues are discussed intensively in the public. These issues were dealt with in some greater detail in the survey through follow-up questions. When confronted with a breakdown of regulatory and environmental issues, $63 \%$ of the respondents did not believe that they faced such issues. Of those who did identify them as significant the primary concern related to occupational health and safety. Further, $46 \%$ of the respondents indicated that they would have the ability to provide safety data related to nanotechnology while a slight majority of $52 \%$ indicated that they would not be able to do so.

\section{Summary}

- Company surveys, undertaken in a few countries, have identified a relatively large number of small, rather than large, companies involved in nanotechnology. Nonetheless, the surveys suggest that the larger companies may be in a better position to manage nanotechnology developments due to their critical mass in R\&D, production and marketing. 
- The surveyed companies are distributed across a broad range of manufacturing industries, highlighting further the general purpose nature of nanotechnology. In terms of nanotechnology sub-areas, a majority of companies covered in these surveys are involved in nanomaterials followed by nanobiotechnology or nanoelectronics. Nanotechnology is considered to both enhance competitiveness in traditional markets and also create new ones.

- Overall the surveys detect an increasing number of companies in nanotechnology over time, and where this data is available, growing R\&D investments and demand for nanotechnology workers. Nonetheless, there are difficulties in recruiting personnel with the required skills. The majority of the surveyed companies expect commercialisation of their $R \& D$ in the range of 2-3 years.

- All of the surveys highlight challenges in commercialising although it is not always clear whether these challenges are unique to nanotechnology. High processing costs, problems in the scalability of R\&D towards prototypes and industrial scale, the basic research orientation of the field, and concerns about health and safety issues (especially the public perception of these) emerge as the key challenges. High investment costs and a lack of funding are also highlighted.

- While the company case studies provide important insights to complement data on R\&D investments, publications and patents, further qualitative analysis of especially the challenges in commercialisation are important. These challenges may differ significantly by the size of companies, nanotechnology sub-areas and application fields. 
DSTI/DOC(2009)7

\section{CONCLUSION}

Nanotechnology is commonly considered to offer considerable promise, from business opportunities throughout various industries to broader socio-economic benefits, especially in the context of pressing global challenges such as those related to energy, health care, clean water and climate change. Governments around the world have invested heavily in R\&D in this field and companies are also becoming increasingly engaged. Despite this promise, investments and company involvement in nanotechnology developments are still poorly monitored. The objective of this report is to provide a comprehensive overview of these developments through a systematic and critical analysis of available indicators and statistics, while acknowledging that there is a need for further work to both broaden the range of, and develop further, nanotechnology metrics.

Nanotechnology developments essentially stem from key enabling inventions in instrumentation during the 1980s and have, since then, developed rapidly in various technological and application fields. Nanotechnology is still at an early phase of development, its future being hard to forecast. Available forecasts suggest a global market for nanotechnology products in the range of USD 150-3100 billion in the coming years, while some 2 million new jobs could be created. Nonetheless, these forecasts suffer from difficulties in defining the value-added of nanotechnology to existing manufacturing processes as well as its role for generating new products. It should also be noted that the financial/economic crises unfolding since October 2008, has not yet been taken into account.

The global distribution of R\&D investments, publications and patents indicate that nanotechnologyrelated research and development activities are concentrated in a few countries and regions of the world. The United States dominates in this context with regions in the San Francisco, Boston, New York and Los Angeles area, followed by Japan and some of the larger EU countries (Germany, France and the United Kingdom). Nonetheless, some smaller countries also show up as being very active when considering size differences across countries. The rapid entry of "newcomer" countries such as Korea, India and especially China should also be highlighted; all of these countries are characterized by rapid growth rates in the number of publications and patents, although from low starting levels. These results suggest that the thrust of nanotechnology R\&D may partly be shifting away from traditional countries which have had a longer history of involvement in nanotechnology.

Publication data highlight the broad-based, and inter-disciplinary, nature of scientific advances that fuel nanotechnology developments. The number of publications exceeds, by far, patents as is often the case for emerging technologies. Evidence based on the share of patent citations to the scientific literature also suggests that nanotechnology draws on science to a higher degree than other technology fields. Similar to early biotechnology developments, nanotechnology patenting accelerated some 12-13 years after key enabling inventions in instrumentation and related engineering techniques. A further analysis of differences and similarities between bio- and nanotechnologies (and other emerging technologies) could be insightful, especially in light of the cross-pollination and possible convergence between these fields.

Nanotechnology patenting is distributed across a broad range of sub-areas and application fields, pointing to the multiplicity of applications of this emerging technology and its general purpose nature. Most patenting occurs in nanoelectronics and nanomaterials, both of which are generic technology areas in their own right. Nanotechnology patenting shows the highest growth in the application fields of 
electronics, chemicals and instruments, while the growth in nanotechnology patenting is higher than the growth in overall patenting. Major multinational enterprises in the electronics industry account for the lions' share of these patents although the share of patents owned by universities is relatively higher in nanotechnology compared with patents in general. It may be that incremental developments related to 'traditional' top-down approaches to nanoscale engineering explain the proliferation of applications in electronics and materials. More disruptive bottom-up approaches may still be confined to university laboratories. The concept "nanotechnology" is too general to capture sectoral specificities in developments and further analysis would be needed.

Patent data can also be used to highlight the position and specialisation of countries across nanotechnology sub-areas and application fields. Overall, countries tend to either patent relatively more in the fields of electronics or in the field of chemicals, pharmaceuticals and biotechnologies, while most countries are active in nanomaterials. This finding may suggest an emerging division of labour in nanotechnology innovation, a finding that it would be interesting to analyse further as the technological viability and commercial potentials of different nanotechnology application fields become clearer. Overall, the United States and European Union are more diversified in terms of these application fields while Japan has a higher specialisation in electronics. Further, electronics appears to be an application field in which nanotechnology is building on existing areas of strength in most countries. Instruments, pharmaceuticals and biotechnologies represent fields in which nanotechnology is contributing to diversification in new fields.

R\&D investment data on nanotechnology are incomplete due to the lack of commonly agreed definitions and statistical frameworks, while publication and patent data only can provide a limited picture of the variegated nature of technological change and innovation. This report also looked at company surveys that have been undertaken in a few countries (the United States, Canada, Germany, Finland and Australia) for complementary insights. It is difficult to define a nanotechnology company, and the number of such companies is still quite small. Those identified through the company surveys tend to be small and distributed across a broad range of industries, mainly in the manufacturing sector. A majority of these companies develop nanomaterials, nanobiotechnologies or nanoelectronics; this finding is roughly comparable with the distribution of patents by nanotechnology sub-areas and application fields. The surveys suggest that nanotechnology impacts the traditional business areas of companies while also creating new opportunities in new markets.

One common theme addressed by all of these company surveys is challenges in commercialising nanotechnology. High processing costs, problems in the scalability of R\&D for prototype and industrial production, the basic research orientation of the related sciences, funding issues and concerns about environment, health and safety (EHS) issues (especially the public perception of these) emerge as the key challenges. All of these challenges would require further analysis and verification through qualitative company case studies. A key question is whether these challenges are unique to nanotechnology and hence may require new policy approaches. This report has highlighted some unique features in the development, application and commercialisation of nanotechnology. Better metrics, combined with qualitative case studies, would constitute a necessary basis for understanding these unique features better, while also enabling the further monitoring and benchmarking of nanotechnology developments. 


\section{APPENDIX 1}

The classification of patents by nanotechnology sub-areas

\begin{tabular}{|c|c|c|}
\hline Code & Title & Exemplary technologies \\
\hline Y01N2 & Nanobiotechnology & $\begin{array}{l}\text { Nanocapsules as carriers for therapy and pharmaceutical } \\
\text { treatment } \\
\text { Biomolecular motors } \\
\text { Molecular arrangements for biocatalysts } \\
\text { Pre-targeting with peptides or antibodies } \\
\text { Host-guest complexes or radioactive pharmaceutical } \\
\text { preparations }\end{array}$ \\
\hline Y01N4 & Nanoelectronics & $\begin{array}{l}\text { DNA computing } \\
\text { Quantum computing } \\
\text { Single electron logic } \\
\text { Nanotube displays } \\
\text { Biomolecules for electronic and data storage } \\
\text { Read heads with nm precision } \\
\end{array}$ \\
\hline Y01N6 & Nanomaterials & $\begin{array}{l}\text { Nanoparticles, composites, dendrinmes, nanotubes and } \\
\text { fullerenes } \\
\text { Supramolecular systems } \\
\text { Ultrathin functional films } \\
\text { Self-assembling monolayers (SAM) } \\
\text { Hydrogen storage in nanostructured materials } \\
\end{array}$ \\
\hline Y01N8 & Instruments & $\begin{array}{l}\text { Measurement of physical, chemical, biological properties at } \\
\text { surfaces with nm resolution } \\
\text { Measurement of interfaces with lateral resolutions in the nm- } \\
\text { range } \\
\text { Normalisation routines for nanoanalytics } \\
\text { Measurement of size distribution of nanoparticles } \\
\text { Tools for ultraprecision engineering } \\
\text { Use of quantum dot labels for analysing biological material }\end{array}$ \\
\hline Y01N10 & Nanooptics & $\begin{array}{l}\text { Optical quantum well structures } \\
\text { Photonic crystals } \\
\text { Quantum optics } \\
\text { Optical surfaces with nm surface prevision }\end{array}$ \\
\hline Y01N12 & Nanomagnetics & $\begin{array}{l}\text { Low dimensional magnetism } \\
\text { XMR technologies as magnetoimpedance, anisotropic } \\
\text { magnetoresistance, tunnelling magnetoresistance }\end{array}$ \\
\hline
\end{tabular}

Source: Scheu et al. (2006). 


\section{APPENDIX 2}

The classification of patents by application fields

\begin{tabular}{|l|l|}
\hline Main fields & Sub-field \\
\hline Electronics & $\begin{array}{l}\text { Electrical devices - electrical engineering } \\
\text { Audiovisual technology } \\
\text { Telecommunications } \\
\text { Information technology } \\
\text { Semiconductors }\end{array}$ \\
\hline Instruments & $\begin{array}{l}\text { Optics } \\
\text { Analysis, measurement, control } \\
\text { Medical Technology } \\
\text { Nuclear Engineering }\end{array}$ \\
\hline Chemicals & Organic Chemistry \\
& $\begin{array}{l}\text { Macromolecular Chemistry } \\
\text { Chemical Engineering } \\
\text { Treatments/Surface } \\
\text { Materials and Metallurgy }\end{array}$ \\
\hline Pharmaceuticals and biotechnologies & $\begin{array}{l}\text { Biotechnology } \\
\text { Pharmaceuticals and Cosmetics } \\
\text { Food and Agriculture }\end{array}$ \\
\hline Industrial processing & $\begin{array}{l}\text { Technical Processes } \\
\text { Handling, Printing } \\
\text { Material processing } \\
\text { Environment, pollution } \\
\text { Agricultural and Food Processing Machinery } \\
\text { Machines and Tools } \\
\text { Engines, pumps, turbines } \\
\text { Thermal Processes } \\
\text { Mechanical elements } \\
\text { Transports } \\
\text { Space Technology \& Arms }\end{array}$ \\
\hline Consumer goods \\
Civil engineering, building, mining \\
\hline
\end{tabular}

Source: OECD Patent Manual 2008. 
DSTI/DOC(2009)7

\section{APPENDIX 3}

Figure 51. Scatter-plots: technological specialisation and compatibility of nanotechnology application fields

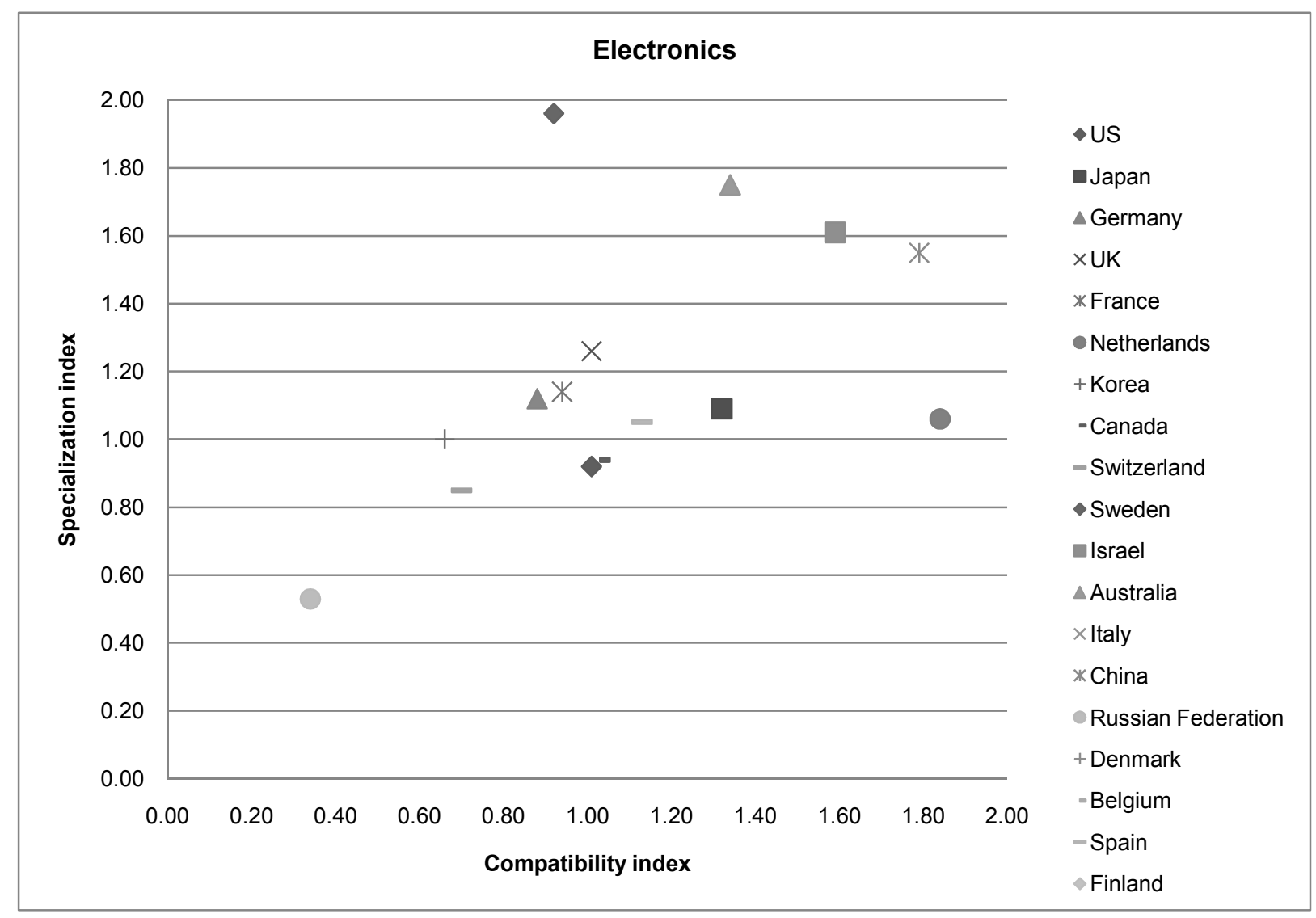

Source : OECD Patent database, January 2008. 


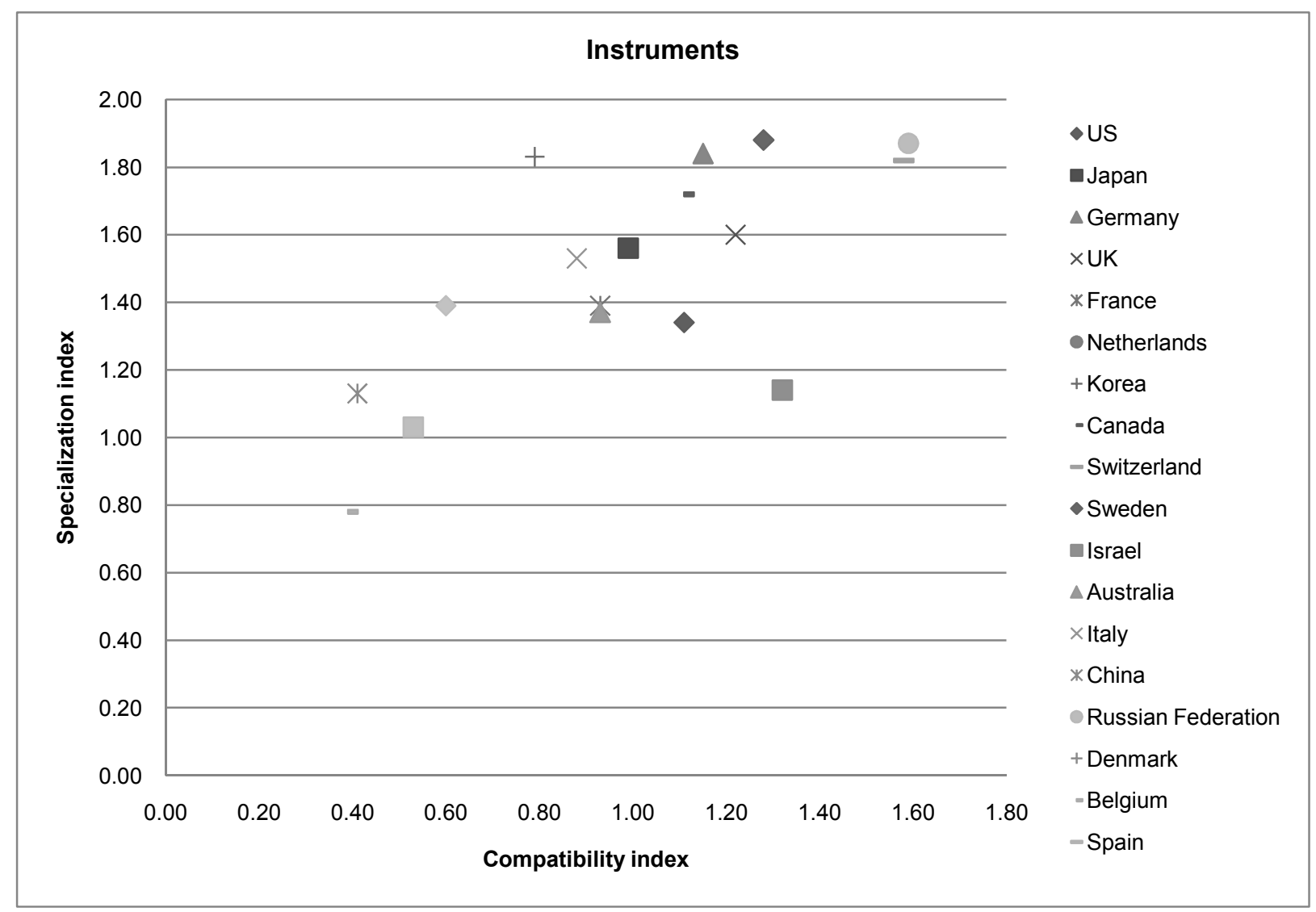

Source : OECD Patent database, January 2008. 


\section{DSTI/DOC(2009)7}

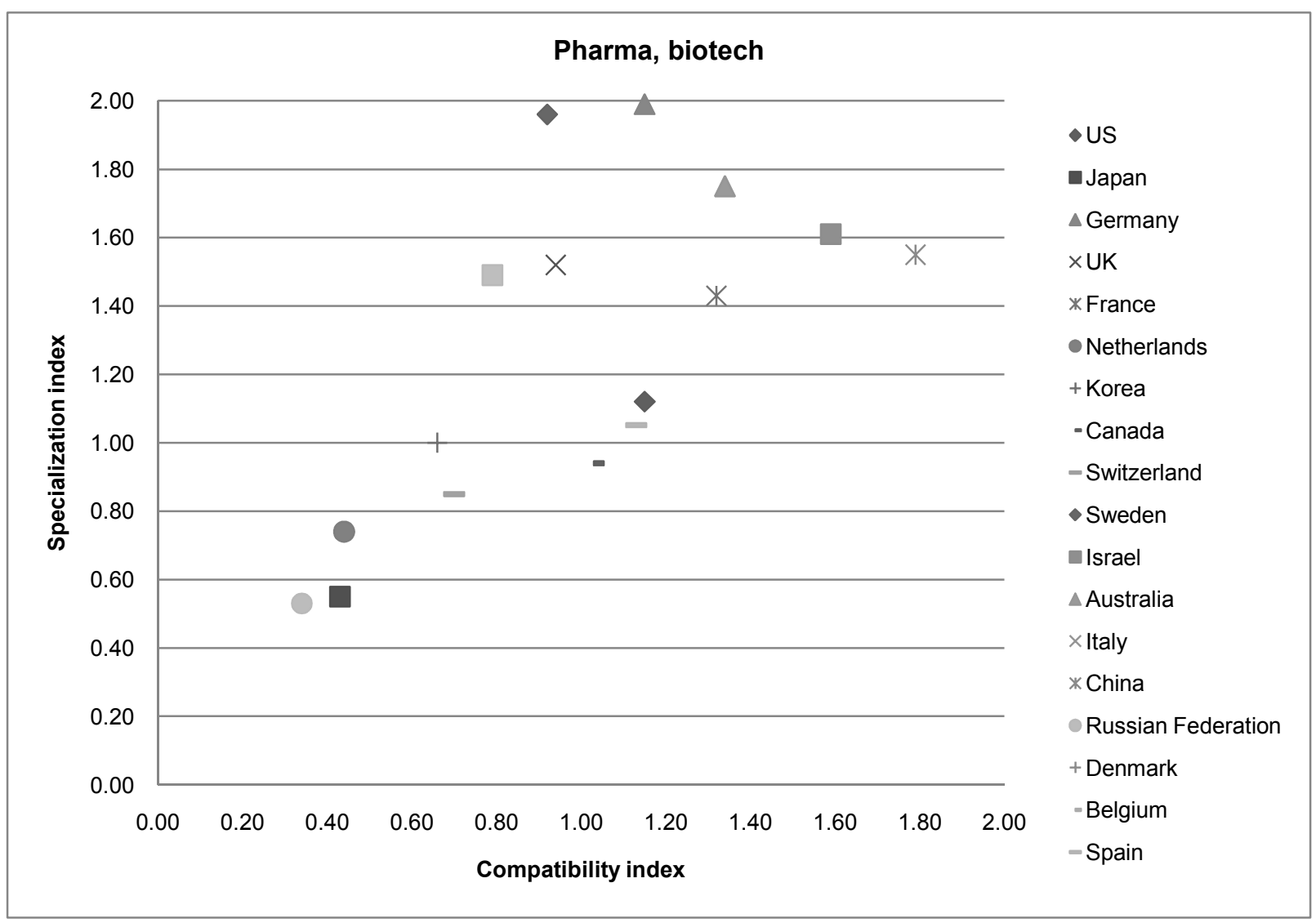

Source : OECD Patent database, January 2008. 


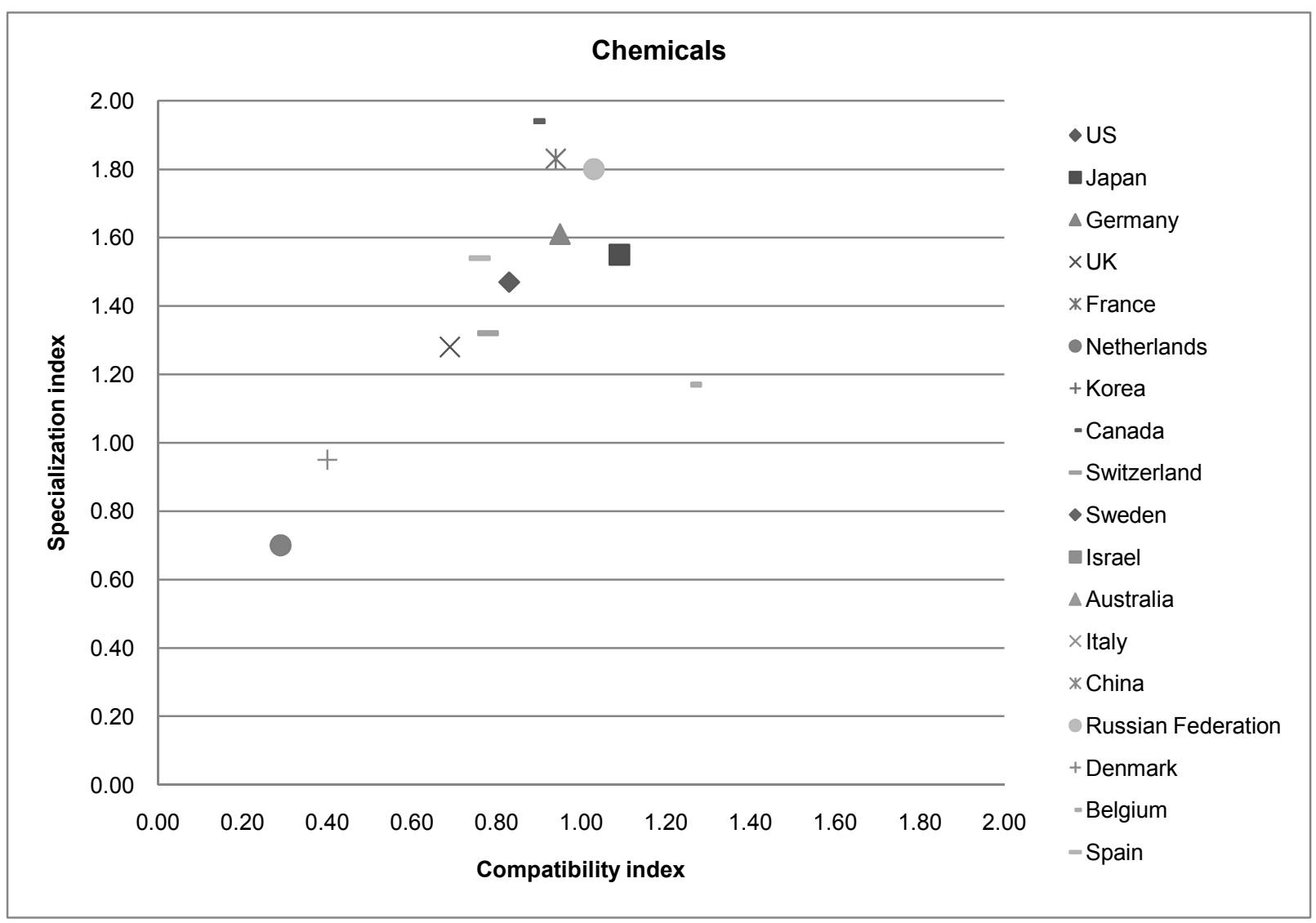

Source : OECD Patent database, January 2008. 


\section{DSTI/DOC(2009)7}

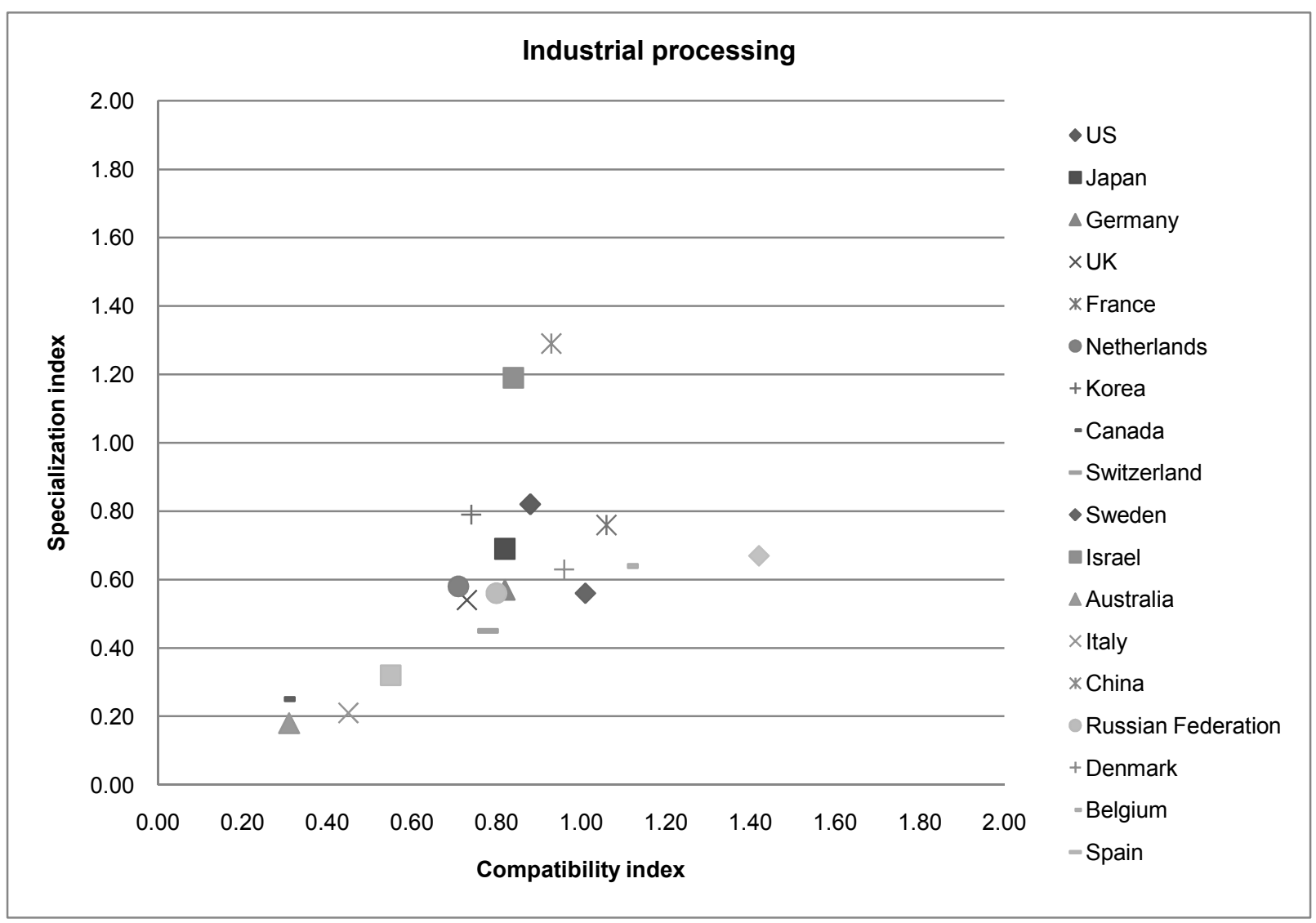

Source : OECD Patent database, January 2008. 


\section{REFERENCES}

Bonaccorsi, Andrea and Thoma, Grid (2007). Institutional complementarity and inventive performance in nano science and technology. Research Policy 36.

Dandolopartners (2006). Nanotechnology business survey.

Darby, Michael and Zucker, Lynne (2003). "Grilichesian Breakthrough: Inventions of Methods of Inventing and Firm Entry in Nanotechnology.” NBER Working Paper, No. W9825.

European Commission (EC) (2005), Some Figures about Nanotechnology R\&D in Europe and Beyond.

Grodal, Stine and Thoma, Grid (2007)," Cross-pollination in Science and Technology: The Emergence of the nanobio Subfield". Unpublished manuscript.

Hall, Storrs (2005), Nanofuture. Promenthus Books.

Heinze, Thomas (2004), "Nanoscience and nanotechnology in Europe: Analysis of Publications and patent Applications including Comparisons with the United States." Nanotechnology, Law \& Business, vol. 1.4.

Helpman, E (ed.) (1998). “General Purpose Technologies and Economic Growth..” MIT Press.

Huang, Zan, Chan, Hsinchun, Chen, Zhi-Kai, and Rocco, Mihail, (2004) "International nanotechnology development in 2003." Country, institution, and technology field analysis based on USPTO patent database. Journal of Nanoparticle Research 6.

Huang, Zan, Chen, Hsinchun, Yan, Lijun and Rocco, Mihail (2005). "Longitudinal nanotechnology development (1991-2002): National Science Foundation and its impact on patents." Journal of Nanoparticle Research 7.

Hullmann, Angela (2007). "Measuring and assessing the development of nanotechnology." Scientometrics, vol. 70, no.3 (see also "The economic development of nanotechnology - An indicators based analysis", European Commission, DG Research, and "Who is winning the global nanorace?" In Nature, 2006, vol. 1).

Igami, Masatsura and Saka Ayaka. (2007), "Capturing the evolving nature of science, the development of new scientific indicators and the mapping of science". OECD Science, Technology and Industry Working Papers, 2007/1, Directorate for Science, Technology and Industry, OECD, Paris, www.oecd.org/sti/wprking-papers

Igami, Masatsura and Okazaki, Teruo (2007), "Capturing Nanotechnology's Current State of Development via Analysis of Patents.” OECD Science, Technology and Industry Working Papers, 2007/4, Directorate for Science, Technology and Industry, OECD, Paris, www.oecd.org/sti/wprking-papers

Leydersdorff, Loet and Zhou, Ping (2006). "Nanotechnology as a Field of Science: Its Dellineation in terms of Journals and Patent." Draft working paper. 


\section{DSTI/DOC(2009)7}

LuxResearch (2006), “The nanotech report.” Lux Research Incorporated.

Kaiser, D (2006), 'Notes Toward a Nanotech Timeline.” OSTI Working Paper 6-06-001.

Li, Xin, Lin, Tiling, Chen, Hsinchun, and Rocco, Mihail, (2007), "Worldwide nanotechnology development: a comparative study of USPTO, EPO and JPO patents (1976-2004)." Journal of Nanoparticle Research 9.

Lipsey, Richard, Carlaw, Kenneth and Bekar, Clifford, (2005), Economic Transformations - General Purpose Technologies and Long-Term Economic Growth. Oxford University Press.

Malanowski, N, Heimar, T, Luther, W and Werner, M, (2006), Growth market Nanotechnology - An analysis of technology and innovation. Wiley VCH Verlag.

Malanowski, Norbert and Zweck, Axel, (2007), "Bridging the gap between foresight and market research: integrating methods to assess the economic potential of nanotechnology." Technological Forecasting \& Social Change 74.

Marinova, Doera and McAleer, Michael, (2003), "Nanotechnology Strength Indicators: International Rankings Based on US Patents."

McNiven, (2007), "Overview and discussion of the Results of the Pilot Survey on Nanotechnology in Canada." Statistics Canada, Working Paper, BBF0006XIE, no. 005.

Meyer, M. 2000. Patent citations in a novel field of technology: an exploration of nano-science and nanotechnology. Scientometrics 51(1).

Meyer, M (2007), "What do we know about innovation in nanotechnology? Some propositions about an emerging field between hype and path-dependency." Scientometrics, 70 (3), 779-810.

Meyer, Martin and Persson, Olle, (1998), "Nanotechnology - Interdisciplinarity, patterns of collaboration and differences in application." Scientometrics 42.

Miyazaki, K and Islam, N, (2007), "Nanotechnology systems of innovation - An analysis of industry and academic research activities." Technovation 27.

NCMS and NSF, (2006),. 2005 NCMS Survey of Nanotechnology in the US Manufacturing Industry.

Mogoutov, Andrei and Kahane, Bernard (2007), "Data search strategy for science and technology emergence: A scalable and evolutionary query for nanotechnology tracking." Research Policy 36, 893-903.

Nikulainen, T (2007), "Identifying nanotechnological linkages in the Finnish economy - An explorative study." ETLA Discussion papers no. 1101.

Noyons, E, Buter, R, van Raan, A, Schmooch, U, Heinze, T, Hinze, S and Rangnow, R (2003), "Mapping Excellence in Scienec and technology across Europe nanoscienec and nanotechnology." Final Report to the Euroepan Commission.

OECD (2007), "Capturing nanotechnology's current state of development via analysis of patents.". OECD Science, Technology and Industry Working Papers, 2007/4, Directorate for Science, Technology and Industry, OECD, Paris, www.oecd.org/sti/wprking-papers 
OECD (2007), OECD Science, Technology and Industry Scoreboard 2007.

OECD (2008), Nanotechnology innovation - An overview, (secretariat working document, not unclassified).

Palmberg, C. and Nikulainen, T. (2008), "Nanotechnology and industrial renewal in Finland. A synthesis of key findings." ETLA, Finland.

Perez, Charlota (2002), Technological Revolutions and Financial Capital: The Dynamics of Bubbles and Golden Ages. Edward Elgar.

Porter, A., Youtie, J., Shapira, P. and Schoeneck, J. (2006)., "Refining Search Terms for nanotechnology." Briefing Paper. Georgia Insititute of Technology, Atlanta, United States.

Rafols, Ismael and Meyer, Martin (2007), "How cross-disciplinary is bionanotechnology? Explanations in the speciality of molecular motors." Scientometrics, vol. 70, no.3.

Rafols, I and Porter, A. (2008), Mapping nanotechnology (1991-2007). Manuscript.

Leydersdorff, L. and Rafols, I. (2008), "A Global Map of Science Based on the ISI Subject categories." Journal of American Society for Information Science and Technology (under review, forthcoming)

Robinson, D. Rip, A. and Mangematin, V. (2007), "Technological agglomeration and the emergence of clusters and networks in nanotechnology." Research policy 36.

Roco, M.C. and Bainbridge, W (eds.). 2001. Converging Technologies for Improving Human Performance. NSF Report, Arlington, VA

Roco, M. 2003. Broader Societal Issues of Nanotechnology. Journal for Nanoparticle Research, vol. 5, nos. 3-4.

Roco, M.C. (2007). The NNI: Past, Present and Future. In (ed. Goddard, W.A et al.) Handbook on Nanoscience, Engineering and Technology. CRC, Taylor and Francis, Boca Raton and London, 2007, pp. 3.1-3.26.

Scheu, M. Veefkind, V. Verbandt, Y. Molina, E. Galan, R. Absalom, A. and Forster, W., "Mapping nanotechnology patents: The EPO approach.” World Patent Information 28.

Schummer, J. (2004), "Multidisciplinarity, interdisciplinarity, and patterns of research collaboration in nanosciences and nanotechnology." Scientometrics 59.

Statistics Canada (2006), "Overview and Discussion of the Results of the Pilot Survey on Nanotechnology in Canada." Science, Innovation and Electronic Information Division.

Stephan, Paula., Black, Grant and Chang, Tanwin (2007), "The small size of the small scale market: The early-stage labor market for highly skilled nanotechnology workers." Research policy 36, 887-892.

True Nano. Published by National Institute of Science and Technology policy, MEXT (2007).

Wagner, Volker, Dullart, Anwyn, Bock, Anne-Katrin and Zweck, Axel (2006), "The emerging nanomedicine landscape." Nature Biotechnology, vol. 24, no. 10. 


\section{DSTI/DOC(2009)7}

Youtie, Jan, Iacopetta, Maurizio and Graham, Stuart. (2008), "Assessing the nature of nanotechnology: can we uncover an emerging general purpose technology." Journal of Technology Transfer, vol. 33, no. 3.

Youtie, Jan and Shapira, Philip (2008), "Emergence of Nanodistrics in the United States." Economic Development Quarterly, vol. 22, no. 3, 187-199.

Leydesdorff, L. and Zhou, P. (2007), "Nanotechnology as a Field of Science: Its Delineation in Terms of Journals and Patents." Scientometrics, 70(3), 693-713.

Zucker, Lynne and Darby, Michael (2005), "Socio-economic impact of nanoscale science: Initial results and nanobank." NBER Working paper 11181 March. 